\title{
CONTROL ENDÓGENO Y EXÓGENO DE LA MADURACIÓN EXTERNA DE LOS FRUTOS CÍTRICOS
}

\author{
Tesis Doctoral \\ Giuliana Gambetta Romaso \\ Director \\ Prof. Manuel Agustí Fonfría
}

Valencia, 2009 

D. Manuel Agustí Fonfría, Dr. Ingeniero Agrónomo, Catedrático de Universidad del Departamento de Producción Vegetal de la Universidad Politécnica de Valencia

Expone:

Que la presente Tesis Doctoral 'Control endógeno y exógeno de la maduración externa de los frutos cítricos', realizada por la Ingeniera Agrónoma Giuliana Gambetta Romaso para optar al grado de Doctora, se ha llevado a cabo bajo mi dirección en el Departamento de Producción Vegetal de la Universidad Politécnica de Valencia, y por la presente

Autoriza:

La presentación de la memoria adjunta a los efectos académicos oportunos.

En Valencia, 9 de noviembre de 2009

Fdo. Manuel Agustí Fonfría 

A mis padres

por transmitirnos el valor del conocimiento y enseñarnos a disfrutar del aprendizaje 



\section{Agradecimientos}

A mis queridos profesores Manuel Agustí y Alfredo Gravina, con quienes aprendí que investigar no es solo cuestionar, estudiar, descubrir, aprender, transmitir,.... es una forma de vivir. A Manolo quiero agradecer todo el apoyo brindado para que fuera posible la realización de esta tesis; su invalorable contribución en lo académico y, fundamentalmente, su sensibilidad, afecto y amistad. A Alfredo, mi profesor y amigo, por impulsarme siempre hacia el crecimiento profesional, por su apoyo incondicional y por el tiempo que me ha dedicado durante todos estos años.

A mis queridos amigos Ampa, Carmina y Carlos, con quienes he aprendido, disfrutando horas de campo, laboratorio y oficina en España y Uruguay. A los tres muchas gracias por su permanente colaboración, solidaridad y cariño.

A todas las personas que han transitado por el laboratorio de citricultura de la UPV, y que de alguna manera han colaborado con este trabajo: Gema, Gracia, Bartolomé, Vicent, Sandra, Diego, Enri, Peter, Carmela, Mariano y Vicente.

A mis queridos amigos del grupo de ecofisiología de citrus de Uruguay por las horas de campo y laboratorio compartidas durante esta tesis: al inicio con Ale, Mariana, Elisa, Mariela, y al final con Xime, Ceci, Caro, Cristian y Seba, a todos gracias por hacer el trabajo más ameno, por las largas charlas y.... por estar siempre.

A Tito, Lucía, Gabriela, Tato, Vivian, Joanna, Matías y Valentina de Uruguay, por la colaboración recibida en distintas etapas de esta tesis.

A Jaime Cebolla y Ana Pérez del Instituto Universitario de Conservación y Mejora de la Agrodiversidad Valenciana de la UPV (España), por su apoyo durante el uso del lector de placas. 
Al grupo del laboratorio de Bioquímica de la Facultad de Agronomía, Uruguay, en especial a los profesores Omar Borsani, Pedro Díaz, Pilar Irisarri y Mariana Sotelo, por su importante contribución y por poner el laboratorio a disposición.

A Mercedes Peyrou e Inés Ponce de León, del Instituto de Investigaciones Biológicas Clemente Estable (Uruguay), por facilitarme el laboratorio.

A la Dra. Laura García de la Facultad de Ciencias y al Ing.Agr. Enrique Verdier (MGAP) de Uruguay, por su excelente disposición con el liofilizado de las muestras.

Al Departamento de Biometría, Estadística y Computación de la Facultad de Agronomía, Uruguay, en especial a Oscar Bentancur por los análisis estadísticos y a Alejandra Borges por el asesoramiento en el diseño de los experimentos.

A la Dra Virginia Luna y al Mic. Oscar Masciarelli, por la posibilidad de realizar los análisis de giberelinas en el Laboratorio de Fisiología Vegetal de la FCEFQyN, Universidad Nacional de Río Cuarto, Argentina.

Agradezco también, a todos los que me han apoyado emocional y logísticamente en ambos países durante todos estos años. A mis padres, a Guille y Agustín, Flavia y Sergio, Vivi y Jean, Flo y Martín, Cla y Enio, Ceci y Santi, María del Huerto, Lili, Abu, Lala, Saúl y Graciela, Merxe, Uge, Naty, Elena, Adrit, Rosi, Eli, Mercedes G., Teresa, Alfonso, María, Vero R., Dora, Mariángeles, Quique, Leo, a todos ellos, sencillamente muchas gracias.

Y especialmente, a Juan, por su constante apoyo durante todos estos años y por depositar en mí la confianza y seguridad necesarias para seguir adelante, y a mis hijos, Mateo y Pierina, por enriquecerme con sus experiencias e inquietudes y por demostrarme día a día que vale la pena educar, y que es maravilloso aprender. 


\section{Reconocimientos}

Una parte importante de este doctorado se realizó con el apoyo del Programa ALßAN, Programa de becas de alto nivel de la Unión Europea para América Latina, № de identificación E03D15012UR.

En diversas oportunidades se contó con el apoyo económico del Programa de Recursos Humanos, Pasantías en el Exterior, de la Comisión Sectorial de Investigación Científica (CSIC) de la Universidad de la República, Uruguay.

Al Programa de Becas de Apoyo para la Finalización de Estudios de Posgrado en la Universidad de la República Uruguay (Ilamado 2008).

A los establecimientos citrícolas dónde se realizaron los experimentos: en España, a la empresa Agrimarba S.A. de Huelva, la Cooperativa Agrícola de Llíria, Valencia y al Instituto Valenciano de Investigaciones Agrarias (IVIA); en Uruguay, a los establecimientos 'El Repecho' y 'El Timbó' en Paysandú, 'Agriyú' en Kiyú y ‘El Espinillo' en Montevideo. 

Índices 

INDICE

\begin{tabular}{lr}
\hline INDICE DE TABLAS & $\mathrm{VII}$ \\
\hline INDICE DE FIGURAS & $\mathrm{X}$ \\
\hline RESÚMENES & $\mathrm{XIV}$ \\
\hline RESUMEN & $\mathrm{XVII}$ \\
ABSTRACT & $\mathrm{XIX}$ \\
RESUM & $\mathrm{XXI}$ \\
\hline \multicolumn{1}{c}{ INTRODUCCIÓN } & 1 \\
\hline
\end{tabular}

1.1. Marco de referencia 3

1.2. Regulación endógena de la maduración: Frutos climatéricos y noclimatéricos

1.3. Maduración de los frutos cítricos 8

1.3.1. Características Varietales 9

1.3.2. Evolución de pigmentos en el flavedo de los frutos 11

1.3.3. Aspectos hormonales relacionados con la maduración 13

1.3.3.1. Principales hormonas asociadas con la promoción de la maduración 13

$\begin{array}{ll}\text { 1.3.3.1.1. Etileno } & 13\end{array}$

$\begin{array}{ll}\text { 1.3.3.1.2. Ácido Abscísico } & 15\end{array}$

1.3.3.2. Principales hormonas asociadas con el retraso de la maduración

$\begin{array}{ll}\text { 1.3.3.2.1. Giberelinas } & 16\end{array}$

$\begin{array}{ll}\text { 1.3.3.2.2. Auxinas } & 18\end{array}$

$\begin{array}{ll}\text { 1.3.3.2.3. Citoquininas } & 18\end{array}$

$\begin{array}{lr}\text { 1.3.3.2.4. Poliaminas } & 19\end{array}$

$\begin{array}{ll}\text { 1.3.3.3. Interacción hormonal } & 19\end{array}$ 
1.3.4. Aspectos nutricionales relacionados con la maduración

$\begin{array}{ll}\text { 1.3.4.1. Carbohidratos } & 20\end{array}$

$\begin{array}{ll}\text { 1.3.4.2. Nitrógeno } & 22\end{array}$

1.3.4.3. Otros nutrientes minerales $\quad 23$

1.3.5. Factores ambientales relacionados con la maduración $\quad 24$

1.3.5.1. Relación entre la temperatura y el cambio de color de los frutos

$\begin{array}{ll}\text { 1.3.5.1.1. Temperatura del aire } & 25\end{array}$

1.3.5.1.2. Temperatura del sistema radicular 28

1.3.5.2. Relación entre la luz y el color de los frutos 29

1.4. Hipótesis y objetivos 31

\begin{tabular}{ll}
\hline 2. MATERIALES Y MÉTODOS & 33 \\
\hline
\end{tabular}

2.1. Estrategia de trabajo 35

2.2. Localización de los experimentos 35

2.3. Material Vegetal 36

2.4. Factores endógenos relacionados con la coloración del flavedo: $\begin{array}{ll}\text { Experimentos } & 37\end{array}$

2.4.1. Alteración de la evolución del color: clorofilas y carotenoides $\quad 37$

2.4.1.1. Diseño de experimentos $\quad 39$

\begin{tabular}{ll} 
2.4.1.2. & Mediciones \\
\hline
\end{tabular}

2.4.2. Interrupción del transporte: anillado del pedúnculo 39

2.4.2.1. Diseño de experimentos $\quad 41$

2.4.2.2. Mediciones $\quad 41$

2.5. Factores exógenos relacionados con la coloración del flavedo: Experimentos $\quad 42$

2.5.1. Diseño de experimentos $\quad 44$

$\begin{array}{ll}\text { 2.5.2. Mediciones } & 44\end{array}$

2.6. Determinaciones analíticas $\quad 45$

IV 
2.6.2. Pigmentos, contenidos hormonales y nutricionales en el flavedo del fruto ó en la corteza del pedúnculo $\quad 45$

$\begin{array}{lll}\text { 2.6.2.1. Pigmentos } & 46\end{array}$

$\begin{array}{lll}\text { 2.6.2.2. Etileno } & 46\end{array}$

$\begin{array}{ll}\text { 2.6.2.3. Ácido abscísico } & 47\end{array}$

2.6.2.4. Giberelinas 1 y $4\left(\mathrm{GA}_{1}\right.$ y $\left.\mathrm{GA}_{4}\right) \quad 48$

$\begin{array}{lll}\text { 2.6.2.5. Carbohidratos solubles } & 48\end{array}$

2.6.2.6. Nitrógeno $\left(\mathrm{N}-\mathrm{NH}_{4}{ }^{+}, \mathrm{N}-\mathrm{Prot}, \mathrm{N}-\mathrm{NO}_{3}{ }^{-}+\mathrm{NO}_{2}{ }^{-}\right)$

$\begin{array}{ll}\text { 2.6.3. Maduración interna } & 50\end{array}$

2.7. Análisis estadísticos $\quad 50$

3. RESULTADOS 53

3.1. Factores endógenos relacionados con la coloración del flavedo 55

3.1.1. Alteración de la evolución del color: clorofilas y carotenoides 55

3.1.1.1. Color del flavedo

$\begin{array}{lll}\text { 3.1.1.2. Pigmentos en el flavedo } & 61\end{array}$

3.1.2. Interrupción del transporte: anillado del pedúnculo 79

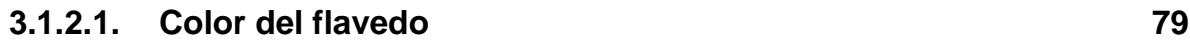

$\begin{array}{lll}\text { 3.1.2.2. Tamaño del fruto } & 83\end{array}$

3.1.2.3. Etileno, ácido abscísico y giberelinas 84

$\begin{array}{ll}\text { 3.1.2.3.1. Etileno } & 84\end{array}$

3.1.2.3.2. Ácido Abscísico $\quad 84$

$\begin{array}{ll}\text { 3.1.2.4. Carbohidratos y nitrógeno } & 90\end{array}$

$\begin{array}{ll}\text { 3.1.2.4.1. Carbohidratos } & 90\end{array}$

$\begin{array}{ll}\text { 3.1.2.4.2. Nitrógeno } & 93\end{array}$ 
3.2. Factores exógenos relacionados con la coloración del flavedo

4. DISCUSIÓN 111

5. CONCLUSIONES 125

6. REFERENCIAS BIBLIOGRÁFICAS 129 
Tabla 1. Descripción de experimentos realizados a plantas completas (Uruguay, 2004 y 2005) y a frutos individuales (Uruguay 2006, España 200809), para alterar la evolución del color.

Tabla 2. Descripción de experimentos con interrupción del transporte, realizados a frutos individuales en Uruguay $(2006,2008)$ y España $(2006)$.

Tabla 3. Descripción de experimentos realizados para disminuir la temperatura del suelo, en España y Uruguay.

Tabla 4. Evolución del índice de color (ICC) de frutos de Satsuma cvs. 'Okitsu' y 'Owari', control y tratados antes del cambio de color con NFZ (1 mM) y $\mathrm{GA}_{3}$ (10 $\mathrm{mg} \mathrm{L}^{-1}$ ), (año 2005).

Tabla 5. Índice de color (ICC) de frutos de naranjo dulce cv. 'Washington navel' control y tratados con NFZ $(2 \mathrm{mM})$ y $\mathrm{GA}_{3}\left(10 \mathrm{mg} \mathrm{L}^{-1}\right)$ antes del cambio de color, al inicio y al final del experimento (año 2006).

Tabla 6. Índice de color (ICC) y concentración de ácido abscísico en el flavedo de frutos de Satsuma cvs. 'Okitsu' y 'Owari' procedentes, de árboles control y

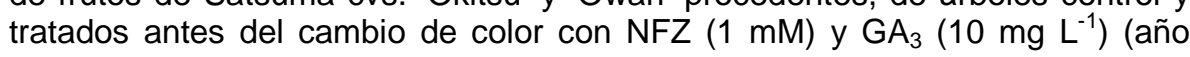
2005).

Tabla 7. Índice de color (ICC) y concentración de ácido abscísico en el flavedo de frutos de naranjo dulce cvs. 'Navelina', 'Washington navel' y 'Navelate' a los 15,30 y 50 días después del tratamiento (DPT), respectivamente (año 2005).

Tabla 8. Índice de color (ICC) y concentración de ácido abscísico en el flavedo de frutos de naranjo dulce cv. 'Washington navel' (2006, Uruguay) tratados antes del cambio de color con NFZ $(2 \mathrm{mM}) \circ \mathrm{GA}_{3}\left(10 \mathrm{mg} \mathrm{L}^{-1}\right)$, a los 60 días de efectuados los tratamientos.

Tabla 9. Índice de color (ICC) y concentración de ácido abscísico en el flavedo de frutos de naranjo dulce cv. 'Valencia Late' (2008-09, España), tratados antes del cambio de color con NFZ (1 mM) ० $\mathrm{GA}_{3}\left(10 \mathrm{mg} \mathrm{L}^{-1}\right)$.

Tabla 10. Concentración de azúcares reductores (Fructosa+Glucosa, mg g $\left.{ }^{1} \mathrm{PS}\right)$ y sacarosa ( $\mathrm{mg} \mathrm{g}^{-1} \mathrm{PS}$ ) en el flavedo de los frutos de naranjo dulce cvs. 'Navelina', de maduración temprana, 'Washington navel', de maduración intermedia y 'Navelate', de maduración tardía (año 2005).

Tabla 11. Concentración de azúcares solubles totales (Fructosa+ Glucosa+Sacarosa, $\mathrm{mg} \mathrm{g}^{-1} \mathrm{PS}$ ) en el flavedo de frutos de mandarino Satsuma cv. 'Okitsu' de maduración muy temprana y 'Owari' de maduración temprana, 
procedentes de árboles control y tratados antes del cambio de color con norflurazona (NFZ $1 \mathrm{mM}$ ) y ácido giberélico $\left(\mathrm{GA}_{3} 10 \mathrm{mg} \mathrm{L}^{-1}\right)$, (año 2005). 75

Tabla 12. Concentración de azúcares reductores (fructosa, glucosa) y sacarosa ( $\mathrm{mg} \mathrm{g}^{-1} \mathrm{PS}$ ) en el flavedo de frutos de naranjo 'Washington navel' (2006, Uruguay) tratados antes del cambio de color con NFZ $(2 \mathrm{mM}) \circ \mathrm{GA}_{3}(10 \mathrm{mg} \mathrm{L}$ ${ }^{1}$ ), a los 60 días después del tratamiento.

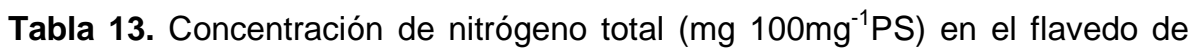
frutos de mandarino Satsuma cv. 'Okitsu', de maduración muy temprana, y 'Owari', de maduración temprana, procedentes de árboles control y tratados antes del cambio de color con norflurazona (NFZ $1 \mathrm{mM})$ y ácido giberélico $\left(\mathrm{GA}_{3}\right.$ $\left.10 \mathrm{mg} \mathrm{L}^{-1}\right)$.

Tabla 14. Color de los frutos de naranjo dulce cv. 'Valencia Delta Seedless' (2006, España), expresado como relación a/b, croma y ángulo-tono HUE (Hunter Lab) a los 42 días de realizados los tratamientos: control (C), anillado de pedúnculo a $0.5-1 \mathrm{~cm}$ del fruto $(\mathrm{A})$, anillado de pedúnculo a $8-10 \mathrm{~cm}$ del fruto $(\mathrm{AMH})$ y anillado de pedúnculo a $8-10 \mathrm{~cm}$ del fruto eliminando las hojas entre el fruto y el anillado (AM).

Tabla 15. Diámetro ecuatorial promedio $(\mathrm{mm})$ de frutos de naranjo dulce cv. 'Washington navel' (2006, 2008; Uruguay) y 'Valencia Delta Seedless' (2006; España) al final del experimento.

Tabla 16. Índice de color (ICC) y concentración de ácido abscísico en el flavedo de frutos de naranjo dulce cv. 'Washington navel' (2006, Uruguay) y 'Valencia Delta Seedless' (2006, España) a los 60 y 40 días de efectuados los tratamientos (DPT), respectivamente.

Tabla 17. Concentración de ácido abscísico ( $\mu \mathrm{g} \mathrm{g}^{-1}$ Peso Seco) en la corteza del pedúnculo de frutos de naranjo dulce cv. 'Washington navel' (2006, Uruguay) y 'Valencia Delta Seedless' (2006, España) a los 60 y 40 días del tratamiento (DPT), respectivamente.

Tabla 18. Índice de color (ICC) y relación $\mathrm{GA}_{1}: \mathrm{GA}_{4}$ en el flavedo de frutos y en la corteza de pedúnculos anillados a 8-10 cm del fruto, eliminando las hojas entre el fruto y el anillado (AM) y frutos sin anillar (control), de naranjo 'Washington navel' (2008, Uruguay).

Tabla 19. Concentración de azúcares reductores (fructosa, glucosa) y sacarosa ( $\mathrm{mg} \mathrm{g}^{-1} \mathrm{PS}$ ) en el flavedo de frutos de naranjo 'Washington navel' (2006, Uruguay) y 'Valencia Delta Seedless' (2006, España) 60 y 40 días después del tratamiento (DPT), respectivamente.

Tabla 20. Concentración de fructosa, glucosa, sacarosa y azúcares solubles totales (Total) en la corteza de pedúnculos anillados y sin anillar de frutos de naranjo dulce cv. 'Valencia Delta Seedless' (2006, España) a los 40 días del tratamiento.

Tabla 21. Concentración de nitrógeno proteico $(\mathrm{N}-\mathrm{P})$, amoniacal $\left(\mathrm{N}-\mathrm{NH}_{4}{ }^{+}\right)$y total (NT) en el flavedo de frutos de naranjo dulce cv. 'Valencia Delta Seedless' 
(2006, España) con pedúnculo anillado y sin anillar, a los 40 días del tratamiento.

Tabla 22. Porcentaje de frutos con ICC $\geq 0$ (CIELab) de plantas de mandarino Clementino, cv. 'Clemenules' control (C) y con cobertura de suelo, malla plateada (MP) y cal (CAL: $\mathrm{CaOH}_{2}$; D: Dolomita), durante los meses previos a la recolección. Valores correspondientes a Uruguay.

Tabla 23. Influencia de la cubierta de suelo con cal o mallas instaladas en julio (M-Jul) o en septiembre (M-Sep) sobre el peso medio del fruto, el color y la maduración interna (sólidos solubles totales -SST- y acidez titulable) de la mandarina Clementina cv. 'Clemenpons' en el momento de la recolección (año 2006, España).

Tabla 24. Porcentaje de horas con temperatura del aire superior a $25^{\circ} \mathrm{C}$ e inferior a $22^{\circ} \mathrm{C}, 18^{\circ} \mathrm{C}, 13^{\circ} \mathrm{C}$ y $7^{\circ} \mathrm{C}$; porcentaje de días con amplitud térmica (AT) $\geq 10^{\circ} \mathrm{C}$, y temperaturas máximas y mínimas diarias $\left({ }^{\circ} \mathrm{C}\right)$ con $\mathrm{AT} \geq 10^{\circ} \mathrm{C}$, durante los años 2007 y 2008, Kiyú (Uruguay).

Tabla 25. Porcentaje de horas con temperatura de suelo inferior a $21^{\circ} \mathrm{C}, 18^{\circ} \mathrm{C}$, $15^{\circ} \mathrm{C}$ y $13^{\circ} \mathrm{C}$ en el control y con dos tipos de cobertura de suelo, malla plateada (MP) y cal (CAL: $\mathrm{CaOH}_{2}$; D: Dolomita), durante los años 2007 y 2008, Kiyú (Uruguay).

Tabla 26. Influencia del tipo de cobertura del suelo sobre el porcentaje de frutos de mandarina Clementina cv. 'Clemenpons' cosechados en la primera fecha de recolección (años 2005 al 2008, España). 
Figura 1. Esquema de tejidos y principales procesos involucrados en la maduración y senescencia de los frutos cítricos. Adaptado de Goldschmidt (2000).

Figura 2. Árboles de plantaciones comerciales de mandarino Satsuma, cv. 'Okitsu' en Uruguay (A) y naranjo dulce cv. 'Valencia Delta Seedless' en España (B).

Figura 3. Frutos con pedúnculo anillado: $A$ ) anillado próximo al fruto (A); $B$ ) anillado en la zona media del pedúnculo, con hojas ( $\mathrm{AMH})$; y $\mathrm{C}$ ) anillado en la zona media del pedúnculo, sin hojas (AM). D) Zonas del pedúnculo: basal (porción del pedúnculo conectada a la rama y aislada del fruto por el anillado), y apical (porción del pedúnculo en contacto con el fruto y desconectada de la rama por el anillado).

Figura 4. Mallas plásticas blancas colocadas bajo la copa de los árboles a 50 $\mathrm{cm}$ de altura en España (A), mallas plásticas plateadas colocadas directamente sobre el suelo en Uruguay (C) y tratamiento de cal esparcida debajo de los árboles en España (B) y Uruguay (D).

Figura 5. Frutos de mandarino Satsuma cv. 'Owari' control y tratados antes del cambio de color con norflurazona (NFZ $1 \mathrm{mM})$ y ácido giberélico $\left(\mathrm{GA}_{3} 10 \mathrm{mg} \mathrm{L}\right.$ ${ }^{1}$ ), a los 70 días de la aplicación (año 2005).

Figura 6. Curvas ajustadas de la evolución del índice de color (ICC) de frutos de naranjo dulce 'Navelina' de maduración temprana (A), 'Washington navel' de maduración intermedia (B) y 'Navelate' de maduración tardía (C), procedentes de árboles control y tratados con norflurazona (NFZ $1 \mathrm{mM}$ ) y ácido giberélico $\left(\mathrm{GA}_{3} 20 \mathrm{mg} \mathrm{L}^{-1}\right)$ (año 2005).

Figura 7. Índice de color (ICC) de frutos de naranjo dulce cv. 'Valencia Late' en las localidades UPV (A) y Llíria (B), procedentes de árboles control y tratados con norflurazona (NFZ $1 \mathrm{mM}$ ) y ácido giberélico $\left(\mathrm{GA}_{3} 10 \mathrm{mg} \mathrm{L}^{-1}\right)$ el 3 y el 11 de noviembre, en UPV y Llíria respectivamente.

Figura 8. Evolución de la temperatura ambiente (Ta) y del suelo (Ts) a lo largo de la época de maduración del fruto y hasta su reverdecimiento en la localidad de Llíria. Valores para 2008-09.

Figura 9. Concentración de clorofila a en el flavedo de frutos de naranjo dulce cv. 'Valencia Late' en las dos localidades de España, UPV (A) y Lliria (B), procedentes de árboles control y tratados con norflurazona (NFZ $1 \mathrm{mM}$ ) y ácido giberélico $\left(\mathrm{GA}_{3} 10 \mathrm{mg} \mathrm{L}^{-1}\right)$ el 3 y el 11 de noviembre, en UPV y Llíria respectivamente. 
Figura 10. Concentración de carotenoides totales en el flavedo de frutos de naranjo dulce cV. 'Valencia Late' en las dos localidades de España, UPV (A) y Lliria (B), procedentes de árboles control y tratados con norflurazona (NFZ 1 $\mathrm{mM})$ y ácido giberélico $\left(\mathrm{GA}_{3} 10 \mathrm{mg} \mathrm{L}^{-1}\right)$ el 3 y el 11 de noviembre, en UPV y Llíria respectivamente.

Figura 11. Concentración de fitoeno $(A)$, fitofluoeno $(B)$, luteína $(C)$ y $\beta$ caroteno (D) en el flavedo de frutos de naranjo dulce cv. 'Valencia Late', procedentes de árboles control y tratados con norflurazona (NFZ $1 \mathrm{mM}$ ) y ácido giberélico $\left(\mathrm{GA}_{3} 10 \mathrm{mg} \mathrm{L}^{-1}\right)$ el 11 de noviembre, Llíria (España).

Figura 12. Concentración de carotenoides $\beta$-criptoxantina ( $\mathrm{A}$ y $B$ ), $\beta$-citraurina $(C$ y D) y cis-violaxantina $(E$ y $F$ ) en el flavedo de frutos de naranjo dulce cv. 'Valencia Late', procedentes de árboles control y tratados con norflurazona (NFZ $1 \mathrm{mM})$ y ácido giberélico $\left(\mathrm{GA}_{3} 10 \mathrm{mg} \mathrm{L}^{-1}\right)$, en las dos localidades de España, UPV (A, C y E) y Llíria (B, D, F).

Figura 13. Azúcares reductores (Fructosa+Glucosa) y sacarosa en el flavedo de frutos de naranjo dulce cvs. 'Navelina' de maduración temprana (A, B), 'Washington navel' de maduración intermedia (C, D), y 'Navelate' de maduración tardía (E, F). Influencia de la aplicación previa al cambio de color de norflurazona (NFZ $1 \mathrm{mM}$ ) y ácido giberélico $\left(\mathrm{GA}_{3} 20 \mathrm{mg} \mathrm{L}^{-1}\right)$.

Figura 14. Curvas ajustadas del índice de color (ICC) de frutos de naranjo dulce cv. 'Washington navel' con pedúnculo anillado y sin anillar (2006, Uruguay).

Figura 15. Curvas ajustadas de la evolución del índice de color (ICC) de los frutos de naranjo dulce cv. 'Washington navel', año 2006 (A) y 2008 (B) en Uruguay, y cv. 'Valencia Delta Seedless', 2006 (C), en España.

Figura 16. Frutos de naranjo dulce cv. 'Valencia Delta Seedless' a los 35 días de realizados los tratamientos: control $(C)$, anillado de pedúnculo a $0.5-1 \mathrm{~cm}$ del fruto $(A)$, anillado de pedúnculo a $8-10 \mathrm{~cm}$ del fruto $(A M H)$ y anillado de pedúnculo a 8-10 cm del fruto eliminando las hojas entre el fruto y el anillado (AM).

Figura 17. Curvas ajustadas de la evolución del diámetro ecuatorial de los frutos de naranjo dulce cv. 'Washington navel' con el pedúnculo anillado y sin anillar (2008, Uruguay).

Figura 18. Concentración de $\mathrm{GA}_{1}(\mathrm{~A})$ y $\mathrm{GA}_{4}(\mathrm{~B})$ en el flavedo de frutos de naranjo dulce $\mathrm{cv}$. 'Washington navel', con el pedúnculo anillado a 8-10 cm del fruto, eliminando las hojas entre el fruto y el anillado (AM) y frutos control sin anillar (C), (2008, Uruguay).

Figura 19. Concentración de $\mathrm{GA}_{1}(\mathrm{~A})$ y $\mathrm{GA}_{4}(\mathrm{~B})$ en la corteza de pedúnculos anillados a 8-10 cm del fruto, eliminando las hojas entre el fruto y el anillado (AM) y frutos control sin anillar (C) de naranjo dulce cv. 'Washington navel' (2008, Uruguay). 
Figura 20. Índice de color de frutos (ICC) de plantas de mandarino Clementino cv. 'Clemenules', control y con cobertura de suelo: malla plateada (MP) y cal (D: Dolomita), durante los meses previos a la recolección (2008, Uruguay).

Figura 21. Índice de color de los frutos (ICC) de plantas de mandarino Clementino cv. 'Clemenpons' control y con cobertura de suelo, malla colocada en julio (M-Jul) ó septiembre (M-Sep) y cal aplicada en julio (CAL-Jul), durante los meses previos a la recolección (2007, España.

Figura 22. Intensidad de radiación (A), Radiación Fotosintéticamente Activa PAR- (B) reflejada desde el suelo (Control) o desde la cobertura utilizada: malla plateada (MP) o Cal, instaladas en marzo, e Intensidad de radiación total y PAR incidente (C), a $1.2 \mathrm{~m}$ de altura (2007, Uruguay).

Figura 23. Cambios estacionales de los valores máximos y mínimos de la temperatura del suelo provocados por la cobertura de cal instalada en julio (Cal-Jul), o de mallas instaladas en julio (M-Jul) o en septiembre (M-Sep). Valores correspondientes al año 2007, España.

106

Figura 24. Tiempo de permanencia en horas de la temperatura del suelo entre $21^{\circ} \mathrm{C}$ y $25^{\circ} \mathrm{C}$, provocados por la cobertura de cal instalada en julio, o de mallas instaladas en julio (M-Jul) o en septiembre (M-Sep). Valores correspondientes al año 2007, España. 


Resúmenes 

En esta Tesis Doctoral se estudió el proceso de regulación de la maduración externa de los frutos cítricos, con el objetivo de determinar los factores endógenos y exógenos que lo afectan. Los factores hormonales y nutricionales implicados en el proceso, se estudiaron: a) en cultivares de naranjos y mandarinos de maduración temprana, intermedia y tardía, y b) modificando el proceso en etapas próximas al cambio de color, mediante aplicaciones de reguladores de crecimiento y sustancias nitrogenadas, o interrumpiendo la conexión floemática entre el fruto y la planta (anillado de pedúnculo). El estudio de los factores exógenos (temperatura del aire y del suelo) se realizó en mandarinos de maduración temprana, a través de la disminución de la temperatura radicular cubriendo el suelo con mallas o cal, y su asociación con la temperatura del aire.

Las principales conclusiones resultantes de este trabajo fueron:

- Las giberelinas $\mathrm{GA}_{1}$ y $\mathrm{GA}_{4}$ deben exportarse desde el flavedo de los frutos para permitir el cambio de color.

- La aplicación de $\mathrm{GA}_{3}$ no solo retarda la pérdida de clorofilas, sino que reduce la concentración de pigmentos carotenoides coloreados ( $\beta$-criptoxantina, cisviolaxantina y $\beta$-citraurina) y aumenta la de pigmentos propios de los frutos verdes ( $\beta$-caroteno y luteína) a lo largo de todo el periodo de maduración.

- Con el cambio de color se incrementa la concentración de ABA en el flavedo, pero éste no es el de promotor del proceso.

- Se verifica una relación inversa entre el color y la concentración de nitrógeno en el flavedo en condiciones in vivo. Las evidencias de que el incremento de GAs es, por una parte, la señal endógena primaria que limita el cambio de color y promueve, por otra, el incremento del $\mathrm{N}$ endógeno, permiten postular un papel subsidiario de éste en el proceso de la maduración externa de los frutos cítricos.

- El cambio de color de los frutos es promovido por el descenso de la temperatura del suelo por debajo de un umbral crítico asociado al portainjerto.

- La disminución de la temperatura de la zona radicular, lograda con el sombreado del suelo con cobertura de malla blanca o de cal durante los dos 
meses previos al cambio de color, permite adelantar el inicio de éste en frutos de mandarino Clementino, incrementando el porcentaje de frutos cosechados en la primera fecha de recolección.

Considerando la relación entre los factores endógenos y exógenos se propone que el inicio del cambio de color de los frutos cítricos es consecuencia del descenso de la temperatura del suelo, mediada por la temperatura del aire, que provoca el cese del desarrollo vegetativo y de la raíz. Como consecuencia de ello, se reduce la síntesis y el transporte de giberelinas desde las raíces, al mismo tiempo que se inicia su exportación desde los frutos. Adicionalmente, disminuye la absorción de $\mathrm{N}$ y su concentración y aumenta la de azúcares reductores y de $A B A$ en el flavedo. 


\begin{abstract}
The purpose of this thesis was to state the endogenous and exogenous factors involved in the regulation of citrus fruit external ripening (degreening). Hormonal and nutritional factors were studied: a) in cultivars of oranges and mandarins with early, intermediate and late season maturation; and b) modifying the external ripening before colour break, either by the application of growth regulators and nitrogen, or by interrupting the phloem connection between fruit and the rest of the plant (peduncle girdling). Exogenous factors (air and soil temperature) were evaluated in early ripening mandarins by lowering root temperature, shading the soil with a plastic net or a thick lime cover, and in relation to air temperature.

The main findings were the followings:

- Gibberellins $\left(\mathrm{GA}_{1}\right.$ y $\left.\mathrm{GA}_{4}\right)$ need to be exported from citrus flavedo to allow colour break.

- The application of $\mathrm{GA}_{3}$ not only delays the loss of chlorophyll, but also reduces colored carotenoids concentration ( $\beta$-cryptoxanthin, cis-violaxanthin y $\beta$ citraurine), and increases typical green fruit carotenoids ( $\beta$-carotene and lutein) during ripening.

- ABA concentration in the flavedo increases during fruit degreening without having a target role.

- It is demonstrated in vivo that there is an inverse relationship between colour and nitrogen concentration in the flavedo. The evidence that GA increment is the primary endogenous signal controlling colour break, and that it promotes a rise in endogenous $\mathrm{N}$, allow us to state that $\mathrm{N}$ is of secondary importance to citrus fruit external maturation.

- Fruit colour development is promoted by a drop in soil temperature below a certain threshold, associated to rootstock.

- The soil temperature fall, due to the use of the white plastic net or thick lime cover during two months before colour break, promotes a Clementine mandarin earlier degreening, and consecuently increases crop percentage at the first harvest time.

Considering the relationship between endgenous and exogenous factors, it is
\end{abstract}


possible to establish that fruit degreening is caused by the soil temperature drop, which depends on the air temperature. This change in temperature leads to a cessation of both, vegetative and root growth. As a consequence of this, there is a reduction of GAs synthesis and transport from roots, and their exportation from fruit flavedo is commenced. Furthermore, $\mathrm{N}$ absortion and its concentration in the flavedo diminish, as well as reducing sugars and $A B A$ increase. 


\section{RESUM}

En esta Tesi Doctoral es va estudiar el procés de regulació de la maduració externa dels fruits cítrics, amb l'objectiu de determinar els factors endògens $i$ exògens que l'afecten. Els factors hormonals i nutricionals implicats en el procés es van estudiar: a) en cultivars de tarongers i mandariners de maduració primerenca, intermèdia $i$ tardana, i b) modificant el procés en etapes pròximes al canvi de color, per mitjà d'aplicacions de reguladors de creixement $i$ substàncies nitrogenades, 0 interrompent la connexió floemàtica entre el fruit $\mathrm{i}$ la planta (anellat de peduncle). L'estudi dels factors exògens (temperatura de l'aire i del sòl) es va realitzar en mandariners de maduració primerenca, a través de la reducció de la temperatura radicular cobrint el sòl amb malles o calç, i la seua associació amb la temperatura de l'aire.

Les principals conclusions resultants d'aquest treball van ser:

- Les giberelines $\mathrm{GA}_{1}$ i GA 4 han d'exportar-se des del flavedo dels fruits per a permetre el canvi de color.

- L'aplicació de $\mathrm{GA}_{3}$ no sols retarda la pèrdua de clorofil-les, sinó que reduïx la concentració de pigments carotenoids amb color (B-criptoxantina, cisviolaxantina i B-citraurina) i augmenta la de pigments propis dels fruits verds ( $B$ caroteno i luteïna) al llarg de tot el període de maduració.

- Amb el canvi de color s'incrementa la concentració d'àcid abscísic (ABA) en el flavedo, però aquest no és el promotor del procés.

- Es verifica una relació inversa entre el color i la concentració de nitrogen en el flavedo en condicions in vivo. L'increment de $\mathrm{GA}_{1} \mathrm{i} \mathrm{GA}_{4}$ és, d'una banda, el senyal endogen primàri que limita el canvi de color i promou, d'una altra, l'increment del $\mathrm{N}$ endogen. Açó permet postular un paper subsidiari del nitrogen en el procés de la maduració externa dels fruits cítrics.

- El canvi de color dels fruits és promogut pel descens de la temperatura del sòl per davall d'un llindar crític associat al patró.

- La disminució de la temperatura de la zona radicular, aconseguida amb l'ombreig del sòl amb cobertura de malla blanca o de calç durant els dos mesos previs al canvi de color, permet avançar l'inici d'este en fruits de mandariner 
Clementí, incrementant el percentatge de fruits collits en la primera data de recol-lecció.

Considerant la relació entre els factors endògens i exògens es proposa, que l'inici del canvi de color dels fruits cítrics és conseqüència del descens de la temperatura del sòl, influenciada per la temperatura de l'aire, que provoca el cessament del desenvolupament vegetatiu i de l'arrel. Com a conseqüència d'això, es reduïx la síntesi i el transport de giberelines des de les arrels, alhora que s'inicia la seua exportació des dels fruits, i disminuïx l'absorció de $\mathrm{N}$ i la seua concentració, i augmenta la de sucres reductors i d'ABA en el flavedo. 




\section{Introducción}





\subsection{Marco de referencia}

El comercio mundial de fruta cítrica para el consumo en fresco requiere la obtención de productos de alta calidad. Este concepto, calidad, abarca características externas e internas, e involucra el cumplimiento de las particularidades típicas de la especie y cultivar de que se trate. Externamente, el color, la forma, el tamaño y el grosor de la piel son la referencia del fruto. Internamente, el sabor (relación azúcares: ácidos), pulpa ligera y ausencia de semillas, son las características más apreciadas.

El color de la piel de los frutos es un factor determinante para su comercialización. Su evolución natural se ha asociado a factores exógenos, fundamentalmente climáticos, y a factores endógenos, nutricionales y hormonales, pero aún no se ha dilucidado la regulación de los mismos. La mayoría de los cítricos madura a partir del inicio del otoño, cuando el árbol reduce la absorción y el transporte de nitrógeno, la síntesis de giberelinas y la competencia por carbohidratos. Pero algunos cultivares tempranos de mandarinas y naranjas logran la madurez interna antes de adquirir completamente la coloración, lo que hace necesario desverdizarlos artificialmente con etileno para estimular su maduración exterior. El estudio de algunos factores endógenos y exógenos, y su interacción se abordan en esta Tesis Doctoral.

\subsection{Regulación endógena de la maduración: Frutos climatéricos y no- climatéricos}

La maduración es la etapa del desarrollo del fruto en la cual éste adquiere los caracteres organolépticos distintivos y apropiados para su consumo. Es un proceso complejo que involucra cambios fisiológicos y bioquímicos asociados a un control endógeno y ambiental. Se ha relacionado positivamente con el aumento de la respiración, la producción de etileno y ácido abscísico (ABA) y con el transporte de carbohidratos (CHOs), y negativamente con las giberelinas (GAs) y el metabolismo del nitrógeno $(\mathrm{N})$. 
Los frutos han sido clasificados como 'climatéricos' y 'no climatéricos' de acuerdo con la presencia o ausencia de un aumento de la tasa respiratoria y de la producción autocatalítica de etileno asociada a la maduración. El término climatérico fue utilizado inicialmente para describir el incremento en la tasa respiratoria que acompaña la maduración de manzanas (Kidd y West, 1925) y generalizado posteriormente a otros frutos. Los frutos climatéricos, en general, pueden madurar organolépticamente tanto en el árbol como separados de él, siempre y cuando se cosechen después de haber alcanzado la madurez fisiológica (Vendrell y Buesa, 1989, Mikal y Saltveit, 1993). En cambio, los frutos no climatéricos no maduran tras ser separados del árbol (Soule y Grierson, 1978; Rodrigo y Zacarías, 2007)

El aumento de la respiración y su relación con el etileno y el proceso de maduración aún no han sido esclarecidos completamente. En los frutos climatéricos, la tasa de producción de $\mathrm{CO}_{2}$ desciende durante el desarrollo y aumenta bruscamente luego de alcanzar la madurez fisiológica, tanto en frutos que permanecen en el árbol como en frutos cosechados (Kidd y West, 1925; Reid et al., 1973). En el caso de los frutos separados del árbol, el pico de liberación de $\mathrm{CO}_{2}$ se da en los primeros 5-10 días post-cosecha y luego disminuye (Biale et al., 1954; Reid et al., 1973; Vendrell y Buesa, 1989; Arellano-Gómez et al., 2005). Este proceso es irreversible y, en general, es precedido por un aumento en la producción de etileno.

En naranjas, frutos no-climatéricos de muy baja producción de etileno y sin aumentos en la tasa respiratoria, ésta aumenta a niveles similares a los de frutos climatéricos si se los trata exógenamente con etileno (Reid y Pratt, 1970). No obstante, la información disponible indica que, en condiciones naturales, la respiración tiene un comportamiento decreciente con el tiempo (Bain, 1958; Aharoni, 1968; Eaks, 1970, Holland et al., 2002, Mulas et al., 2004, Win et al., 2006). Con respecto a la vida post-cosecha, Peng y Rabe (1997) encontraron un pico de la tasa de respiración a las dos semanas de almacenamiento, aproximadamente, y un descenso posterior similar al de los trabajos mencionados anteriormente.

La síntesis de etileno en los frutos climatéricos es un proceso autocatalítico y es esencial como disparador de la maduración. Existen diferentes patrones de su biosíntesis que han sido clasificados como sistemas I 
y II. La producción de etileno del sistema I tiene una tasa basal baja y se inhibe con aplicaciones exógenas del mismo (autoinhibición). Este sistema opera en frutos no climatéricos, en el estado pre-climatérico de frutos climatéricos y en los tejidos vegetativos (Mc Murchie et al., 1972; Oetiker y Yang, 1995). El sistema II implica el incremento rápido de etileno de modo autocatalítico que acompaña el proceso de maduración de los frutos climatéricos. En este tipo de frutos, el inicio de la maduración involucra una transición del sistema I al II en la biosíntesis de etileno (Mc Murchie et al., 1972; Lincoln et al., 1987; Oetiker y Yang, 1995; Nakatsuka et al., 1998; Trainotti et al., 2005).

La función de este regulador del desarrollo en la maduración de frutos climatéricos ha sido extensamente revisada (Oetiker y Yang 1995; Giovannoni, 2004; Zhu et al., 2005; Pech et al., 2008). Se ha demostrado que el etileno controla los procesos de maduración a través de la regulación de la transcripción de genes y, por lo tanto, se ha generado gran información en el área de la biosíntesis y respuesta al mismo (Lincoln et al., 1987; Nakatsuka et al., 1998; Giovannoni, 2004; Zhu et al., 2005). Asimismo, se han realizado grandes avances en relación al uso potencial en agricultura, como es el caso de la obtención de mutantes de tomate con mayor vida post-cosecha. En esta especie, la represión, vía expresión antisentido de la ACC sintasa (ACS) o ACC oxidasa (ACO), reduce la producción de etileno y retrasa $O$ inhibe la maduración (Hamilton et al. 1990; Oeller et al. 1991); del mismo modo, la mutación del receptor de etileno $\mathrm{Nr}$ resulta en frutos insensibles al etileno, que no maduran nunca, y la introducción de un alelo dominante del receptor $N R$ (homólogo de ERS1) inhibe toda respuesta cuantificable de etileno, incluso la maduración del fruto (Wilkinson et al. 1995; 1997; Yen et al. 1995). Estos avances han sido ampliamente revisados por Alexander y Grierson (2002) y Moore et al. (2002).

Por el contrario, la información sobre el mecanismo de acción del etileno en frutos no-climatéricos es más escasa, aunque en cítricos (Rodrigo y Zacarías, 2007) se ha encontrado una respuesta común a los tomates (Hoeberichts et al., 2002) y albaricoques (Marty et al., 2005) en lo que se refiere a la activación de genes de la biosíntesis de carotenoides, incrementando la producción de precursores y el flujo de la ruta metabólica en respuesta al etileno, independientemente del comportamiento climatérico o no 
de los frutos. Se infiere, por tanto, que ambos sistemas podrían compartir rutas comunes (White, 2002; Pech et al., 2008), además de contener programas únicos de desarrollo y maduración, con atributos particulares debido a las diferencias anatómicas y fisiológicas (Cercós et al., 2006).

Los frutos no climatéricos, que carecen de pico autocatalítico de producción de etileno, se han clasificado en dos categorías según respondan o no a la aplicación exógena de este regulador (Goldschmidt, 1997). Los cítricos pertenecen al primer grupo, en la medida que la producción de etileno es constante y extremadamente baja durante la maduración (Aharoni, 1968; Eaks, 1970; Goldshmidt et al., 1993), pero las aplicaciones exógenas de etileno estimulan el cambio de color de los frutos y aceleran la senescencia de los mismos (Apelbaum et al., 1976; Pons et al., 1992; Goldschmidt et al., 1993). Existe una sola referencia sobre el incremento en la producción de etileno endógeno en la naranja 'Tarocco', 34 semanas después del cuajado, y en menor magnitud en 'Valencia', 30 semanas post cuajado (Mulas et al., 2004).

$\mathrm{Si}$ bien existe consenso en lo referente a la clasificación de frutos en climatéricos y no climatéricos, ésta es una simplificación de la realidad y, en ocasiones, es motivo de controversia. Así, hay cultivares de una misma especie que se comportan de manera diferente, como es el caso del melón en el que el cv. 'Charentais melon' (Cucumis melo var. Cantalupensis cv. Védrantais) es típicamente climatérico, mientras que el 'Songwhan Charmi PI 161375' (C. melo var. Chinensis) es no climatérico (Périn et al., 2002). En melón (Pech et al., 2008) y tomate (Moore et al., 2002) se ha descubierto la presencia de eventos de la maduración (climaterio respiratorio, ablandamiento de la pulpa, producción de aromas, color, etc.) tanto dependientes como independientes del etileno.

En el mismo sentido, todavía existe debate respecto a la clasificación de otras especies, como las zarzamoras, frambuesas e híbridos, probablemente por las dificultades derivadas de diferenciar el etileno generado por los procesos de abscisión y de maduración, de las variaciones que pueden existir entre frutos unidos y separados de la planta (Burdon y Sexton, 1990; PerkinsVeazie et al., 2000), o por la mencionada coexistencia de procesos dependientes e independientes. 
Los cambios asociados a la maduración y senescencia son procesos genéticamente controlados. En frutos climatéricos, como bananas (Brady et al., 1970), peras (Frenkel et al., 1968), tomates (Speirs et al., 1984) y aguacates (Tucker y Laties, 1984), se ha registrado un aumento en la síntesis de proteínas a medida que avanza la maduración, como consecuencia de la incorporación de aminoácidos. Por otro lado, la cicloheximida, inhibidor de la síntesis proteica, retarda la senescencia de peras (Frenkel et al., 1968), bananas (Brady et al., 1970) y cítricos (Riov et al., 1969). En tomates maduros (Baker et al., 1985) y manzanas (Lara y Vendrell, 2000) se observó la síntesis de proteínas preexistentes, la disminución de otras y la síntesis de nuevas proteínas. Algunos de los ARN mensajeros que aumentan durante la maduración han sido identificados con las enzimas que codifican. La síntesis de poligalacturonasa, enzima cuyo ARNm está ausente en frutos verdes, comienza a detectarse cuando se inicia la síntesis de etileno y aumenta sensiblemente los días después de iniciada la producción masiva de éste. Sin embargo, la aplicación exógena de etileno a frutos verdes no provoca la acumulación de la enzima, lo que indica que el gen responsable de su síntesis requiere, además de la presencia de etileno, otros factores que están ausentes en los frutos verdes (Speirs y Brady, 1991). Lo mismo ocurre con la expresión de los genes responsables de la codificación de las enzimas ACS y ACO (Nakatsuka et al., 1998). En frutos no-climatéricos como los cítricos, la aplicación de etileno también induce proteínas específicas de la maduración (Alonso et al., 1995; Rodrigo et al., 2006; Agustí, et al., 2007; Fujii et al., 2007) y aumento de la tasa respiratoria (Reid y Pratt, 1970).

Los procesos anabólicos requeridos durante la maduración (síntesis de proteínas y ARNm, pigmentos y compuestos aromáticos) demandan energía y esqueletos carbonados, suministrados, al igual que en otros tejidos, por la respiración. La tasa de consumo de azúcares y ácidos está supeditada, en gran medida, a la actividad respiratoria del fruto, la cual depende fundamentalmente de la especie y la temperatura (Sozzi, 2007). Pero este aspecto no se ha esclarecido totalmente, en la medida que la respiración y la síntesis proteica pueden ser estimuladas por concentraciones de etileno insuficientes para provocar la maduración o en mutantes incapaces de madurar, y, por otra parte, 
el etileno incrementa la respiración de frutos tratados con inhibidores de la síntesis proteica.

\subsection{Maduración de los frutos cítricos}

El fruto cítrico es una baya especial denominada 'hesperidio', que difiere de las bayas clásicas por poseer una piel compacta, independiente, que rodea la pulpa, porción comestible del mismo. La piel consiste en un exocarpo coloreado, llamado flavedo, y un mesocarpo esponjoso de color blanco, llamado albedo. La pulpa es el resultado de la formación de vesículas que proceden de la pared dorsal de los carpelos a los que llenan completamente y con la que, conjuntamente, forman el endocarpo. Estas vesículas constan de un cuerpo, que alberga el zumo, y un pedúnculo, que las une permanentemente a la pared dorsal del carpelo y por el que se nutren. El crecimiento y desarrollo del fruto puede llevar entre 6 y 12 meses, según la especie y cultivar. La curva de crecimiento del mismo sigue un patrón sigmoidal, que se ha dividido en tres fases: una primera caracterizada por la división celular (fase I), seguida por un período determinado, básicamente, por el agrandamiento celular y la acumulación de agua, en la que el fruto incrementa notablemente su tamaño (fase II), y finalmente la fase III en la que se ralentiza el crecimiento y comienza el proceso de maduración (Bain, 1958).

Durante la fase III se dan una serie de cambios, algunos de los cuales afectan la corteza y son los responsables de la maduración externa, y otros afectan las características del zumo y condicionan la maduración interna. Con respecto a la primera, ésta se define básicamente por el cambio de color como resultado de la disminución de los pigmentos verdes y el aumento de los pigmentos amarillo-rojizos; la maduración interna involucra la disminución de la acidez y el aumento de los azúcares del zumo.

La piel y la pulpa de los frutos cítricos se comportan de forma relativamente independiente; la falta de conexiones vasculares puede ser una de las razones de dicha independencia (Monselise, 1977). La Figura 1 ayuda a comprender este fenómeno. Así, los procesos relacionados con la maduración de la piel responden a tratamientos exógenos de etileno como promotor de la 
maduración y senescencia, y de giberelinas y citoquininas como antisenescentes. Los procesos de la pulpa, sin embargo, no responden a las aplicaciones exógenas de estas sustancias, y ello permite controlar las alteraciones de la corteza sin afectar la maduración interna de los frutos (Kuraoka et al., 1977; Agustí et al., 1988).

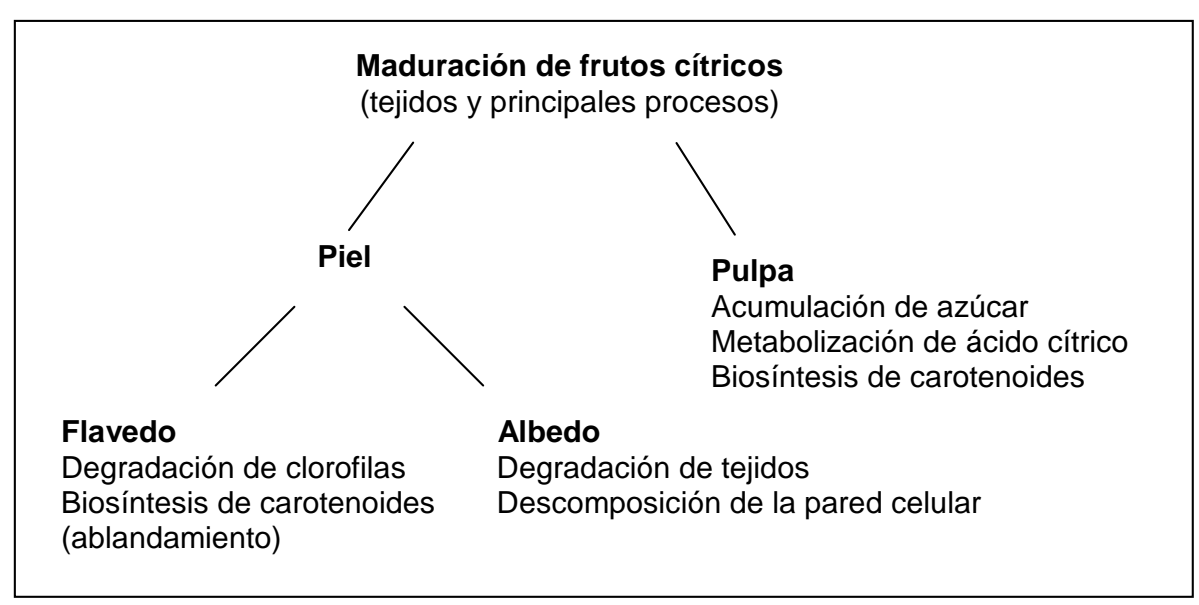

Figura 1. Esquema de tejidos y principales procesos involucrados en la maduración y senescencia de los frutos cítricos. Adaptado de Goldschmidt (2000).

\subsubsection{Características Varietales}

Las diferencias de coloración entre las distintas especies y cultivares de mandarinas, naranjas, pomelos o limones se explican mayoritariamente por la composición de carotenoides del flavedo. Los frutos cítricos de color naranja (mandarinas, naranjas y naranjo amargo) contienen cantidades relativamente altas de una mezcla compleja de carotenoides, como el anaranjado $\beta$ criptoxantina ( $\beta$ - $\beta$-caroten-3-ol) y el rojo $\beta$-citraurina (3-hidroxy-8'-apo- $\beta$ caroten-8'-al), que se encuentran en pequeñas cantidades pero posee una coloración muy intensa (Gross, 1981).

Dentro de las mandarinas, los frutos del grupo Satsuma (Citrus unshiu Marc.) son de coloración amarillo-naranja y acumulan $\beta$-criptoxantina en el flavedo y en las vesículas de zumo de sus frutos maduros (Goodner et al., 
2001; Ikoma et al., 2001). La mandarina 'Dancy' (Citrus reticulata Blanco), de color naranaja intenso, presenta altos contenidos de violaxantina $(50 \%)$, pero los responsables de su atractiva coloración son la $\beta$-citraurina (8\%) y $\beta$ criptoxantina (14\%), que se encuentran en alta proporción en relación con el contenido de estos pigmentos en otros cultivares (Gross, 1981).

Los frutos maduros de naranjo dulce (Citrus sinensis L.Osb.) acumulan, predominantemente, isómeros de la violaxantina (Lee y Castle, 2001), principalmente 9-cis-violaxantina (Molnár y Szabolcs, 1980; Rodrigo et al., 2003; 2006).

Los frutos maduros de las especies amarillas (pummelo, pomelo, limón y limas) presentan menor concentración de carotenoides totales que las naranjas $y$ un alto porcentaje de carotenoides incoloros (fitoeno y fitoflueno). En frutos maduros de limón 'Eureka', el fitoflueno representa el 18\% de los carotenoides del flavedo (Yokohama y Vandercook, 1967). En el pomelo 'Marsh seedless' (Citrus Paradisi Macf.), el fitoeno y el fitoflueno suponen, respectivamente, el $46 \%$ y $16 \%$ de los carotenoides del flavedo (Romojaro et al., 1979). La acumulación de estos precursores incoloros es consecuencia de un bloqueo metabólico, genéticamente determinado, que impide los pasos siguientes de deshidrogenación que dan lugar a los carotenoides. En los cultivares de pomelos rosados y rojos, los principales carotenoides, sobre todo en la pulpa, son licopeno y $\beta$-caroteno, lo que indica que en éstos se ha levantado el bloqueo genético (Yokoyama y Keithley, 1991).

Con respecto al momento de maduración, existen diferencias entre especies, y cultivares aún dentro de un mismo grupo. Dentro de las mandarinas tempranas del grupo de las Satsumas, la 'Hashimoto' en España madura 15-20 días antes que la 'Okitsu' o la 'Clausellina', las cuales, a su vez, maduran entre 5-10 días antes que la 'Owari', de la cual se originaron espontáneamente por mutación gemaria (Saunt, 2000). En el grupo de las clementinas, existe una diferencia de, por lo menos, dos meses en el período de maduración de los cultivares más tempranos, como 'Marisol' u 'Oroval', pasando por cultivares de maduración intermedia, como 'Fina' o su mutante 'Nules', hasta los más tardíos, como 'Hernandina' o el híbrido 'Fortune' (Saunt, 2000). En las naranjas del grupo navel, la 'Navelina', 'Newhall' y 'Bahianinha', originadas probable por mutación gemaria de la 'Washington navel', maduran por lo menos dos 
semanas antes que ésta, mientras que la 'Navelate' y la 'Lane Late', (mutaciones espontáneas de la 'Washington navel') lo hacen posteriormente (36 semanas) (Saunt, 2000).

Se ha citado, también, la posible asociación del portainjerto con el momento de maduración de los frutos, pero la información disponible no es consistente. La mayoría de los estudios indican que los pies que tienden a producir árboles más vigorosos (Citrus jambhiri, C. macrophylla, $C$. pennivesiculata, $C$. limonia) retrasan el viraje de color respecto a los menos vigorosos [C. aurantium, citranges 'Troyer' y 'Carrizo' $(P$. trifoliata $\times C$. sinensis), Poncirus trifoliata)] (Sing, 1948, 1954, Bitters, 1961, Bowden, 1968). En caso de producirse reverdización, ésta se da más tempranamente y de forma más intensa en los patrones vigorosos (Harding et al., 1940, Reitz y Embleton, 1986). Por el contrario, Albert (1973) encontró que el pie más vigoroso (C. aurantium) adelanta la maduración externa de mandarinas Satsumas en comparación con $C$. reshni. Finalmente, algunos autores no han encontrado relación entre la coloración de los frutos y el portainjerto utilizado (Harding et al., 1940, Ortiz et al., 1986).

\subsubsection{Evolución de pigmentos en el flavedo de los frutos}

Durante el crecimiento y desarrollo del fruto se producen cambios cuantitativos y cualitativos en la composición de pigmentos en el flavedo. En las dos primeras fases de crecimiento, las clorofilas son los pigmentos preponderantes. En la tercera, sobreviene la degradación de las mismas, que revela la presencia de carotenoides que, a su vez, aumentan en la corteza (Eilati et al., 1969b; Gross, 1981, Alós et al., 2006). El desarrollo del color es consecuencia de la transformación de los cloroplastos fotosintéticamente activos en cromoplastos (Thomson, 1966; Gross et al., 1983). El mismo depende del contenido de carotenoides, de la disposición fisicoquímica en los plástidos y del patrón de localización de los plástidos en el tejido (Gross, 1977).

El desverdizado natural de los frutos cítricos se caracteriza por la reducción de las clorofilas a y $b$, junto con la disminución de $\beta, \varepsilon$-carotenoides, $\beta$-caroteno, neoxantina y todos los E-violaxantina, y el aumento de $\beta, \beta$ - 
xantofilas [principalmente (9-cis)-violaxantina y $\beta$-criptoxantina]. Estos cambios se relacionan a nivel de transcriptores, con una reducción marcada del 1deoxy-D-Xilulosa 5 -fosfato sintasa (DXS) y geranylgeranyl reductasa (CHL P), y un incremento en la expresión génica de la feorbófido oxigenasa $(\mathrm{PaO})$ y fitoeno sintasa (PSY) (Alós et al., 2006).

La evolución de clorofilas estudiada in situ en tres zonas del fruto (peduncular, ecuatorial y estilar) de naranjo dulce 'Valencia', es irregular en la superficie del mismo. Durante el período de degradación de clorofilas, la zona peduncular retiene este pigmento por más tiempo que la zona estilar y el reverdecimiento también se da más fuertemente, obteniendo mayor concentración de clorofilas en dicha zona que en la distal (Huff, 1984). Se han encontrado excepciones a este modo de evolución del color como es el caso del naranjo dulce 'Navelate'. La desverdización natural del fruto es un proceso reversible (Huff, 1983). Cuando ocurre reverdecimiento, éste consiste en regenerar la construcción de clorofila y las membranas de los cloroplastos y restaurar parcialmente las actividades fotosintéticas (Thomson et al., 1967; Saks et al., 1988). Existen cultivares como la naranja 'Valencia' (Coggins y Lewis, 1962; Huff, 1984) y el tangor 'Ortanique' (Gravina et al., 2004) que pasado el período de maduración, si los frutos permanecen en la planta reverdecen, y en el caso de 'Valencia' el proceso se acelera con aplicaciones exógenas de sal potásica de ácido giberélico (Coggins y Lewis, 1962) y de nitrógeno (Jones y Embleton, 1959; Embleton et al., 1973).

La clorofilasa se expresa constitutivamente a lo largo del desarrollo del fruto y no parece incrementarse durante las etapas de maduración y senescencia (Jacob-Wilk et al., 1999). Sin embargo, la aplicación exógena de etileno incrementa el contenido de ARNm de la clorofilasa en la piel, los niveles de la enzima y las pérdidas de clorofila, especialmente en los dos meses previos al cambio de color, y reprime la biosíntesis de la clorofila (Fujii et al., 2007). Los bajos niveles constitutivos de etileno son necesarios, por tanto, para la baja expresión constitutiva de los genes de la clorofilasa. Esto explicaría por qué el bloqueo de la percepción del etileno retrasa el desverdizado (Goldschmidt et al., 1993), por qué existe respuesta a la aplicación exógena del mismo (desverdizado y aumento de niveles de ARNm de clorofilasa) y por qué el $\mathrm{GA}_{3}$, que reduce la abundancia de $\mathrm{ARNm}$ de la clorofilasa, disminuye el 
desverdizado. Los niveles de clorofila, bajo este punto de vista, estarían determinados por un balance entre su síntesis y su degradación y el cambio de color ocurriría como consecuencia del desplazamiento de dicho balance hacia la disminución de la síntesis de clorofila (Jacob-Wilk et al., 1999).

Durante el proceso de desverdizado, la piel de los cítricos acumula grandes cantidades de carotenoides oxigenados responsables de la coloración (Eilati et al., 1969b; Goldschmidt et al., 1973; Molnár y Szabolcs, 1980; Gross, 1981; Rodrigo et al., 2003, 2006). La concentración y composición de éstos varía considerablemente entre las distintas especies y cultivares y depende de las condiciones ambientales (Gross, 1977). Se ha demostrado que la intensidad de la coloración se asocia al incremento en el contenido de (9Z)violaxantina y $\beta$-citraurina, junto con la disminución de la relación (9Z)violaxantina: $\beta$-citraurina (Oberholster et al., 2001). El desverdizado de frutos de mandarina 'Satsuma' y naranja 'Valencia' se asocia a la desaparición de los transcriptores CitLCYe y al incremento de los transcriptores CitLCYb, los cuales causan el cambio de ruta de síntesis de $\beta, \varepsilon$-carotenoides a $\beta, \beta$ carotenoides. Simultáneamente aumenta la expresión de los genes (CitPSY, CitPDS, CitZDS, CitLCYb, CitHYb y CitZEP) que dan lugar a la acumulación masiva de $\beta$ - $\beta$-xantofila en el flavedo y en las vesículas de jugo (Kato et al., 2004).

\subsubsection{Aspectos hormonales relacionados con la maduración}

\subsubsection{Principales hormonas asociadas con la promoción de la maduración}

\subsection{Etileno}

Los frutos cítricos presentan una producción de etileno baja y constante durante la maduración (Aharoni, 1968; Eaks, 1970; Goldshmidt et al., 1993), pero su aplicación exógena estimula el cambio de color (Pons et al., 1992; Goldschmidt et al., 1993), al mismo tiempo que la aplicación de inhibidores de la acción del etileno como nitrato de plata $\left(\mathrm{AgNO}_{3}\right)$, norbornadiene (NBD) 
(Goldschmidt et al., 1993) o 1-MCP (1-metilciclopropeno) (Porat et al., 1999), disminuyen la pérdida de clorofilas de naranjas cosechadas verdes.

Se ha probado que la aplicación de etileno promueve la degradación de clorofilas (Shimokawa et al., 1978, Katz et al., 2004; Fujii et al., 2007) a través de la síntesis de novo de la fenilamonioliasa (Riov et al., 1969) y la síntesis de novo (Trebitsh et al., 1993) y la actividad (Purvis y Barmore, 1981) de la clorofilasa. En el flavedo de los frutos, el ARNm de la clorofilasa se incrementa fuertemente en respuesta al tratamiento de etileno (Jacob-Wilk et al., 1999; Fujii et al., 2007). Por el contrario, éste suprime la transcripción del gen que codifica la magnesio-quelatasa, primera y única enzima en la ruta de biosíntesis de la clorofila que media la inserción del $\mathrm{Mg}^{2+}$ en protoporfirina IX. También inhibe la transcripción de la proteína de ligamento de clorofila a/b, de la subunidad del fotosistema I y de la ribulosa 1,5-bifosfato carboxilasa (Fujii et al., 2007). Por lo tanto, se ha probado que a nivel transcripcional el etileno tiene dos funciones: una promoviendo la descomposición de la clorofila y otra suprimiendo la biosíntesis de la misma.

Con respecto a los carotenoides y su relación con la aplicación de etileno, por un lado se cita que no varía el contenido total de carotenoides en el flavedo de los frutos (Fujii et al., 2007) y contrariamente Rodrigo y Zacarías (2007) encuentran un aumento del $55 \%$ tras el tratamiento. En ambos casos los autores demuestran que el etileno exógeno afecta la composición de los carotenoides. En el caso de la mandarina Satsuma, duplica el contenido de $\beta$ criptoxantina y disminuye la relación trans-violaxantina: 9-cis-violaxantina $(29 \%$ y $46 \%$ en tratados con etileno y control, respectivamente) (Fuji et al., 2007). La expresión de la mayoría de los genes en respuesta a la aplicación exógena de etileno ocurre también durante el curso natural de la maduración de la piel de los frutos (Rodrigo et al., 2006). Esto sugiere que el nivel endógeno de esta hormona tiene efecto en la regulación de la maduración, y que aplicado exógenamente reproduce y acelera los cambios fisiológicos y moleculares que ocurren durante la degradación de clorofilas y biosíntesis de carotenoides.

En síntesis, el etileno reprime la transcripción de la mayoría de los genes involucrados en la fotosíntesis y la biogénesis de los cloroplastos, e induce la transcripción de genes relacionados con la biosíntesis de los carotenoides, con 
diferentes patrones de respuesta y sensibilidad al etileno, afectando directamente la composición de los mismos en los frutos (Fujii et al., 2007).

\subsubsection{2. Ácido Abscísico}

El ácido abscísico (ABA) pertenece a la clase de metabolitos conocidos como isoprenoides o terpenoides derivados de un precursor común: el isopentenil (IDP). Inicialmente se creía que todos los isoprenoides provenían del ácido mevalónico (MVA), sin embargo, recientemente se descubrió una ruta alternativa, independiente de la MVA, Ilamada MEP (2-C-metil-D-eritritol-4fosfato). En las plantas superiores coexisten ambas rutas, y aunque el ABA contiene 15 átomos de carbono, no deriva directamente del precursor $C_{15}$ farnesil difosfato (FDP), sino que se origina por clivaje de un carotenoide $\mathrm{C}_{40} \mathrm{a}$ través de la ruta MEP, compuesto originado a partir del gliceraldehido-3-fosfato y piruvato. Existen revisiones recientes en las que se describen las rutas de biosíntesis de ABA, particularmente la MEP, para otras especies vegetales (Eisenreich et al., 2004; Fraser y Bramley, 2004), así como también la ruta posterior a la formación de xantofilas y las rutas catabólicas (Nambara y Marion-Poll, 2005).

Con respecto a los frutos cítricos, en la última década ha habido importantes avances en el estudio de la biosíntesis de los carotenoides y, consecuentemente, del ABA. Durante la maduración, la piel de los frutos acumula carotenoides oxigenados (Molnár y Szabolcs, 1980; Rodrigo et al., 2003, 2006) y ácido abscísico (Goldschmidt, 1976; Aung et al., 1991; Lafuente et al., 1997, Rodrigo et al., 2003, Agustí et al., 2007). Los epoxy-carotenoides, violaxantina y neoxantina, son precursores del ABA (Rock y Zeevaart, 1991). Se ha probado que diferentes transcriptores de la enzima CsNCED, que controla el paso crítico en la biosíntesis del ABA, se expresan en mayores niveles en frutos cítricos maduros que inmaduros (Rodrigo et al., 2006, Agustí et al., 2007) lo que reafirma la importancia del ABA en el desarrollo del color de los frutos. Recientemente se descubrió que 'Pinalate', un mutante del naranjo dulce 'Navelate' con fruto de color amarillo, contiene entre tres y seis veces menos contenido de ABA en el flavedo que su parental, debido a una alteración 
específica del fruto en la ruta de desaturación de carotenoides, probablemente en la $\zeta$-caroteno desaturasa (Rodrigo et al., 2003).

Por otro lado, la aplicación exógena de ABA aumenta el contenido endógeno del mismo en el flavedo de los frutos, sin afectar el del albedo, y no afecta la producción de etileno (Rasmussen, 1974). Sin embargo, cuando el ABA es introducido por el pedúnculo del fruto, provoca un aumento en la producción de etileno (Rasmussen, 1974), probablemente debido a la síntesis de ACC (Riov et al., 1990) y/o de ACO (Riov y Hausman, 1988).

\subsubsection{Principales hormonas asociadas con el retraso de la maduración}

\subsection{Giberelinas}

Las giberelinas (GAs) son ácidos diterpenoides tetracíclicos con un sistema de anillo ent-giberelano. Existen dos grandes tipos de giberelinas, las $\mathrm{C}_{20}$-GAs con 20 átomos de carbono y las $\mathrm{C}_{19}$-GAs que han perdido el vigésimo $C$, y en las que el ácido carboxílico del $C_{19}$, en general, se une al del $C_{10}$. En cítricos se ha determinado que el crecimiento vegetativo y reproductivo depende, en gran medida, de los niveles de $\mathrm{GA}_{1}$ (Talón et al., 1992).

El papel antisenescente de las giberelinas ha sido estudiado durante más de cuatro décadas. En los frutos cítricos se ha citado que la mayor actividad tipo-GAs se da desde la antesis hasta, aproximadamente, 14 semanas después de la caída de pétalos, (Ali-Dinar et al., 1988; Hofman, 1990; Murti, 1989), o hasta el comienzo de la pérdida de clorofilas (García-Luis et al., 1985) y disminuye rápidamente cuando el fruto llega a la madurez (Kuraoka et al., 1977). Asimismo, se ha registrado mayor nivel de GAs en el flavedo y albedo de frutos con piel rugosa y coloración más verde (Erner et al., 1976), y mayor actividad de GAs en el flavedo que precede el reverdecimiento de la naranja 'Valencia' (Rasmussen, 1973). Igualmente se ha sugerido que la aplicación de giberelato de potasio promueve la síntesis de clorofilas a y b en el flavedo de los frutos aún iniciado el cambio de color (Lewis et al., 1964). Parece, pues, que los frutos cítricos comienzan a madurar externamente cuando el contenido endógeno de GAs en el flavedo disminuye. 
Por otro lado, el ácido giberélico $\left(\mathrm{GA}_{3}\right)$ aplicado previo al cambio de color retrasa la pérdida de color de los frutos (Goldschmidt and Eilati, 1970, Kuraoka et al., 1977) a través de un retraso en la degradación de clorofilas (Agustí et al., 1988; Alós et al., 2006) y en algunos casos en la síntesis de carotenoides (Lewis y Coggins, 1964; García-Luis et al., 1985). Adicionalmente, mantiene la firmeza de la piel, es decir, mantiene a ésta durante más tiempo en un estado juvenil, en distintas especies y cultivares de Citrus (Coggins et al., 1960a,b; Goldschmidt y Eilati, 1970, Kuraoka et al., 1977, Agustí et al., 1981; García-Luis et al., 1985).

En el mismo sentido, se ha citado que la aplicación de un inhibidor de la biosíntesis de las giberelinas (prohexadione calcio), promueve la coloración en naranjas 'Navelina', 8 y 15 días después de su aplicación, a través del aumento de carotenoides en el flavedo y de una leve, pero no significativa, disminución del contenido de clorofila a (Barry y van Wyk, 2004). El mismo inhibidor mejora el color de la piel de 'Clementina de Nules', 'Navelina' y 'Palmer' navel a través del incremento del contenido de carotenoides y la disminución del de clorofilas en el flavedo de los frutos, antes y después del desverdizado con etileno (Barry y le Roux, 2008).

A nivel bioquímico, la aplicación de ácido giberélico además de retrasar la acumulación total de carotenoides altera su composición. En frutos de mandarina clementina tratados con $\mathrm{GA}_{3}$ se mantiene por más tiempo los carotenoides típicos de frutos verdes (luteina, $\alpha$-caroteno, $\beta$-caroteno, todos los $E$-violaxantinas y neoxantina) y se reduce la acumulación de $\beta, \beta$-xantofila [fitoeno y (9-cis)-violaxantina] (Alós et al., 2006). A nivel de transcriptores, se retrasa la reducción de la expresión de la DXS y la inducción de la acumulación de los transcriptores $\mathrm{PaO}$ y PSY, sin afectar la $\mathrm{CHL}$ P. Estos resultados sugieren que en los frutos cítricos, el retraso de la toma de color causado por las giberelinas es debido a la represión de la expresión natural de PaO y PSY, lo que explicaría los elevados niveles de clorofila y la baja concentración de carotenoides encontrados en los frutos tratados (Alós et al., 2006). 


\subsection{Auxinas}

En las plantas se encuentran naturalmente diversos tipos de auxinas que incluyen las indólicas, como el ácido 3-indol acético (IAA) y sus derivados halogenados, el ácido 4-clorindol-3-acetico (4-Cl-IAA) y el ácido 3-indol butírico (IBA), así como varios ácidos fenólicos, como el ácido fenilacético.

La información disponible sobre el efecto de las auxinas en la fase de maduración de frutos cítricos es escasa. Se ha citado que aplicadas exógenamente retrasan la senescencia (Frenkel y Dick, 1973) y abscisión de los frutos (Gardner, 1941; Cooper et al., 1968; Tzur y Goren, 1977; Agustí et al., 2006). Asi, el control de la caída pre-cosecha de frutos con la aplicación foliar de 2,4-D (éster isopropílico del ácido 2,4-diclorofenoxiacético) o 2,4-DP (éster 2-etilhexil del ácido 2,4-diclorofenoxipropiónico) se ha mostrado eficaz en los cvs. de naranjo dulce 'Washington navel' y 'Navelate' (Agustí et al, 2006). Se ha demostrado que el 2,4-D actúa a través de la inhibición de la actividad celulasa (Goren, 1993) y se ha sugerido el mismo modo de acción para el caso del NAA (ácido naftalenacético), el 3,5,6-TPA (ácido 3,5,6-tricloro-2piridiloxiacético) (Anthony y Coggins, 2001) y el 2,4-DP (Agustí et al., 2006).

\subsection{Citoquininas}

La principal citoquinina libre en la mayoría de las plantas es la transzeatina, aunque también se encuentran presentes la adenina dihidrozeatina y la isopentenil-6-adenina, así como los ribósidos y ribótidos de zeazatina, dihidrozeatina e isopenteniladenosina.

La información respecto de la acción de las citoquininas sobre la maduración y senescencia de los frutos cítricos no es consistente. Por un lado, se ha citado que la benciladenina retrasa el cambio de color del flavedo de las naranjas, asociado al mantenimiento de los niveles endógenos de giberelinas y a la prevención del aumento del ácido abscísico y del etileno (van Staden et al., 1988), por otro, García-Luis et al. (1986) no lograron retrasar el desverdizado con benciladenina ni con cinetina en mandarina Satsuma. 


\subsection{Poliaminas}

Las poliaminas (PAs) son un grupo de compuestos nitrogenados de bajo peso molecular que se presentan en las células de todos los seres vivos (Galston, 1983). Por su carácter policatiónico pueden unirse y formar complejos con moléculas polianiónicas tales como algunas proteínas, los fosfolípidos, las pectinas, el ADN y el ARN, entre otras (Galston 1983). Las más abundantes en las plantas son la putrescina (Put), la espermidina (Spd) y la espermina (Spm).

La síntesis de las poliaminas Spd y Spm ocurre a partir de la adición a la Put de uno o dos grupos aminopropilo donados por la S-adenosilmetionina descarboxilada (dSAM), que deriva de la descarboxilación del SAM (Slocum, 1991; Andersen et al. 1998). En este sentido, las PAs podrían considerarse competidoras del etileno en su síntesis y, por tanto, en su abundancia en la planta (Kushad y Dumbroff, 1991), pero esta hipótesis está aún por confirmar.

En coherencia con ello, las PAs se comportan como efectivos agentes antisenescentes en numerosas especies vegetales, ya que retrasan la pérdida de clorofilas, el deterioro de las membranas y los incrementos de las actividades ARNasas y proteasas (Evans y Malmberg, 1989). La aplicación exógena de Put a limones en dos estados de desarrollo (al cambio de color y totalmente amarillos), mejora la firmeza de los frutos y disminuye la pérdida de peso en la post-cosecha. El tratamiento retrasa el cambio de color y disimuye el contenido endógeno de ABA. Por otro lado, incrementa el nivel endógeno de Put y Spd en los frutos más maduros (Valero et al., 1998). Pero el papel hormonal de las PAs es controversial. Así durante el cuajado de las mandarinas se les ha atribuido un papel como fuente de nitrógeno, más que un papel hormonal regulador del proceso (Arias et al., 2005).

\subsubsection{Interacción hormonal}

Con respecto a las hormonas asociadas a la promoción de la maduración, se ha reportado que la aplicación de etileno induce un incremento del contenido total de ABA en el flavedo de los frutos cítricos (Goldschmidt et al., 1973, Lafuente et al., 1997, Rodrigo et al., 2006). En este sentido, se ha 
probado que la expresión de la mayoría de los genes que codifican enzimas que actúan promoviendo la ruta de biosíntesis de carotenoides en el flavedo de los frutos, aumenta inducida por la aplicación de etileno durante la maduración (Rodrigo et al., 2006; Fujii et al., 2007), dando lugar al mencionado incremento de ABA.

Por otra parte, la aplicación de $\mathrm{GA}_{3}$ contrarresta la degradación de la clorofila inducida por el etileno (Goldschmidt et al., 1977; García Luis et al., 1986). Se ha probado que el $\mathrm{GA}_{3}$, y en menor medida la $\mathrm{N}^{6}$-benciladenina, disminuye la actividad de la proteína clorofilasa inducida por éste (Trebitsh et al., 1993) y que el $\mathrm{GA}_{3}$ disminuye los niveles de ARNm de la clorofilasa (JacobWilk et al., 1999). De igual manera, el $\mathrm{GA}_{3}$ parece contrarrestar el efecto del etileno reprimiendo la transcripción de genes de la biosíntesis de los carotenoides estimulados por el mismo (Rodrigo y Zacarías, 2007; Fujii et al., 2008). Considerando que los cítricos producen bajos niveles de etileno, el nivel endógeno de giberelinas podría repercutir de forma importante en la regulación endógena de la maduración y senescencia de los frutos.

Las GAs y el ABA tienen en su ruta de síntesis puntos en común, vía síntesis de terpenos. El farnesil pirofosfato puede dar lugar al $A B A$ a través de los carotenoides, o dar lugar al GGPP, mediante la adición de una molécula de IPP, diterpeno que mediante una ciclación forma el ent-kaureno, considerado el paso inicial de la síntesis de GAs. Además las GAs regulan positivamente la expresión del gen CYP707A3 (Saito et al., 2004), que codifica la ABA 8'hidroxilasa, y, por lo tanto, promueve el primer paso en la inactivación del ABA (Nambara y Marion-Poll, 2005).

\subsubsection{Aspectos nutricionales relacionados con la maduración}

\subsubsection{Carbohidratos}

Durante la fase I del crecimiento del fruto, éste consume carbohidratos para sustentar la división celular, mientras que a partir de la fase II se convierte en una fosa de almacenamiento (Mehouachi et al. 1995; Gómez-Cadenas et al. 2000). La concentración de sacarosa (principal carbohidrato de translocación) y 
de glucosa y fructosa (principales hexosas en cítricos) aumenta a lo largo del desarrollo del fruto.

El color del flavedo también se relaciona positivamente con su concentración de azúcares solubles (Huff, 1984, Sala et al., 1992, Holland et al., 1999). En naranja 'Valencia' se ha encontrado una correlación negativa lineal entre el contenido de clorofila y los azúcares del epicarpo (Huff, 1984). En 'Navelina' se ha comprobado una regresión positiva lineal entre el color anaranjado del fruto y el contenido de glucosa, fructosa, azúcares totales y la relación azúcares reductores: azúcares no reductores (Sala et al., 1992). En mandarina Satsuma la aplicación de sacarosa in vivo acelera el cambio de color, incrementa la concentración endógena de sacarosa y reduce la de nitrógeno (Iglesias et al., 2001).

En el otoño, el extremo peduncular del fruto de naranja 'Valencia' tiene menor concentración de azúcares solubles que el extremo estilar, inversamente a lo que ocurre con el contenido de clorofilas en ambas zonas del fruto. En la primavera se revierte la situación y la zona peduncular contiene los mayores valores de $\mathrm{CHOs}$, pero cuando comienza a reverdecer nuevamente, pierde los azúcares y reverdece más rápidamente. Las mayores fluctuaciones durante el desverdizado y reverdecimiento del flavedo se dan en los azúcares reductores (Huff, 1984).

Las hojas cercanas al fruto parecen estar fuertemente involucradas en el proceso de desverdizado. En efecto, la defoliación bloquea la acumulación de sacarosa y la reducción de nitrógeno en el flavedo de los frutos, lo que inhibe la pérdida de clorofila de los mismos (Iglesias et al., 2001).

Adicionalmente, a nivel molecular se ha probado que la aplicación de etileno, que promueve el desverdizado de los frutos, reprime la transcripción de la mayoría de los genes involucrados en la fotosíntesis, la biogénesis de los cloroplastos y el metabolismo de los azúcares, excepto el de un transportador de sacarosa y el de la invertasa ácida, estimulados en la piel de los frutos por este regulador (Fujii et al., 2007). En el mismo sentido, la aplicación exógena de $\mathrm{GA}_{3}$, que retrasa el cambio de color, reprime la transcripción del gen CitINV1 (Fuji et al., 2008), asociado a la ruptura de sacarosa en hexosas durante la maduración y regula la sacarosa sintasa y la invertasa ácida (Holland et al., 1999; Kubo et al., 2001). 
En síntesis, el contenido endógeno de carbohidratos en el flavedo, el transporte de sacarosa y su hidrólisis en hexosas, se encuentran directamente asociados al cambio de color de los frutos cítricos.

\subsubsection{Nitrógeno}

El metabolismo del nitrógeno parece estar fuertemente involucrado en el proceso de maduración de los frutos cítricos. Así, aplicaciones tardías (Jones y Embleton, 1959; Sala et al., 1992; Quiñones et al., 2004) y la fertilización abundante con este elemento mineral (Jones y Embleton, 1959; Lee y Chapman, 1988) retrasan el cambio de color y aumentan el porcentaje de frutos verdes en el momento de la cosecha (Koo y Reese, 1977). De igual manera, fertilizaciones nitrogenadas excesivas (Jones y Embleton, 1959; Embleton et al., 1973) o tardías (verano-otoño con respecto a primavera) promueven el reverdecimiento de los frutos (Jones y Embleton, 1959).

Huff (1983) demostró que cuando se mantienen discos de epicarpio de cítricos maduros en un medio de cultivo completo y se van retirando componentes, solo el nitrógeno es necesario para el reverdecimiento de los mismos (Huff, 1983). De las fuentes orgánicas e inorgánicas de $\mathrm{N}$ probadas, las más eficientes fueron las sales de nitratos y más aún las divalentes $\left(\mathrm{CaNO}_{3}, \mathrm{MgNO}_{3}\right)$. Las sales de amonio no produjeron reverdecimiento y el $\mathrm{NH}_{4} \mathrm{NO}_{3}$ tardó más en lograr un menor efecto. De los aminoácidos, el más eficiente fue la L-glutamina, seguido de L-glutamato y L-alanina. La glicina y Larginina se comportaron como el $\mathrm{NH}_{4} \mathrm{NO}_{3}$, mientras que la L-asparragina logró un reverdecimiento muy leve y la L-serina inhibió fuertemente el reverdecimiento (Huff, 1983).

La relación entre el cambio de color de los frutos y el contenido endógeno de fracciones nitrogenadas no es tan consistente. Algunos autores no han encontrado cambios en el contenido de proteínas totales (Lewis et al., 1967), N total (Huff, 1984, Win et al., 2006) o aminoácidos en C.sinensis y C.madurensis (Huff, 1984) durante la maduración de los frutos. Collado et al. (1996), sin embargo, encuentran mayor concentración de proteínas totales en 
el flavedo de frutos cítricos maduros, pero Iglesias et al. (2001) hallan menor concentración de nitrógeno total en éstos.

La aplicación de nitratos previa a la maduración retarda la pérdida de clorofilas y altera la composición y el contenido total de carotenoides en el flavedo de los frutos, fundamentalmente debido a la represión de la expresión natural de PaO y PSY, de un modo similar a lo que ocurre con la aplicación de $\mathrm{GA}_{3}$ (Alós et al., 2006).

En general, la aplicación de nitrógeno, especialmente nitratos, ralentiza el proceso de desverdizado de los frutos cítricos, disminuyendo la pérdida de clorofilas y la síntesis de carotenoides en el flavedo. El contenido endógeno de nitrógeno en este tejido parece estar inversamente relacionado al color de los frutos, pero aún existen inconsistencias entre los resultados.

\subsubsection{Otros nutrientes minerales}

Se ha citado que fertilizaciones con altos niveles de potasio retrasan el viraje de color y aumentan la proporción de frutos verdes (Embleton et al., 1967; Koo y Reese, 1977; Lee y Chapman, 1988). En el caso de naranja 'Valencia' aumenta también la proporción de frutos que reverdizan (Reuther y Smith, 1952). Sin embargo, Bañuls et al., (2004) lograron mejorar el índice de color de la mandarina 'Clementina de Nules' con tres aplicaciones foliares de $\mathrm{KNO}_{3}(0.5 \%, 1 \%$ y $1.5 \%)$ en primavera-verano, verano y verano-otoño, respecto de los árboles sin tratar.

Con respecto a la aplicación de fósforo, los resultados no son consistentes. En general la toma de color de los frutos se ha relacionado negativamente con este nutriente. Se ha logrado una coloración más intensa en árboles deficientes en fósforo (Chapman y Reyner, 1951) y al aumentar el contenido foliar de este mineral $(0.10 \%$ a $0.21 \%)$ se observa un ligero reverdecimiento de frutos (Embleton et al., 1971). Sin embargo, en otros trabajos no se encuentran diferencias en el color de naranjas (Koo y Reese, 1976) y limones (Embleton et al., 1967) tratados con distintas concentraciones de $P$. 
El calcio es un mineral esencial en lo que respecta al mantenimiento de las paredes celulares, en especial por reducir la permeabilidad de la cutícula (Zaragoza et al., 1996), y está demostrada su eficacia en el control de algunos desórdenes fisiológicos relacionados con la senescencia, como el 'creasing' (Treeby et al., 2000) y el 'peel pitting' (Zaragoza et al., 1996). En el mismo sentido, el tratamiento con cloruro de calcio de frutos de limón en etapas inmediatamente anteriores al cambio de color, retrasa su coloración y mantiene la firmeza de los mismos durante la post-cosecha (Valero et al., 1998).

\subsubsection{Factores ambientales relacionados con la maduración}

Con respecto a la regulación climática, esta última fase del desarrollo del fruto se ha asociado al descenso de la temperatura, en la medida en que la mayoría de los cítricos comienza a madurar externamente a partir del inicio del otoño, cuando el árbol reduce la absorción y el transporte de nitrógeno, la síntesis de giberelinas, y la competencia por carbohidratos entre el fruto y el desarrollo vegetativo, beneficia a aquél. La existencia de diferencias de coloración (intensidad y momento de viraje) a lo largo de los años para un mismo cultivar en una misma parcela, y en condiciones similares de cultivo, permite suponer que los factores ambientales regulan el cambio de color de los frutos.

Por otro lado, los frutos que crecen en condiciones tropicales nunca logran alcanzar la coloración completa (Erickson, 1960; Reuther y RíosCastaño, 1969; Samson, 1980). Sin embargo, existen excepciones como es el caso del 'Calamondín' (C.madurensis Lour.) que no requiere bajas temperaturas para madurar externamente, de hecho lo hace varias veces al año y sus frutos no reverdecen (Huff, 1984).

La luz también se ha citado como factor importante promoviendo la maduración (Sites y Reitz, 1949, Iwagaki, 1981). 


\subsubsection{Relación entre la temperatura y el cambio de color de los frutos}

\subsection{Temperatura del aire}

Estudios realizados con los naranjos dulces 'Hamlin', 'Parson Brown' y 'Pineapple' indican que el viraje de color en esta especie se da cuando las temperaturas mínimas del aire descienden por debajo de 12,8 $\mathrm{C}$ (Stearns y Young, 1942). En el mismo sentido, el reverdecimiento de los frutos de naranja 'Valencia' es promovido por temperaturas relativamente altas $\left(30^{\circ} \mathrm{C} / 15^{\circ} \mathrm{C}\right.$ día/noche) (Coggins et al., 1981). Un estudio realizado sobre la influencia de la temperatura en la evolución del color de frutos de limón indica que las coordenadas colorimétricas Hunter muestran mayor correlación con las temperaturas mínimas que con las temperaturas medias (Manera et al., 2008). Particularmente, la pérdida del tono verde comienza cuando las temperaturas mínimas descienden hasta aproximadamente $12^{\circ} \mathrm{C}$ y el aumento de la coloración amarilla a los $14^{\circ} \mathrm{C}$.

La temperatura nocturna también se ha relacionado con la coloración, en la medida que los frutos cítricos necesitan temperaturas nocturnas inferiores a $12^{\circ} \mathrm{C}$ para desarrollar óptimamente su color (Young y Erickson, 1961). Asimismo, se ha citado la importancia de la amplitud térmica entre el día y la noche durante el período de maduración. En trabajos experimentales realizados con el naranjo dulce 'Valencia' se ha logrado mejor coloración y menor retención de clorofilas con la exposición durante dos meses a temperaturas diurnas/nocturnas de $20^{\circ} \mathrm{C} / 5{ }^{\circ} \mathrm{C}$, que a $30^{\circ} \mathrm{C} / 10^{\circ} \mathrm{C}$ o $28^{\circ} \mathrm{C} / 18^{\circ} \mathrm{C}$ (Erickson, 1960).

El inicio de la coloración en respuesta a las bajas temperaturas se ha atribuido fundamentalmente a la inhibición de la translocación de giberelinas desde las raíces (Eilati et al., 1969a) y a la reducción de la absorción de nitrógeno (Chapman y Parker, 1942) y translocación de éste desde las raíces hacia la parte aérea en plantones de limonero y naranjo (Wallace, 1953). Se ha probado que el epicarpio de 'Washington navel' pierde $\mathrm{N}$ en el otoño-invierno y lo recupera en la primavera, principalmente como $\mathrm{N}$ soluble y como aminoácidos libres (Lewis et al., 1967). El aumento de las temperaturas en 
primavera aumenta la absorción de $\mathrm{N}$, renovando el flujo de este elemento mineral al fruto.

En un estudio con mandarina Satsuma, Nii et al. (1970) encontraron menor contenido de clorofilas en la corteza de frutos de árboles mantenidos a bajas temperaturas durante las fases de expansión celular y de maduración, y un aumento importante del contenido de clorofilas con altas temperaturas nocturnas. De igual manera la temperatura afectó el contenido de xantofilas en el flavedo de los frutos, aumentando a $15^{\circ} \mathrm{C}, 20^{\circ} \mathrm{C}$ y $25^{\circ} \mathrm{C}$ y disminuyendo a $30^{\circ} \mathrm{C}$. En 'Calamondín' y Satsumas el viraje de color a $12-14{ }^{\circ} \mathrm{C}$ se da $4-6$ semanas antes que a $25-30^{\circ} \mathrm{C}$ (Sonnen et al, 1979).

Por otra parte, los frutos situados en laderas poco iluminadas tienen mejor coloración y casi el doble de carotenoides que los de las laderas más iluminadas (Miller et al., 1940, Stewart y Wheaton, 1973), por lo que se sugiere que las altas temperaturas a que están expuestos estos últimos impiden la formación de $\beta$-citraurina (pigmento que explica la diferencia). Por el contrario la menor concentración de clorofilas de las naranjas situadas en las zonas poco iluminadas del árbol se justifica por estar expuestas constantemente a temperaturas más bajas $\left(15^{\circ} \mathrm{C}-20^{\circ} \mathrm{C}\right)$ que las situadas en otras orientaciones $\left(25^{\circ} \mathrm{C}-30^{\circ} \mathrm{C}\right.$ ) (Nii et al., 1970). Adicionalmente, se ha observado que la cara interior de los frutos expuestos al sol tiene mejor coloración que la exterior, explicado también por permanecer a menor temperatura (Aranda, 1986); en efecto, se han citado diferencias de hasta $9^{\circ} \mathrm{C}$ entr e las zonas de los frutos expuesta y no expuesta a los rayos solares (Syverstsen y Albrigo, 1980).

Las bajas temperaturas provocan incrementos en la concentración de azúcar en la piel de los cítricos (Lewis et al., 1967). Así, en el epicarpio de frutos de pomelo se acumulan azúcares totales y reductores en respuesta a temperaturas inferiores a $10^{\circ} \mathrm{C}$, mientras que a fines del invierno, la concentración de azúcares totales en el epicarpio de C. paradisi se estabiliza, y con el aumento de las temperaturas hay una caída de la concentración de azúcares reductores y un incremento de la de sacarosa (Purvis y Grierson, 1982). Es probable que los factores ambientales, como la temperatura, actúen indirectamente sobre el metabolismo celular (Huff, 1984).

Con respecto al desverdizado de frutos almacenados, existen algunas diferencias sobre la temperatura óptima que promueve la formación de 
carotenoides pero en todos los casos el proceso se acelera a temperaturas inferiores a $25^{\circ} \mathrm{C}$. Así en trabajos realizados en naranjas 'Valencia, mandarinas 'Dancy', 'Robinson', 'Temple' y tangelo ‘Orlando' se determinó un rango óptimo entre $15^{\circ} \mathrm{C}$ y $25^{\circ} \mathrm{C}$, en relación a $30^{\circ} \mathrm{C}$ (Wheaton y Stewart, 1973), lo que coincide con el mejor desverdizado de las mandarinas 'Robinson' y 'Dancy', la naranja 'Hamlin', la lima 'Bearss' y el pomelo 'Marsh' logrado a $16^{\circ} \mathrm{C}$ que a $21^{\circ} \mathrm{C}$ ó $27^{\circ} \mathrm{C}$ (Jahn, 1973). Por otro lado, frutos de 'Ortanique' almacenados durante tres meses, obtuvieron mejor coloración a temperaturas entre $5 \stackrel{\circ}{\circ}$ y $8^{\circ} \mathrm{C}$ que a $11^{\circ} \mathrm{C}$ ó $17^{\circ} \mathrm{C}$ (Cohen et al., 1990).

La exposición de discos de flavedo a $4^{\circ} \mathrm{C}$ durante 2 a 10 horas y su posterior incubación a $20^{\circ} \mathrm{C}$ mejoró la coloración de los mismos, lo que sugiere que un 'shock de frío' favorece la acumulación de carotenoides en el flavedo (Oberholster, 2001). De igual manera, la realización de un 'shock térmico' (a $2^{\circ} \mathrm{C}$ durante 30 minutos y a $4^{\circ} \mathrm{C}$ durante 6 horas) a frutos de 'Clementina de Nules' mejoró su coloración a través de la reducción del contenido de clorofilas y el incremento de los carotenos en el flavedo (Barry y van Wyk, 2006). El tratamiento fue efectivo solamente si la fruta provenía de parcelas en las que la temperatura mínima del aire había sido superior a $13^{\circ} \mathrm{C}$.

Existen diferentes hipótesis acerca de cómo actúa la temperatura en el proceso. Según Goldschmidt (1988), la temperatura por sí misma no debe ser la causante de la degradación de las clorofilas y la síntesis de carotenoides, sino que probablemente actúe disminuyendo el crecimiento vegetativo. Éste es antagonista de la conversión de los cloroplastos en cromoplastos y, por lo tanto, retrasa la degradación de clorofilas y la síntesis de carotenoides. Por su lado, Huff (1983) propone que el cambio de color de los frutos en respuesta a las bajas temperaturas, podría reflejar la reducción del aporte de nitrogeno al fruto, acompañado por el aumento de los azúcares reductores. El reverdecimiento como consecuencia del aumento de la temperatura en primavera estaría asociado a la renovación del flujo de $\mathrm{N}$ y al reinicio del desarrollo de cloroplastos con los azucares reductores. 


\subsection{Temperatura del sistema radicular}

En los cítricos, el crecimiento radicular tiene lugar ininterrumpidamente mientras la temperatura del suelo, la humedad y la aireación sean adecuadas (Spiegel-Roy y Goldschmidt, 1996). La elongación de la raíz en estas especies se correlaciona linealmente con la temperatura del suelo entre $18^{\circ} \mathrm{C}$ y $28^{\circ} \mathrm{C}$ (Bevington y Castle, 1985), aunque el crecimiento más intenso es a partir de $29^{\circ} \mathrm{C}$ (Monselise, 1947), si bien temperaturas superiores a $36^{\circ} \mathrm{C}$ restringen su crecimiento (Castle, 1980). Por debajo de $22^{\circ} \mathrm{C}$ el crecimiento radicular es muy limitado (Bevington y Castle, 1985) y se detiene cuando la temperatura es inferior a $13^{\circ} \mathrm{C}$ (Castle, 1978). En plantones de limonero 'Eureka' y naranjo 'Valencia' se observó que la absorción y el transporte de nitrógeno aumentaba notablemente entre $9^{\circ} \mathrm{C}$ y $23^{\circ} \mathrm{C}$ y disminuía a partir de $27^{\circ} \mathrm{C}$ (Wallace, 1953).

A pesar de que la evidencia experimental es incompleta, la hipótesis de Huff (1983) de que mientras la temperatura permite el crecimiento radicular, las sustancias nitrogenadas llegan al fruto y retrasan su cambio de color debe ser tenida en cuenta. A ello contribuiría la síntesis hormonal (giberelinas y citoquininas) que en estas condiciones tiene lugar en múltiples meristemos apicales, y cuya translocación al fruto retardaría su senescencia y, por tanto, su entrada en color (Agustí, 2003). En el otoño, el descenso de la temperatura disminuye el crecimiento y metabolismo radicular a niveles mínimos, declina el contenido de sustancias radiculares y los frutos comienzan a madurar. El reinicio de la actividad radicular en la primavera, aumenta los niveles hormonales y la absorción de nitrógeno y consecuentemente lleva al reverdecimiento de la fruta que se encuentra en el árbol. En las zonas tropicales, las temperaturas permanecen altas durante todo el año, el crecimiento radicular ocurre ininterrumpidamente y los niveles de sustancias radiculares se encuentran permanentemente altos como para interferir en la toma de color de los frutos. Es por esto que un mismo cultivar que en condiciones sub-tropicales tiene buena coloración, en los trópicos no la logra.

Existen evidencias, por tanto, sobre la importancia que la temperatura de las raíces puede tener en la promoción del proceso. Soonen et al. (1979) trabajando con 'Calamondín' y mandarina satsuma encontraron que cuando la temperatura de las raíces es de $14^{\circ} \mathrm{C}$ el contenido de carotenoides es, 
aproximadamente, el doble que cuando es de $30^{\circ} \mathrm{C}$. Los mismos autores demuestran que la temperatura óptima para la síntesis de criptoxantina, $\beta$ citraurina y violaxantina, pigmentos responsables de la coloración en estos cultivares, se encuentra entre $12^{\circ} \mathrm{C}$ y $14^{\circ} \mathrm{C}$. Por otro lado, Young y Erickson (1961) tras estudiar combinaciones de temperaturas diurnas $\left(20^{\circ} \mathrm{C} \circ 30^{\circ} \mathrm{C}\right)$, nocturnas $\left(7^{\circ} \mathrm{C}, 12^{\circ} \mathrm{C}, 15^{\circ} \mathrm{C}\right.$ o $\left.20^{\circ} \mathrm{C}\right)$ y del suelo $\left(12^{\circ} \mathrm{C}\right.$ o $\left.20^{\circ} \mathrm{C}\right)$, proponen que el cambio de color sería promovido por la temperatura del aire y del suelo en forma conjunta, siendo la combinación óptima una amplitud térmica de $20^{\circ} \mathrm{C}$ diurnos y $7^{\circ} \mathrm{C}$ nocturnos y la temperatura del suelo de $12^{\circ} \mathrm{C}$. En esas condiciones el flavedo de los frutos presenta menor contenido de clorofilas y mayor contenido de xantofilas que en las demás condiciones probadas.

En el mismo sentido, Kennedy et al. (1993) verifican en plantas de tomate que un incremento desde $15^{\circ} \mathrm{C}$ a $25^{\circ} \mathrm{C}$ en la temperatura radicular induce un retraso de entre tres y diez semanas en la maduración de los frutos y que un número importante de frutos no logra madurar.

En suma, el descenso de la temperatura del aire y del suelo se asocia positivamente con el cambio de color de los frutos, lo que se ha relacionado con el metabolismo de los carbohidratos y de los carotenoides, el transporte de nitrógeno y la síntesis y el transporte hormonal, pero aún no ha sido probado. La síntesis de hormonas en las raíces o en los brotes regulan respuestas fisiológicas en zonas distantes de la planta. En cítricos la información sobre síntesis y transporte hormonal desde la raíz y su relación con el proceso de maduración es escasa.

\subsubsection{Relación entre la luz y el color de los frutos}

La luz también juega un papel importante en el cambio de color de los frutos, como ha sido demostrado en el manzano (Faust, 1989). En los cítricos, la proporción de frutos bien coloreados por el exterior del árbol es mayor que por el interior (Sites y Reitz, 1949; Iwagaki, 1981). Por otro lado, la disminución de la intensidad de luz hasta un $40 \%$ de la radiación máxima no afecta el color de los frutos, pero por debajo de ese umbral éste disminuye; es difícil disociar el efecto de la luz del de la temperatura, pero el mayor contenido de clorofilas 
de los frutos en el interior del árbol, a pesar de estar expuestos a menores temperaturas, podría explicarse por la débil iluminación a la que están sometidos (Iwagaki, 1981).

El desverdizado inducido por la presencia de la luz, podría deberse a la fotooxidación de la clorofila (Sironval y Kander, 1958) y es directamente dependiente del tiempo de exposición (Coggins y Hall, 1975). Sin embargo, Lewis et al. (1964) observaron que los frutos que reciben luz directamente, degradan las clorofilas a y $b$ más lentamente que los expuestos a un $5 \%$ de la intensidad normal, probablemente debido a que la síntesis de clorofilas continúa mientras los frutos permanezcan expuestos a la luz.

La influencia de la luz sobre la coloración de los frutos también se ha relacionado con la densidad de plantación en la medida que los frutos que proceden de árboles más espaciados, logran mejor color (Boswell et al., 1970; Ahmed e Higazi, 1983) y se desverdizan antes (Boswell et al., 1982). 


\subsection{Hipótesis y objetivos}

Los aspectos genéticos, así como las señales hormonales, nutricionales y ambientales, en interacción, regulan el proceso de coloración de los frutos cítricos. El descenso de la temperatura ambiente detiene el desarrollo vegetativo y radicular, con lo que disminuye la competencia por carbohidratos del fruto con otros órganos, al mismo tiempo que la absorción de $\mathrm{N}$ y la síntesis hormonal y su transporte al fruto, facilitando la exportación de hormonas desde éste, su cambio de color y su entrada en senescencia.

En esta Tesis Doctoral se estudia el proceso de regulación de la maduración externa de los frutos cítricos, de acuerdo con los siguientes objetivos:

El objetivo general es determinar los factores endógenos y exógenos que afectan la maduración externa de los frutos cítricos.

Los objetivos específicos son:

1. Establecer la importancia del ácido abscísico, etileno y giberelinas en el proceso.

2. Determinar el papel de los carbohidratos y las fracciones nitrogenadas en el mismo.

3. Establecer la relación del proceso con la temperatura ambiente y del suelo. 

2. Materiales

y Métodos 



\subsection{Estrategia de trabajo}

El proceso de regulación de la maduración externa de los frutos se abordó desde dos puntos de vista: 1) el estudio de factores endógenos (hormonales y nutricionales) implicados en el proceso de desverdizado y 2) el estudio de factores exógenos (temperatura del aire y del suelo) como reguladores de la evolución del mismo.

1) La implicancia hormonal y nutricional se estudió: a) en naranjos y mandarinos de maduración temprana, intermedia y tardía, utilizando mutantes de un mismo cultivar que difieren en la fecha de maduración y b) modificando el proceso de maduración externa, en etapas próximas al cambio de color, mediante tratamientos químicos (aplicaciones de reguladores de crecimiento o sustancias nitrogenadas) y tratamientos físicos (interrupción de la conexión floemática entre el fruto y la planta).

2) El efecto ambiental se estudió en mandarinos de maduración temprana, a través de la disminución de la temperatura radicular cubriendo el suelo bajo las plantas con mallas o cal, y su asociación con la temperatura del aire.

\subsection{Localización de los experimentos}

Los experimentos de campo se llevaron a cabo en plantaciones de

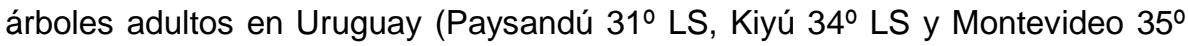
LS) y en España (Valencia, Llíria $39^{\circ}$ LN y Huelva $37^{\circ} \mathrm{LN}$ ), con marcos de plantación entre 5-6 m × 3-4 $\mathrm{m}$ en ambos países. En Uruguay las plantas se encontraban sobre suelos de textura franco-arcillo-limosa con un horizonte $B$ textural a 20-30 $\mathrm{cm}$ de profundidad, con $\mathrm{pH}$ entre 5 y 6 , sin presencia de carbonatos o caliza activa, y con porcentajes de materia orgánica entre $3 \%$ y 4\%. En España los suelos sobre los que se desarrollaron los experimentos fueron de textura franco-arenosa, con pH de 7-8, 50\% de carbonatos totales en promedio y $11 \%$ de caliza activa. Las parcelas contaron con riego localizado (excepto los experimentos realizados a planta completa en Uruguay, años 2004 
y 2005, que se realizaron en secano). El riego se realizó en función de la evapotranspiración del cultivo, calculada a partir de la siguiente ecuación: ETc= EToxKc, donde ETo es la evapotranspiración de referencia (Allen et al., 1998), estimada con datos de una estación meteorológica del huerto, y $\mathrm{Kc}$ es el coeficiente de cultivo para cítricos (García Petillo y Castel, 2007). La fertilización mineral en cada ciclo productivo en Uruguay fue de aproximadamente $300 \mathrm{~g}$ árbol ${ }^{-1}$ de $\mathrm{N}, 150 \mathrm{~g}^{\text {árbol }}{ }^{-1}$ de $\mathrm{P}, 75 \mathrm{~g}^{\text {árbol }}{ }^{-1}$ de $\mathrm{K}, 30 \mathrm{~g}$ árbol $^{-1}$ de $\mathrm{Ca}, 45 \mathrm{~g}_{\text {árbol }}{ }^{-1}$ de $\mathrm{Mg}$ y 5-7 $\mathrm{g}$ árbol $^{-1}$ de Zn. En España los árboles fueron fertirrigados con $800 \mathrm{~g}$ árbol ${ }^{-1}$ de $\mathrm{N}, 120 \mathrm{~g}_{\text {árbol }}{ }^{-1}$ de $\mathrm{P}$ y $350 \mathrm{~g}_{\text {árbol }}{ }^{-1}$ de K. El manejo de plagas y enfermedades se realizó de acuerdo a estándares nacionales de cada país.

\subsection{Material Vegetal}

El estudio de los factores endógenos relacionados con la coloración se realizó: a) en árboles en producción de naranjo dulce [Citrus sinensis (L.) Osb.] cvs. 'Navelina', 'Washington navel', 'Navelate', y en mandarino Satsuma [Citrus unshiu (Mak.) Marc] cvs. 'Okitsu' y 'Owari', injertados sobre Poncirus trifoliata (L.) Raf. (Paysandú, Uruguay) y b) en frutos individuales de naranjo dulce cvs. 'Washington navel' sobre P. trifoliata (L.) Raf. (Montevideo, Uruguay), 'Valencia Delta Seedless' y 'Valencia Late', sobre citrange 'Carrizo' [C. sinensis (L.) Osb. $\times$ P. trifoliata (L.) Raf] (Valencia y Llíria, España).

El estudio de los factores exógenos se realizó en plantaciones comerciales de mandarino Clementino [Citrus clementina Hort ex Tan] cv. 'Clementina de Nules' injertado sobre P. trifoliata (L.) Raf. (Kiyú, Uruguay), y cv. 'Clemenpons' injertado sobre citrange 'Carrizo' [C. sinensis (L.) Osb. $\times P$. trifoliata (L.) Raf], (Huelva, España). 

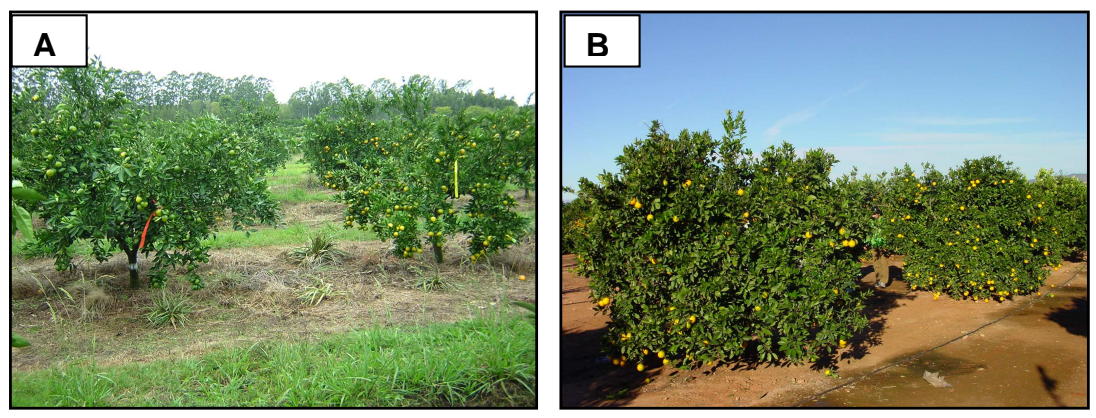

Figura 2. Árboles de plantaciones comerciales de mandarino Satsuma, cv. 'Okitsu' en Uruguay (A) y naranjo dulce cv. 'Valencia Delta Seedless' en España (B).

\subsection{Factores endógenos relacionados con la coloración del flavedo: Experimentos}

\subsubsection{Alteración de la evolución del color: clorofilas y carotenoides}

Los tratamientos realizados para alterar la evolución del color fueron: aplicación foliar de ácido giberélico $\left(\mathrm{GA}_{3}\right)$ a pH 4.5, y aplicación de Norflurazona [NFZ: 4-cloro-5-metilamino-2-(3-triflurometilfenil) piridacin-3-ona)] inhibidor de la síntesis de ABA (Tabla 1). En Uruguay los tratamientos se realizaron a plantas completas y a frutos individuales previamente identificados, mientras que en España solo a frutos individuales. El momento de aplicación fue previo al inicio del cambio de color de los frutos. Las aplicaciones a la planta completa se realizaron con una pulverizadora de puntero, mojando los árboles hasta punto de goteo (4-5 L por planta), mientras que a los frutos individuales se los trató con pulverizador manual, mojando los frutos hasta punto de goteo (5-6 mL por fruto). En todos los casos se incluyó un agente mojante no iónico (Dusilan SP®, $0.25 \mathrm{~mL} . \mathrm{L}^{-1}$ ). En la Tabla 1 se detallan todos los experimentos. 
Tabla 1. Descripción de experimentos (Exp) realizados a plantas completas (Uruguay, 2004 y 2005) y a frutos individuales (Uruguay 2006, España 2008-09), para alterar la evolución del color.

\begin{tabular}{|c|c|c|c|c|c|c|}
\hline \multicolumn{7}{|c|}{ Planta completa } \\
\hline País & Año & Especie & Cultivar & $\begin{array}{l}\text { Época de } \\
\text { maduración }\end{array}$ & Exp & Tratamientos \\
\hline \multirow{4}{*}{ Uruguay } & \multirow{4}{*}{2004} & \multirow{4}{*}{$\begin{array}{l}\text { Naranjo } \\
\text { dulce }\end{array}$} & \multirow{2}{*}{$\begin{array}{c}\text { 'Washington } \\
\text { navel' }\end{array}$} & \multirow{2}{*}{ Intermedia } & \multirow{2}{*}{ A } & Control (C) \\
\hline & & & & & & $\mathrm{GA}_{3}\left(20 \mathrm{mg} \cdot \mathrm{L}^{-1}\right)$ \\
\hline & & & \multirow{2}{*}{ 'Navelate' } & \multirow{2}{*}{ Tardía } & \multirow{2}{*}{ B } & Control (C) \\
\hline & & & & & & $\mathrm{GA}_{3}\left(20 \mathrm{mg} \cdot \mathrm{L}^{-1}\right)$ \\
\hline \multirow{14}{*}{ Uruguay } & \multirow{14}{*}{2005} & \multirow{9}{*}{$\begin{array}{l}\text { Naranjo } \\
\text { dulce }\end{array}$} & \multirow{3}{*}{ 'Navelina' } & \multirow{3}{*}{ Temprana } & \multirow{3}{*}{ C } & Control (C) \\
\hline & & & & & & $\mathrm{GA}_{3}\left(20 \mathrm{mg} \cdot \mathrm{L}^{-1}\right)$ \\
\hline & & & & & & NFZ (1mM) \\
\hline & & & \multirow{3}{*}{$\begin{array}{c}\text { 'Washington } \\
\text { navel' }\end{array}$} & \multirow{3}{*}{ Intermedia } & \multirow{3}{*}{$\mathrm{D}$} & Control (C) \\
\hline & & & & & & $\mathrm{GA}_{3}\left(20 \mathrm{mg} \cdot \mathrm{L}^{-1}\right)$ \\
\hline & & & & & & $\mathrm{NFZ}(1 \mathrm{mM})$ \\
\hline & & & \multirow{3}{*}{ 'Navelate' } & \multirow{3}{*}{ Tardía } & \multirow{3}{*}{$E$} & Control (C) \\
\hline & & & & & & $\mathrm{GA}_{3}\left(20 \mathrm{mg} \cdot \mathrm{L}^{-1}\right)$ \\
\hline & & & & & & $\mathrm{NFZ}(1 \mathrm{mM})$ \\
\hline & & \multirow{5}{*}{$\begin{array}{l}\text { Mandarino } \\
\text { Satsuma }\end{array}$} & \multirow{2}{*}{ 'Okitsu' } & \multirow{2}{*}{$\begin{array}{l}\text { Muy } \\
\text { temprana }\end{array}$} & \multirow{2}{*}{$\mathrm{F}$} & Control (C) \\
\hline & & & & & & $\mathrm{GA}_{3}\left(10 \mathrm{mg} \cdot \mathrm{L}^{-1}\right)$ \\
\hline & & & \multirow{3}{*}{ 'Owari } & \multirow{3}{*}{ Temprana } & \multirow{3}{*}{$\mathrm{G}$} & Control (C) \\
\hline & & & & & & $\mathrm{GA}_{3}\left(10 \mathrm{mg} \cdot \mathrm{L}^{-1}\right)$ \\
\hline & & & & & & $\mathrm{NFZ}(1 \mathrm{mM})$ \\
\hline \multicolumn{7}{|c|}{ Frutos individuales } \\
\hline País & Año & Especie & Cultivar & $\begin{array}{l}\text { Época de } \\
\text { maduración }\end{array}$ & Exp & Tratamientos \\
\hline Uruguay & 2006 & $\begin{array}{l}\text { Naranjo } \\
\text { dulce }\end{array}$ & $\begin{array}{l}\text { 'Washington } \\
\text { navel' }\end{array}$ & Intermedia & $\mathrm{H}$ & $\begin{array}{l}\text { Control }(\mathrm{C}) \\
\mathrm{GA}_{3}\left(10 \mathrm{mg} \cdot \mathrm{L}^{-1}\right) \\
\mathrm{NFZ}(2 \mathrm{mM})\end{array}$ \\
\hline $\begin{array}{l}\text { España } \\
\text { (UPV) }\end{array}$ & \multirow{2}{*}{$\begin{array}{l}2008- \\
09\end{array}$} & \multirow{2}{*}{$\begin{array}{l}\text { Naranjo } \\
\text { dulce }\end{array}$} & $\begin{array}{l}\text { 'Valencia } \\
\text { Late' }\end{array}$ & \multirow{2}{*}{ Tardía } & 1 & $\begin{array}{l}\text { Control }(\mathrm{C}) \\
\mathrm{GA}_{3}\left(10 \mathrm{mg} \cdot \mathrm{L}^{-1}\right) \\
\mathrm{NFZ}(1 \mathrm{mM})\end{array}$ \\
\hline $\begin{array}{l}\text { España } \\
\text { (Llíria) }\end{array}$ & & & $\begin{array}{l}\text { 'Valencia } \\
\text { Late' }\end{array}$ & & $J$ & $\begin{array}{l}\text { Control }(\mathrm{C}) \\
\mathrm{GA}_{3}\left(10 \mathrm{mg} \cdot \mathrm{L}^{-1}\right) \\
\mathrm{NFZ}(1 \mathrm{mM})\end{array}$ \\
\hline
\end{tabular}




\subsubsection{Diseño de experimentos}

El diseño de los experimentos fue de parcelas al azar. En los experimentos realizados a plantas completas se utilizó un árbol como unidad experimental y tres (2005) ó cuatro (2004) repeticiones. La unidad de submuestreo para las variables de contenidos endógenos fue de uno (2004) ó cinco frutos (2005). Las variables color y tamaño de frutos se midieron en 15-30 frutos por árbol. En los experimentos a frutos individuales se utilizaron parcelas de 5-10 frutos como unidad experimental y tres (2008-09) o cinco (2006) repeticiones.

\subsubsection{Mediciones}

En todos los experimentos se midió el color y tamaño de los frutos cada 10, 15 ó 20 días (con cartilla colorimétrica en 2004, ó con colorímetro digital en 2005, 2006 y 2008-09). Se cuantificó la concentración de ABA, carbohidratos solubles (fructosa, glucosa y sacarosa) y nitrógeno (fracción proteica, amoniacal y nitratos) en el flavedo. En los experimentos realizados a frutos individuales se midió además la tasa de producción de etileno, y en los experimentos I y J se determinó la concentración de clorofilas y carotenoides (fitoeno, fitoflueno, luteína, $\beta$-caroteno, $\beta$-criptoxantina, $\beta$-citraurina y cisviolaxantina) en el flavedo.

\subsubsection{Interrupción del transporte: anillado del pedúnculo}

Los tratamientos realizados a frutos individuales de naranjo dulce fueron: control (fruto con pedúnculo sin anillar y sin aplicaciones); anillado del pedúnculo próximo al fruto (A: corte de la corteza de $0.5 \mathrm{~cm}$ de espesor en el pedúnculo del fruto a una distancia de $0.5-1.0 \mathrm{~cm}$ del mismo); anillado en la zona media del pedúnculo entre el fruto y la base de la rama, dejando las 3 hojas próximas a éste $(\mathrm{AMH}$ : corte de la corteza de $0.5 \mathrm{~cm}$ de espesor, a 8-10 $\mathrm{cm}$ del fruto, con hojas); anillado en la zona media del pedúnculo (semejante al 
anterior) pero quitando las hojas entre el anillado y el fruto (AM), (Figura 3); aplicaciones de $\mathrm{NH}_{4} \mathrm{NO}_{3}$ ó de $\mathrm{ABA}$, y combinaciones de los tratamientos anteriores que se detallan en la Tabla 2. El momento de aplicación fue previo al inicio del cambio de color del fruto. El anillado de los pedúnculos fue permanente, es decir que la interrupción floemática duró todo el experimento. Las aplicaciones se realizaron con pulverizador manual, mojando los frutos hasta punto de goteo (5-6 mL por fruto). En todos los casos se incluyó un agente mojante no iónico (Dusilan $\mathrm{SP} \circledast, 0.25 \mathrm{~mL} . \mathrm{L}^{-1}$ ). Todos los frutos fueron marcados e identificados.
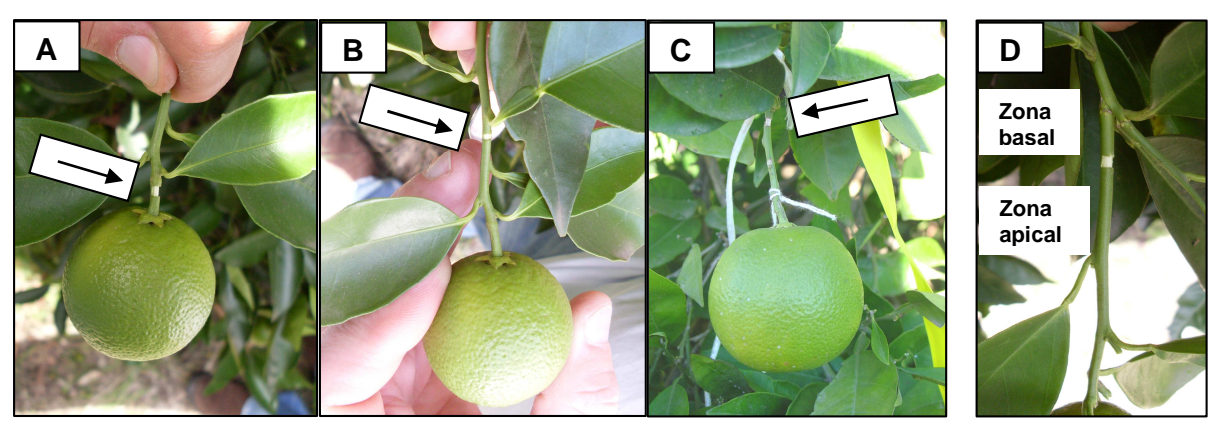

Figura 3. Frutos con pedúnculo anillado: A) anillado próximo al fruto (A); B) anillado en la zona media del pedúnculo, con hojas (AMH); y $\mathrm{C}$ ) anillado en la zona media del pedúnculo, sin hojas (AM). D) Zonas del pedúnculo: basal (porción del pedúnculo conectada a la rama y aislada del fruto por el anillado), y apical (porción del pedúnculo en contacto con el fruto y desconectada de la rama por el anillado). 
Tabla 2. Descripción de experimentos (Exp) con interrupción del transporte, realizados a frutos individuales en Uruguay $(2006,2008)$ y España (2006).

\begin{tabular}{|c|c|c|c|c|}
\hline País & Año & Especie & Exp & Tratamientos \\
\hline Uruguay & 2006 & $\begin{array}{l}\text { Naranjo } \\
\text { 'Washington' } \\
\text { navel }\end{array}$ & K & $\begin{array}{l}C^{z} \\
A^{y} \\
A M H^{x} \\
A-N: A+N_{4} N_{3}\left(20 \mathrm{~g} \cdot L^{-1}\right) \\
N: C+N_{4} N_{3}\left(20 g \cdot L^{-1}\right) \\
A-A B A: A+A B A\left(250 \mathrm{mg} \cdot L^{-1}\right)\end{array}$ \\
\hline España & 2006 & $\begin{array}{l}\text { Naranjo 'Valencia } \\
\text { Delta Seedless' }\end{array}$ & $\mathrm{L}$ & $\begin{array}{l}\mathrm{C} \\
\mathrm{A} \\
\mathrm{AMH} \\
\mathrm{AM}^{\mathrm{w}}\end{array}$ \\
\hline Uruguay & 2008 & $\begin{array}{l}\text { Naranjo } \\
\text { 'Washington' } \\
\text { navel }\end{array}$ & $M$ & $\begin{array}{l}\text { C } \\
A M \\
A B A: C+A B A\left(250 m g \cdot L^{-1}\right) \\
A M-A B A: A M+A B A\left(250 m g \cdot L^{-1}\right)\end{array}$ \\
\hline
\end{tabular}

${ }^{y} \mathrm{~A}$ : anillado a $0.5-1.0 \mathrm{~cm}$ del fruto

${ }^{\mathrm{x}} \mathrm{AMH}$ : anillado a 8-10 $\mathrm{cm}$ del fruto conservando las 3 hojas próximas

${ }^{\mathrm{w}} \mathrm{AM}$ : anillado a 8-10 cm del fruto, eliminando las hojas entre el fruto y el anillado

\subsubsection{Diseño de experimentos}

El diseño de los experimentos $\mathrm{K}$ y $\mathrm{M}$ fue de parcelas al azar con 10-15 frutos por parcela. Se realizaron entre tres y cinco repeticiones por tratamiento en cada fecha de muestreo. El diseño del experimento $L$ fue de bloques completos al azar con 3 repeticiones representadas cada una por un árbol, y se utilizaron 10 frutos por bloque. En todos los experimentos se utilizaron cinco frutos como unidad de submuestreo para las variables de contenidos endógenos y un fruto para las variables color y diámetro; el número inicial de frutos por tratamiento varió entre 60-100.

\subsubsection{Mediciones}

En todos los experimentos se midió el color y diámetro ecuatorial de los frutos cada 7-10 días y se realizó un muestreo de frutos al comienzo (frutos verdes) y al final (cuando los frutos control alcanzaron la madurez). En el experimento $\mathrm{M}$ se realizó además un muestreo a los 30 días del tratamiento y 
otro al momento del cambio de color. En todas las fechas se midió la tasa de producción de etileno. En los experimentos $K$ y $L$ se determinó la concentración de $A B A$, carbohidratos solubles y nitrógeno en el flavedo y en el $\mathrm{M}$ la concentración de giberelinas 1 y $4\left(\mathrm{GA}_{1}\right.$ y $\left.\mathrm{GA}_{4}\right)$ en el flavedo. En la corteza del pedúnculo de los frutos control y con tratamiento de anillado $(A, A M H, A M)$ se analizó la concentración de carbohidratos solubles, $A B A$ (en los experimentos $\mathrm{K}$ y $L$ ), y $\mathrm{GA}_{1}$ y $\mathrm{GA}_{4}$ (en el experimento $M$ ). Cuando el anillado se realizó próximo al fruto $(A)$, el análisis se hizo en la corteza de la zona basal del pedúnculo (conectada a la rama y aislada del fruto por el anillado). Cuando el anillado se realizó en la zona media del pedúnculo, entre el fruto y la base de la rama ( $\mathrm{AMH}$ y $\mathrm{AM}$ ), los análisis se realizaron en la corteza de la zona basal y de la zona apical (en contacto con el fruto y desconectada de la rama por el anillado), (Figura 3).

\subsection{Factores exógenos relacionados con la coloración del flavedo: Experimentos}

Para disminuir la temperatura del suelo se utilizaron mallas plásticas blancas o plateadas y cal. Las mallas se colocaron bajo la copa de los árboles a $50 \mathrm{~cm}$ de altura, excepto en el año 2008 en Uruguay, que se colocaron directamente sobre el suelo. La cal fue esparcida cubriendo en forma total la superficie del terreno debajo de los árboles (Figura 4). Los tratamientos se realizaron entre dos y cuatro meses previos a la fecha estimada de cosecha según se detallan en la Tabla 3. 
Tabla 3. Descripción de experimentos (Exp) realizados para disminuir la temperatura del suelo, en España y Uruguay.

\begin{tabular}{|c|c|c|c|c|}
\hline Año & $\begin{array}{l}\text { Localidad } \\
\text { País }\end{array}$ & $\begin{array}{l}\text { Especie } \\
\text { cultivar }\end{array}$ & Exp & Tratamientos \\
\hline 2005 & $\begin{array}{l}\text { Huelva } \\
\text { España }\end{array}$ & $\begin{array}{l}\text { Mandarino } \\
\text { 'Clemenpons' }\end{array}$ & $\mathrm{N}$ & $\begin{array}{l}\text { C : Control } \\
\text { M-Jul: Malla blanca instalada en julio } \\
\text { M-Sep: Malla blanca instalada en } \\
\text { septiembre }\end{array}$ \\
\hline $\begin{array}{l}2006 \\
2007 \\
2008\end{array}$ & $\begin{array}{l}\text { Huelva } \\
\text { España }\end{array}$ & $\begin{array}{l}\text { Mandarino } \\
\text { 'Clemenpons' }\end{array}$ & $\begin{array}{l}\mathrm{O} \\
\mathrm{P} \\
\mathrm{Q}\end{array}$ & $\begin{array}{l}\text { C } \\
\text { M-Jul } \\
\text { M-Sep } \\
\text { CAL: } \mathrm{CaOH}_{2} \text { colocada en julio o septiembre }\end{array}$ \\
\hline 2007 & $\begin{array}{l}\text { Kiyú } \\
\text { Uruguay }\end{array}$ & $\begin{array}{l}\text { Mandarino } \\
\text { 'Clemenules' }\end{array}$ & $\mathrm{R}$ & $\begin{array}{l}\text { MP: Malla plateada (Alluminet, } 70 \% \text { ) } \\
\text { instalada en marzo } \\
\text { CAL: } \mathrm{CaOH}_{2} \text { colocada en marzo }\end{array}$ \\
\hline 2008 & $\begin{array}{l}\text { Kiyú } \\
\text { Uruguay }\end{array}$ & $\begin{array}{l}\text { Mandarino } \\
\text { 'Clemenules' }\end{array}$ & $S$ & $\begin{array}{l}\text { C } \\
\text { MP } \\
\text { CAL (D): Dolomita }\left(\mathrm{CaCO}_{3} \text { y } \mathrm{MgCO}_{3}, 98 \%\right) \\
\text { colocada en marzo }\end{array}$ \\
\hline
\end{tabular}

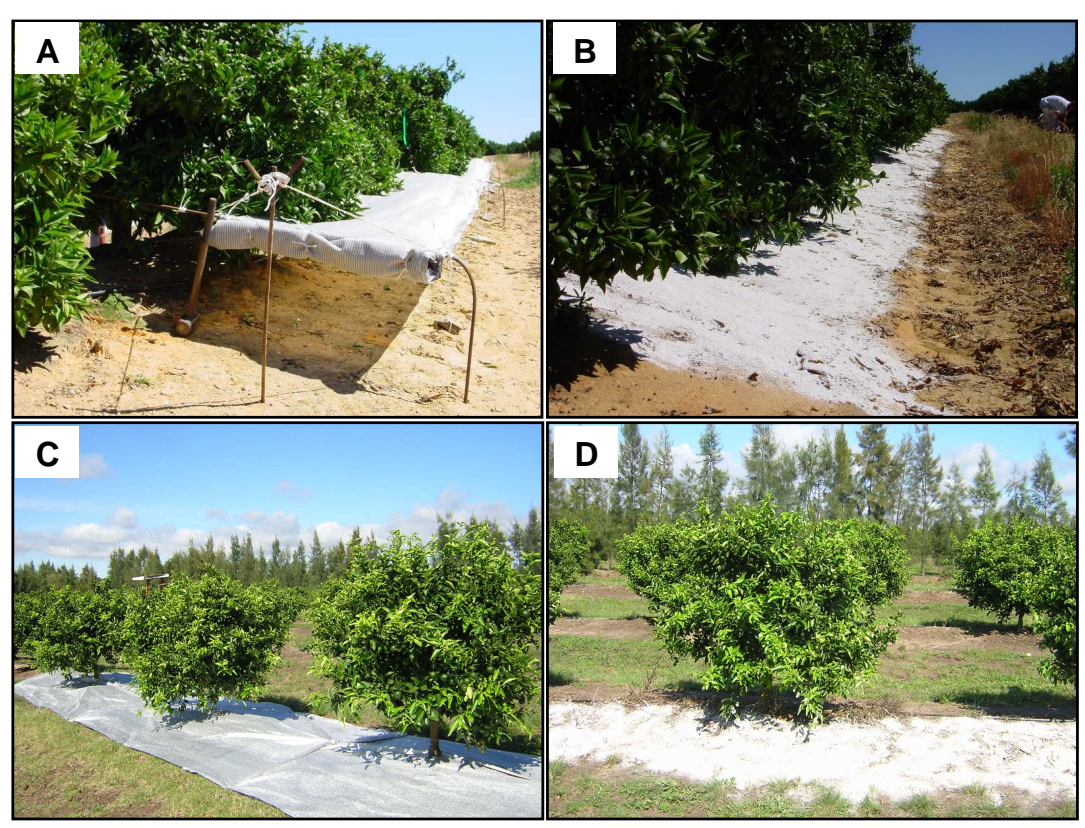

Figura 4. Mallas plásticas blancas colocadas bajo la copa de los árboles a $50 \mathrm{~cm}$ de altura en España (A), mallas plásticas plateadas colocadas directamente sobre el suelo en Uruguay $(C)$ y tratamiento de cal esparcida debajo de los árboles en España (B) y Uruguay (D). 


\subsubsection{Diseño de experimentos}

En los cuatro experimentos de campo realizados en España ( $N$ al Q) se utilizó un diseño de bloques completos al azar, con 2-3 repeticiones, diez árboles como unidad experimental, y 10-15 frutos por árbol como unidad de submuestreo. En los experimentos realizados en Uruguay se utilizó un diseño de parcelas al azar, con 3 repeticiones de ocho (R) ó tres (S) árboles como unidad experimental y 5-10 frutos como unidad de submuestreo.

\subsubsection{Mediciones}

En todos los experimentos se midió el color y el diámetro ecuatorial de los frutos cada 7-15 días y en las cosechas se determinó el índice de madurez interna (porcentaje de zumo, sólidos solubles y acidez titulable). Se realizaron tres o cuatro cosechas por experimento de acuerdo al color y se determinó el número y porcentaje de frutos cosechados por planta en cada fecha de recolección.

En todos los casos se registró la temperatura del aire (Ta) y del suelo (Ts), la humedad relativa del aire $(\mathrm{HR})$, las precipitaciones $(\mathrm{P}, \mathrm{mm})$ y la evapotransipiración de referencia $\left(\mathrm{ET}_{0}, \mathrm{~mm}\right.$ día $\left.^{-1}\right)$, durante los tres ó cuatro meses anteriores al cambio de color del fruto (mediados de julio a mediados de noviembre en España, y marzo a mayo en Uruguay). La Ts se registró cada una hora con sensores colocados a $30 \mathrm{~cm}$ de profundidad (2007) ó a $10 \mathrm{~cm}$ (2008) en Uruguay, y a $60 \mathrm{~cm}$ en España. En Uruguay, la Ta se registró con sensores colocados en la copa del árbol (a $1.5 \mathrm{~m}$ de altura), y se midió la radiación total $\left(\mathrm{W} \mathrm{m}^{-2}\right)$ y fotosintéticamente activa (PAR) a $1.2 \mathrm{~m}$ de altura, reflejada desde el suelo o cobertura utilizada, y la intensidad de radiación solar (total y PAR). La intensidad lumínica (lum feet ${ }^{2}$ ) reflejada desde el suelo (Control) y el tratamiento de malla a $1.2 \mathrm{~m}$ de altura se determinó con sensor HOBBO ${ }^{\circ}$ cada una hora. 


\subsection{Determinaciones analíticas}

\subsubsection{Color y tamaño de frutos}

El color de los frutos se determinó con colorímetro digital (Minolta Chroma Meter CR-10 y CR-300 en los experimentos de Uruguay y España, respectivamente), efectuando 2-3 mediciones en la zona ecuatorial del fruto. En los experimentos realizados a las plantas completas ( $\mathrm{A}$ al $\mathrm{G}$ y $\mathrm{N}$ al $\mathrm{S}$ ) los frutos se seleccionaron al azar, y en los realizados a frutos individuales, marcados $\mathrm{e}$ identificados $(\mathrm{H}$ al $\mathrm{M})$, se midieron todos los frutos. Con los valores de CIELab (Uruguay) y Hunter Lab (España) se calculó la relación a/b, el índice de color para cítricos ICC [(1000×a):(L×b)], variable que involucra todas los parámetros del color y se ha citado como uno de los mejores indicadores para determinar el color de los frutos cítricos (Jiménez-Cuesta et al., 1981), el croma o tinta $\left[\sqrt{ }\left(a^{2}+b^{2}\right)\right]$ y el ángulo Hue $[\operatorname{ArcTg}(a: b)]$.

El tamaño de los frutos se midió bajo las mismas condiciones a través del diámetro ecuatorial de los mismos con calibre digital (definición $0.01 \mathrm{~mm}$ ).

\subsubsection{Pigmentos, contenidos hormonales y nutricionales en el flavedo del fruto ó en la corteza del pedúnculo}

En los experimentos $A$ al $\mathrm{M}$, se extrajo con bisturí el flavedo proveniente de la zona ecuatorial de los frutos, prestando especial atención en no contaminar la muestra con albedo. En los experimentos $\mathrm{K}$ al $\mathrm{M}$ se extrajo el tejido del pedúnculo del fruto compuesto por epidermis, córtex y floema (corteza), con excepción del leño (xilema y médula). En todos los casos las muestras se congelaron inmediatamente con nitrógeno líquido y se almacenaron en freezer a $-20^{\circ} \mathrm{C}$. Las muestras para determinar clorofilas, carotenoides y $\mathrm{ABA}$ de los experimentos I y $\mathrm{J}$ se molieron congeladas, mientras que las destinadas al análisis de carbohidratos solubles, nitrógeno y ácido abscísico de los demás experimentos se liofilizaron y posteriormente se molieron. 


\subsubsection{Pigmentos}

La extracción de pigmentos se realizó de acuerdo a la metodología descrita por Rodrigo et al. (2003). Las clorofilas se extrajeron del material vegetal congelado $(0.5 \mathrm{~g})$ con $\mathrm{N}, \mathrm{N}$-di-metil-formamide $\left(\mathrm{C}_{3} \mathrm{H}_{7} \mathrm{NO}\right)$, se determinaron midiendo la absorbancia a $644 \mathrm{~nm}$ y $662 \mathrm{~nm}$ de longitud de onda, y se cuantificaron con las ecuaciones proporcionadas por Smith y Benitez (1955). Los carotenoides se extrajeron en una solución de tampón Tris-HCL 50 $\mathrm{mM} \mathrm{pH} 7.5, \mathrm{NaCl} 1 \mathrm{mM}$ y metanol $(\mathrm{MeOH})$. La fase orgánica se secó y saponificó usando una solución $\mathrm{KOH}$ (10\%). Los carotenoides fueron subsecuentemente re-extraídos con eter dietílico. Una alícuota del extracto se usó para cuantificar el contendido total de carotenoides a través del especto de absorción de los extractos saponificados. Se registraron los picos de máxima absorbancia y el contenido total se calculó midiendo la absorbancia a $450 \mathrm{~nm}$ de acuerdo a Davies (1976), usando el coeficiente de extinción de $\beta$-caroteno $\left(E^{1 \%}=2500\right)$. Los extractos se secaron en evaporador rotatorio y se almacenaron a $-20^{\circ} \mathrm{C}$ hasta su análisis por Cromatografía Líquida de Alta Resolución (HPLC). Posteriormente, se disolvieron en $\mathrm{MeOH}$ :acetona (2:1 v/v) y se determinaron en HPLC, usando columna $\mathrm{C}_{30}$ Carotenoid $250 \times 4.6 \mathrm{~mm}$, $5 \mu \mathrm{m}$, adjunta a una precolumna $20 \times 4 \mathrm{~mm}, 5 \mu \mathrm{m}$. Los carotenoides fitoeno, fitoflueno, luteína, $\beta$-caroteno, $\beta$-criptoxantina, $\beta$-citraurina y cis-violaxantina se identificaron de acuerdo a sus tiempos de retención, absorción y espectro fino, de acuerdo a la metodología propuesta por Rodrigo et al., (2006). Todas las operaciones se realizaron en hielo y en oscuridad para prevenir la fotodegradación, isomerización y los cambios estructurales de los carotenoides.

\subsubsection{Etileno}

La tasa de producción de etileno se determinó en frutos enteros por cromatografía gaseosa. Se colocaron entre 2 y 5 frutos en un recipiente cerrado herméticamente durante 2-3 horas a temperatura ambiente. Tres alícuotas de $2 \mathrm{ml}$ de aire se extrajeron e inyectaron en cromatógrafo con columna Porapack $\mathrm{Q}$ (largo: $2 \mathrm{~m}$, diámetro interno: $2 \mathrm{~mm}$ ), con temperaturas de 
130, 80 y $110^{\circ} \mathrm{C}$ en el inyector, columna y detector de ionización de llama respectivamente. Se utilizó nitrógeno como gas portador a un flujo de $45 \mathrm{~mL}$ $\min ^{-1}$.

En el flavedo de los frutos se determinó la actividad de la ACS (ácido 1aminociclopropano-1-carboxílico sintasa) siguiendo la metodología propuesta por Acaster y Kende (1983) y Cohen y Kende (1987), con modificaciones menores. Brevemente, a partir de $0.5 \mathrm{~g}$ de material liofilizado se realizó la extracción con tampón fosato $250 \mathrm{mM}, \mathrm{pH} 8$, DTT $4 \mathrm{mM}$, fosfato de piridoxal $0.4 \mu \mathrm{M}(5 \% \mathrm{p} / \mathrm{v})$, PVP $(5 \%)$ y el inhibidor de proteasas $(8 \mu \mathrm{L})$. La solución se centrifugó a $7000 \mathrm{~g}$ y se agregó $1 \mathrm{~mL}$ de extracto al tampón de incubación [fosato $250 \mathrm{mM}, \mathrm{pH} 8$, DTT $5 \mathrm{mM}$, fosfato de piridoxal $10 \mu \mathrm{M}$, EDTA $1 \mathrm{mM}$ y $100 \mu \mathrm{L}$ de S-adenosyl-Met (SAM, $5 \mathrm{mM}$ )]. La muestra se incubó 30 minutos a temperatura ambiente. Se agregó $100 \mu \mathrm{L}$ de $\mathrm{HgCl} 20 \mathrm{mM}$ y $100 \mu \mathrm{L}$ de solución saturada de $\mathrm{NaOH}$ :lejía $(1: 1 \mathrm{v} / \mathrm{v})$, e inmediatamente se cerraron los tubos herméticamente. La muestra se incubó en hielo durante 10 minutos. Se extrajeron $5 \mathrm{~mL}$ de aire y se inyectaron en nuevos tubos herméticos. La concentración de etileno se midió en cromatógrafo de gases de acuerdo al procedimiento descrito para frutos enteros.

\subsubsection{3. Ácido abscísico}

La determinación de ABA se realizó por el método de ELISA indirecto con doble anticuerpo de acuerdo a la metodología propuesta por Zacarías et al. (1995) y Lafuente et al. (1997). En breve, la extracción se realizó a partir de 0.2 $\mathrm{g}$ de tejido liofilizado en oscuridad, a ${ }^{\mathrm{C}} \mathrm{C}$, durant e 6 horas. Se utilizó como extractante ácido cítrico $2.5 \mathrm{mM}$, butilhidroxitolueno $4.5 \mathrm{mM}$, en acetona $80 \%$. Los extractos se centrifugaron 5 minutos a $15000 \mathrm{~g}$. El sobrenadante se diluyó en tampónTris- $\mathrm{HCl} 20 \mathrm{mM} \mathrm{pH} \mathrm{7.5,} \mathrm{NaCl} 500 \mathrm{mM}$ (TBS) a 4ํㅜ, se agregó el anticuerpo monoclonal (MAB) y se mantuvo durante 16 horas en oscuridad a $4^{\circ} \mathrm{C}$. Se utilizó TBS-Tween con albúmina bovina $(0.1 \% \mathrm{p} / \mathrm{v})$ como solución de lavado. Se incubó con proteína IgG de ratón ( $0.1 \%$ en TBS) durante 2 horas en oscuridad a temperatura ambiente. Se agregó fosfato de nitrofenol $(0.1 \%$ en $\mathrm{NaHCO}_{3} \mathrm{pH}$ 9.6) como sustrato. La placa se incubó a $37^{\circ} \mathrm{C}$ y se leyó con lector de placas a $405 \mathrm{~nm}$. 


\subsubsection{Giberelinas 1 y $4\left(\mathrm{GA}_{1}\right.$ y $\left.\mathrm{GA}_{4}\right)$}

La determinación de GAs se realizó por cromatografía líquida y espectrometría de masas (LC-MS/MS), siguiendo la metodología propuesta por Chiwocha et al. (2003), con modificaciones menores. A partir de $200 \mathrm{mg}$ de muestra liofilizada y molida con nitrógeno líquido, se realizó la extracción con 5 ml de solución de extracción $\mathrm{MeOH}: \mathrm{H}_{2} \mathrm{O}: \mathrm{HOAc}$ (80:19:1, a pH 1-3). Se agregaron $100 \mathrm{ng}$ de estándares deuterados $\left({ }^{2} \mathrm{H}_{2}-\mathrm{GA}_{1},{ }^{2} \mathrm{H}_{2}-\mathrm{GA}_{4}\right)$, se agitaron en vortex, y se colocaron a $4^{\circ} \mathrm{C}$ por 12 horas. Posteriormente, se centrifugó a 290 g durante 10 minutos, separando el sobrenadante del pellet para la evaporación de la fase acuosa. Luego, mediante partición por dos veces con acetato de etilo $\left(\mathrm{C}_{4} \mathrm{H}_{8} \mathrm{O}_{2}\right)$, acidificado con $\mathrm{HOAc}(1 \%)$, se reunió la fase orgánica para ser evaporada a sequedad. Se re-suspendió con metanol para su purificación con cartucho C18 (Sep-Pak, Waters-Millipore), la fracción con GAs, se llevó a sequedad en SpeedVac. La muestra se disolvió con $100 \mu \mathrm{L}$ de $\mathrm{MeOH}(100 \%)$ para su identificación y cuantificación en LC-MS/MS. Se inyectaron $10 \mu \mathrm{l}$ en un cromatógrafo líquido (Alliance 2695, Waters Inc), provisto de una columna Restek $\mathrm{C}_{18}(2.1 \times 100 \mathrm{~mm}, 5 \mu \mathrm{m})$, a $25^{\circ} \mathrm{C}$. Se utilizó un gradiente que comenzó ( $40 \% \mathrm{MeOH}: 60 \% \mathrm{H}_{2} \mathrm{O}: \mathrm{HOAc}$ al $0.2 \%$ ) a un flujo de $0.2 \mathrm{~mL} \mathrm{~min}{ }^{-1}$. Las muestras se analizaron a través de un doble quadrupolo (Quatro Ultima ${ }^{\text {tm }}$ Pt., Micromass, UK), utilizando la fuente de iones en modo negativo y un capilar de ionización por electrospray (ESI). Las $\mathrm{GA}_{1}$ y $\mathrm{GA}_{4}$ se identificaron por comparación de tiempos de retención con el estándar puro, y los iones se monitorearon por reacción múltiple (función MRM), siguiendo las masas moleculares y las masas de transición para $\mathrm{GA}_{1}$ y ${ }^{2} \mathrm{H}_{2}-\mathrm{GA}_{1}$ : $348>242$ y $350>244$, mientras que para $\mathrm{GA}_{4}$ y ${ }^{2} \mathrm{H}_{2}-\mathrm{GA}_{4}: 332>244$ y $334>246$. La cuantificación se hizo sacando la relación de áreas endógeno/deuterado, y extrapoladas a través de una curva de calibración elaborada con concentraciones conocidas.

\subsubsection{Carbohidratos solubles}

Los carbohidratos solubles se extrajeron con etanol $\left(80 \%\right.$, v/v) a $85^{\circ} \mathrm{C}$, a partir de $100 \mathrm{mg}$ de muestra liofilizada, de acuerdo a Rivas et al. (2006). Se 
agregó $0.1 \mathrm{~mL}$ de fucosa $\left(60 \mathrm{mg} \mathrm{mL}^{-1}\right)$ como estándar interno. Se centrifugó a $15000 \mathrm{~g}$. El sobrenadante se evaporó con vacío hasta $0.5 \mathrm{~mL}$ a $40^{\circ} \mathrm{C}$. Se purificó con columna catiónica a pH 4.5 (Dowex® $1 \times$ 4-100 50-100 Mesh), suspendida en $\mathrm{HCl} 2 \mathrm{M}$, columna aniónica a pH 7.5 (Dowex® 1 × 4-100 50-100 Mesh), suspendida en $\mathrm{Na}_{2} \mathrm{CO}_{3} 1 \mathrm{M}$, filtro de nylon (membrana de $0.45 \mu \mathrm{m}$, Waters-Millipore) y cartucho C18 (Sep-Pak, Waters-Millipore). Las muestras purificadas se secaron con vacío a $40^{\circ} \mathrm{C}$ y se disolv ieron en $60 \mu \mathrm{L}$ de agua $\mathrm{mQ}$. Una alícuota de $20 \mu \mathrm{L}$ fue analizada por HPLC en un Spectra HPLC System $\circledast$ con columna APS-2 Hypersil, $250 \times 4.6 \mathrm{~mm}$ adjunta a una precolumna $(20 \times 0.65$ $\mathrm{mm}$ ), conectadas a un refractómetro Rl150 y una bomba de vacío P2000. Se utilizó una solución de acetonitrilo:agua (80:20) como solvente, a un flujo de 1 $\mathrm{mL} \mathrm{min}{ }^{-1}$ durante una corrida de 15 minutos. Los azúcares fructosa, glucosa y sacarosa se identificaron por comparación del tiempo de retención con muestras de patrones puros y se cuantificaron por extrapolación con una curva de calibración elaborada con concentraciones conocidas de cada azúcar. Se utilizó un factor de corrección dependiente de la recuperación de fucosa y los resultados se expresaron como $\mathrm{mg}$ de azúcar por gramo de peso seco $\left(\mathrm{mg} \mathrm{g}^{-1}\right.$ PS).

\subsubsection{Nitrógeno $\left(\mathrm{N}-\mathrm{NH}_{4}{ }^{+}, \mathrm{N}-\mathrm{Prot}, \mathrm{N}-\mathrm{NO}_{3}{ }^{-}+\mathrm{NO}_{2}{ }^{-}\right)$}

Las fracciones de nitrógeno amoniacal $\left(\mathrm{N}^{-\mathrm{NH}_{4}}{ }^{+}\right)$, proteico (N-Prot) y

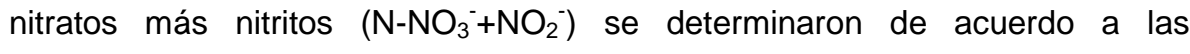
metodologías propuestas por Maquieira et al., (1984), Raigón et al. (1992) y Beljaars et al. (1994), con modificaciones menores.

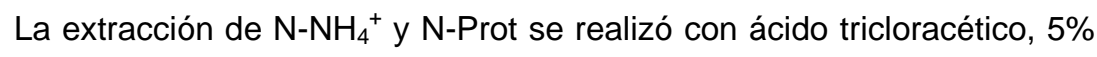
(TCA) a partir de $500 \mathrm{mg}$ de muestra liofilizada y se agitó durante 15 minutos a ${ }^{4} \mathrm{C}$. Se lavó tres veces con TCA, y el sobrenadante se filtró y se almacenó a ${ }^{4} \mathrm{C}$. La fracción amoniacal se determinó con especto fotómetro en equipo FIAstar 5000 Analyzer $\AA^{\circledR}$, se utilizó agua $\mathrm{mQ}$ como transportador. Los reactivos derivatizantes fueron $\mathrm{NaOH}, 0.5 \mathrm{M}$ seguidos de amonio indicador $280 \mathrm{mM}$, $\mathrm{NaOH}, 0.5 \mathrm{mM}$ en etanol:agua 1:20 respectivamente, diluidos al $2 \%$.

La fracción N-Prot se determinó con el método de micro-Kjeldahl descrito por Maquieira et al. (1984) con modificaciones. Al residuo sólido 


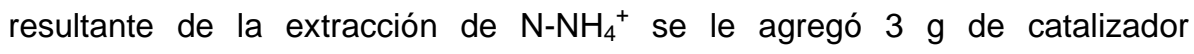
$\left(\mathrm{K}_{2} \mathrm{SO}_{4}: \mathrm{CuSO}_{4}:\right.$ Se en una relación 10:1:0.1), $10 \mathrm{~mL}$ de ácido sulfúrico (96\%) y $10 \mathrm{~mL}$ de peróxido de hidrógeno (35\%). La digestión se realizó durante 30 minutos a $450{ }^{\circ} \mathrm{C}$. Se agregó $50 \mathrm{~mL}$ de agua destilada y se destiló durante 4 minutos en equipo Foss Kjeltec 2200 Auto Destillation®. Se utilizó $\mathrm{NaOH} \mathrm{(40 \% )}$ como alcalinizante y ácido bórico como solución indicadora $\left(\mathrm{H}_{3} \mathrm{BO}_{3} 2 \%\right.$, rojo de metilo y verde de bromocresol). Se realizó la valoración con ácido clorhídrico $(0.1 \mathrm{~N})$.

La fracción de nitratos y nitritos se analizó de acuerdo a Beljaars et al. (1994), a partir de una muestra de 500 mg de material liofilizado. Se agitó durante 30 minutos con agua $\mathrm{mQ}(50 \mathrm{~mL})$ y se filtró. Los $\mathrm{N}-\mathrm{NO}_{3}{ }^{-}+\mathrm{NO}_{2}{ }^{-}$se determinaron por espectrofotometría $(540 \mathrm{~nm})$ en equipo FIAstar 5000 Analyzer®, con columna de reducción de cadmio (para reducir nitratos a nitritos). Se utilizó agua $\mathrm{mQ}$ como transportador y como reactivos derivatizantes $\mathrm{NH}_{4} \mathrm{Cl} 1.0 \mathrm{M}, \mathrm{NH}_{4} \mathrm{OH}, \mathrm{pH} 8.5$, sulfanilamida, $\mathrm{HCl} 0.6 \mathrm{~N}, 1 \%(\mathrm{p} / \mathrm{v})$ y N-1-naftil-etilendiamina, $0.1 \%(p / v)$.

\subsubsection{Maduración interna}

El porcentaje de zumo se determinó por peso a partir de 3-5 frutos por repetición. El contenido de sólidos solubles se determinó con refractómetro digital (ํㅜㅅㅡ), se realizaron dos mediciones por repetición. La acidez titulable (\%) se analizó en $10 \mathrm{~mL}$ de zumo, por valoración con $\mathrm{NaOH}(0.1 \mathrm{~N})$ y 3 gotas de fenolftaleina (1\% en etanol 95\%) como solución indicadora. Se calculó el índice de madurez (ratio) a través del cociente entre los sólidos solubles y la acidez titulable.

\subsection{Análisis estadísticos}

Las variables continuas (color, diámetro, pigmentos, ABA, GAs, $\mathrm{N}$ y $\mathrm{CHOs}$ ) se analizaron ajustando modelos lineales generales (ANOVA) donde se efectuaron comparaciones entre los cultivares, tratamientos y fechas (cuando 
se midieron más de una vez), y sus interacciones. En los modelos donde se compararon distinto número de tratamientos según cultivar, se consideró el efecto anidado de tratamiento dentro del cultivar. Las medias de los efectos significativos fueron comparadas usando la prueba de Tukey. En el caso de mediciones en más de un momento, se modeló la correlación entre mediciones según modelos autorregresivos de orden 1 o simétrica compuesta. Se usó el procedimiento MIXED del paquete estadístico SAS versión 9.1.3 (SAS Institute, Cary, NC, 2005).

Para estudiar la proporción de frutos cosechados, se ajustaron modelos lineales generalizados asumiendo distribución binomial de la variable analizada con función de enlace logit $(\mathrm{Ln}[\mathrm{p} /(1 / \mathrm{p})])$. Las pruebas estadísticas usadas fueron de razón de verosimilitud (LRT). Se usó el procedimiento GLIMMIX del mismo paquete estadístico.

En algunos casos específicos (ICC, CHOs, N) también se usaron modelos lineales generales de medidas repetidas en el tiempo donde se compararon curvas de evolución. Las mismas fueron de tipo polinomial de hasta grado 3. Las curvas de los diferentes tratamientos fueron comparadas mediante contrastes. Tambien se compararon grupos de tratamientos (anillados y no anillados).

El estudio de la variable subjetiva ICC según cartilla colorimétrica (experimentos del año 2004), fue efectuada ajustando modelos lineales generalizados asumiendo una distribución multinomial ordinal de la misma. Se compararon los perfiles de distribución de los valores de ICC según cultivar, tratamiento, fecha e interacción. La comparación de los efectos significativos se efectuó por contrastes. Se usó el procedimiento GLIMMIX.

Para comparar las series de clima según tratamiento y localidad (Ta, Ts), se efectuó un estudio descriptivo contando la proporción de horas con valores por debajo o encima de cierto umbral $\left(25^{\circ} \mathrm{C}, 22^{\circ} \mathrm{C}, 21^{\circ} \mathrm{C}, 18^{\circ} \mathrm{C}, 15^{\circ}, 13^{\circ} \mathrm{C}, 7^{\circ} \mathrm{C}\right)$, o la proporción de días (en el caso de la amplitud térmica) cuya diferencia superaba determinado umbral $\left(10^{\circ} \mathrm{C}\right)$. 

3. Resultados 



\subsection{Factores endógenos relacionados con la coloración del flavedo}

\subsubsection{Alteración de la evolución del color: clorofilas y carotenoides}

\subsubsection{Color del flavedo}

La aplicación de ácido giberélico $\left(\mathrm{GA}_{3}\right)$ y norflurazona (NFZ), tanto a la planta completa como a frutos individuales, se hizo previo al inicio del cambio de color de los frutos. En Uruguay en los experimentos realizados a la planta completa, los valores promedio del índice de color para cítricos (ICC CIELab) en el momento de la aplicación fueron: -25 en las Satsumas cvs. 'Okitsu' y 'Owari', -11 en 'Navelina', -15 en 'Washington navel' y -7 en 'Navelate'. En el experimento realizado a frutos individuales con el cv. 'Washington navel', el ICC inicial fue -9. En España en los experimentos realizados a frutos individuales se hicieron en el cv. 'Valencia Late' en dos localidades (UPV y Llíria). En el experimento en UPV, el ICC de los frutos en el momento de la aplicación fue -15 y en Llíria, dónde se realizaron dos aplicaciones, de -14 y -3.

En Uruguay, en los experimentos realizados a planta entera, los frutos control iniciaron el cambio de color 15-20 días después del tratamiento en 'Okitsu' y 55 en 'Owari'; 15 días en 'Navelina', 20 días en 'Washington navel' y 25-30 días en 'Navelate'. Desde el momento de la aplicación hasta la recolección, los frutos de la cultivar 'Navelina' presentaron significativamente mayor grado de desverdizado que los de 'Washington navel' y 'Navelate', y los de éstas no se diferenciaron entre sí hasta 60 días después del tratamiento para 'Washington navel' y 50 días para 'Navelate', cuando los frutos de la primera exhibían coloración más naranja (ICC: +4.9) que los de la segunda (ICC: +3.5). Nótese que en ambos cultivares los valores de ICC ya eran positivos.

En todos los experimentos el $\mathrm{GA}_{3}$ (10 ó $20 \mathrm{mg} \mathrm{L}^{-1}$ ) retrasó el desverdizado de los frutos, mientras que la aplicación de NFZ no provocó cambios significativos (Figura 5). En el cv. 'Okitsu' de la mandarina Satsuma, las diferencias del tratamiento de $\mathrm{GA}_{3}$ respecto al control alcanzaron la significación estadística a los 45 días del tratamiento, cuando el ICC de los 
frutos tratados era más de tres veces mayor que el de los controles (Tabla 4). En el cv. 'Owari', las diferencias del $\mathrm{GA}_{3}$ respecto del control y de la aplicación de NFZ comenzaron a observarse a partir de los 60 días del tratamiento (Tabla 4), alcanzando significación estadística en todas las variables del color evaluadas. En los naranjos, los frutos tratados con $\mathrm{GA}_{3}$ se diferenciaron estadísticamente de los control a partir de los 15 días del tratamiento para el caso de ICC y de 28 días para el resto de las variables de color estudiadas. Por el contrario, los tratados con NFZ no lograron diferenciarse de los control en ninguna de las mediciones hasta la recolección (40, 60 y 70 días después del tratamiento para el caso de 'Navelina', 'Washington navel' y 'Navelate' respectivamente).

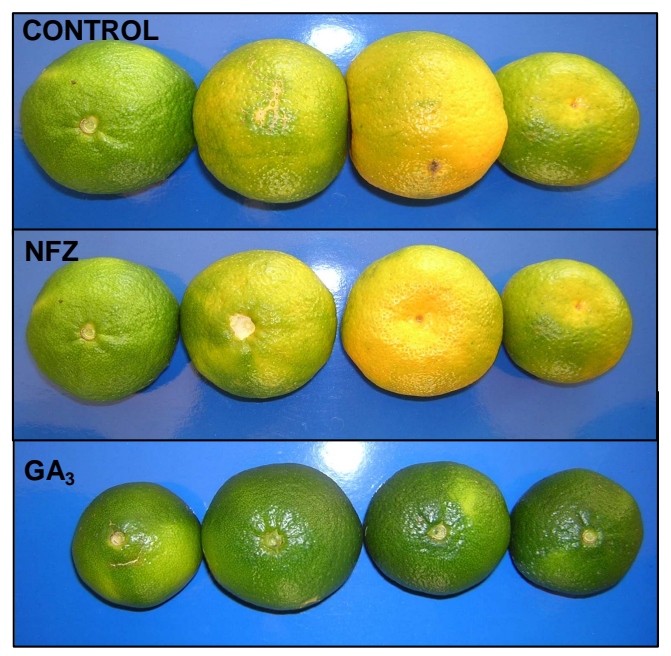

Figura 5. Frutos de mandarino Satsuma cv. 'Owari' control y tratados antes del cambio de color con norflurazona (NFZ 1mM) y ácido giberélico $\left(\mathrm{GA}_{3} 10 \mathrm{mg} \mathrm{L}^{-1}\right)$, a los 70 días de la aplicación (año 2005). 
Tabla 4. Evolución del índice de color (ICC) de frutos de Satsuma cvs. 'Okitsu' y 'Owari', control y tratados antes del cambio de color con NFZ (1 mM) y $\mathrm{GA}_{3}$ (10 mg L' ${ }^{1}$ ). Cada valor es la media de 3 repeticiones de 10 frutos cada una (año 2005).

\begin{tabular}{cccccc}
\hline \multirow{2}{*}{ Cultivar } & \multirow{2}{*}{ Tratamiento } & \multicolumn{4}{c}{ Días después del tratamiento } \\
\cline { 3 - 6 } & & 45 & 60 & 70 & 90 \\
\hline \multirow{2}{*}{ 'Okitsu' } & Control & $-2.37 \mathrm{a}^{\mathrm{z}} \mathrm{A}^{\mathrm{y}}$ & $3.33 \mathrm{a} \mathrm{A}$ & $6.51 \mathrm{a} \mathrm{A}$ & $9.86 \mathrm{a} \mathrm{A}$ \\
& $\mathrm{GA}_{3}$ & $-8.39 \mathrm{~b}$ & $-6.67 \mathrm{~b}$ & $-6.62 \mathrm{~b}$ & $4.43 \mathrm{~b}$ \\
\hline \multirow{2}{*}{ 'Owari' } & $\mathrm{Control}$ & $-11.14 \mathrm{~B}$ & $-7.08 \mathrm{a} \mathrm{B}$ & $-2.15 \mathrm{a} \mathrm{B}$ & $6.10 \mathrm{a} \mathrm{B}$ \\
& $\mathrm{NFZ}$ & -12.36 & $-7.82 \mathrm{a}$ & $-2.03 \mathrm{a}$ & $5.87 \mathrm{a}$ \\
& $\mathrm{GA}_{3}$ & -12.74 & $-10.80 \mathrm{~b}$ & $-9.89 \mathrm{~b}$ & $-2.55 \mathrm{~b}$ \\
\hline
\end{tabular}

${ }^{\bar{z}}$ Letras minúsculas diferentes en una misma columna y para un mismo cultivar indican diferencias significativas ( $p \leq 0.05)$

'Letras mayúsculas diferentes en una misma columna indican diferencias significativas entre cultivares $(p \leq 0.05)$

Con respecto al patrón de evolución del color, en todos los casos las curvas ajustadas del ICC evidenciaron diferencias significativas entre el tratamiento de $\mathrm{GA}_{3}$ y el de NFZ y el control, que no se diferenciaron significativamente entre sí. El color de los frutos tratados con $\mathrm{GA}_{3}$ evolucionó más lentamente que el de los otros dos tratamientos en todas los cultivares. En la Figura 6 se presenta la evolución del color de frutos de naranjo 'Washington navel' y sus mutantes 'Navelina', de maduración temprana, y 'Navelate', de maduración tardía. 


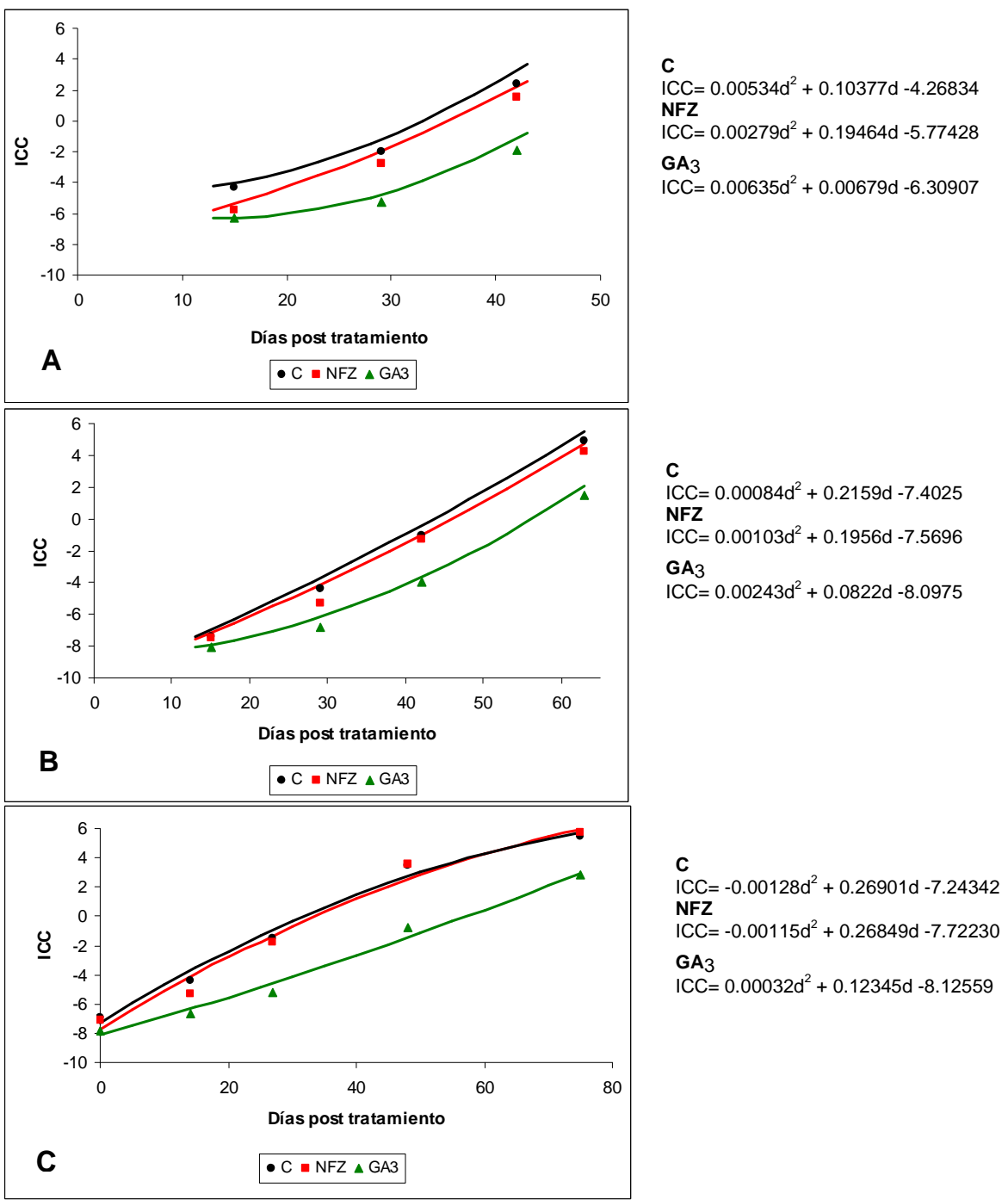

Figura 6. Curvas ajustadas de la evolución del índice de color (ICC) de frutos de naranjo dulce 'Navelina' de maduración temprana (A), 'Washington navel' de maduración intermedia (B) y 'Navelate' de maduración tardía (C), procedentes de árboles control y tratados con norflurazona (NFZ $1 \mathrm{mM}$ ) y ácido giberélico $\left(\mathrm{GA}_{3} 20 \mathrm{mg}\right.$ $\mathrm{L}^{-1}$ ). Las curvas se ajustaron utilizando en cada fecha 30-40 frutos por tratamiento (año 2005). d: días post tratamiento. 
Las aplicaciones realizadas a frutos individuales en el cv. 'Washington navel' dieron resultados similares en Uruguay, dónde el tratamiento con NFZ no afectó la evolución del color de los frutos, mientras que la aplicación de $\mathrm{GA}_{3}$ retrasó su entrada en color y su intensidad final respecto de los frutos sin tratar (Tabla 5).

Tabla 5. Índice de color (ICC) de frutos de naranjo dulce cv. 'Washington navel' control y tratados con NFZ $(2 \mathrm{mM})$ y $\mathrm{GA}_{3}\left(10 \mathrm{mg} \mathrm{L}^{-1}\right)$ antes del cambio de color, al inicio y al final del experimento. Cada valor es la media de 5 repeticiones de 5 frutos cada una (2006).

\begin{tabular}{lcc}
\hline Tratamiento & $\begin{array}{c}\text { ICC inicial } \\
(30 / 03 / 06)\end{array}$ & $\begin{array}{c}\text { ICC final } \\
(26 / 05 / 06)\end{array}$ \\
\hline Control & -9.17 & $4.41 \mathrm{a}^{2}$ \\
$\mathrm{NFZ}$ & -9.23 & $4.02 \mathrm{a}$ \\
$\mathrm{GA}_{3}$ & -9.14 & $0.59 \mathrm{~b}$ \\
\hline
\end{tabular}

${ }^{z}$ Letras diferentes en una misma columna indican diferencias significativas $(p \leq 0.05)$

En los dos experimentos realizados en España, la NFZ no retrasó la entrada en color de los frutos, pero, sin embargo, disminuyó la intensidad de color alcanzada por éstos (Figura 7). Esta diferencia se debió, fundamentalmente, a la disminución del valor de la variable 'a' de HunterLab. El $\mathrm{GA}_{3}$, en ambos experimentos, por el contrario, retrasó el inicio del cambio de color y además su intensidad final, de forma similar a lo ocurrido en Uruguay. En la localidad de Llíria, dónde el experimento se mantuvo hasta que los frutos reverdecieron, a los seis meses de realizadas las aplicaciones los frutos tratados con NFZ se igualaron en color a los frutos control, mientras que los tratados con $\mathrm{GA}_{3}$ permanecieron más verdes que aquellos (Figura 7). 

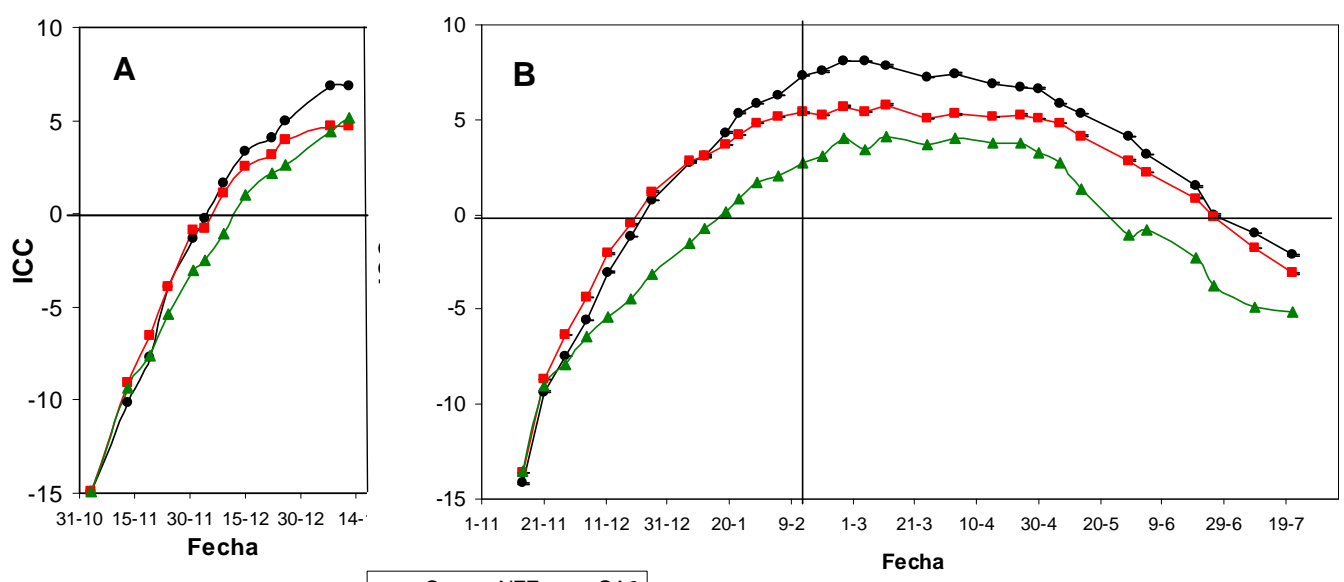

$\rightarrow-\mathrm{C} \rightarrow-\mathrm{NFZ} \rightarrow-\mathrm{GA} 3$

Figura 7. Índice de color (ICC) de frutos de naranjo dulce cV. 'Valencia Late' en las localidades UPV (A) y Llíria (B), procedentes de árboles control y tratados con norflurazona (NFZ $1 \mathrm{mM})$ y ácido giberélico $\left(\mathrm{GA}_{3} 10 \mathrm{mg} \mathrm{L}^{-1}\right)$ el 3 y el 11 de noviembre, en UPV y Llíria respectivamente. Cada valor es la media de 3 repeticiones de 10 frutos cada una (UPV) o de 5 repeticiones de 20 frutos cada una (Llíria), (2008-09). En la Figura B, la línea vertical indica el momento en el cual los frutos control de Llíria alcanzaron la misma coloración que en UPV al final del experimento. 
En Lliria se evaluó también, la evolución de la temperatura ambiente y del suelo (Figura 8). El inicio del cambio de color (ICC $\geq 0,11 / 12$ ) se logró después de un mes con temperaturas del suelo por debajo de $13^{\circ} \mathrm{C}$. Del mismo modo, el inicio del reverdecimiento (21/03) comenzó a darse cuando la misma se elevó por encima de dicho umbral (a partir de marzo-abril), y los valores de ICC volvieron a ser negativos (29/06, Figura 7) después de permanecer 20 días con la temperatura del suelo por encima de $20^{\circ} \mathrm{C}$ (Figura 8 ).

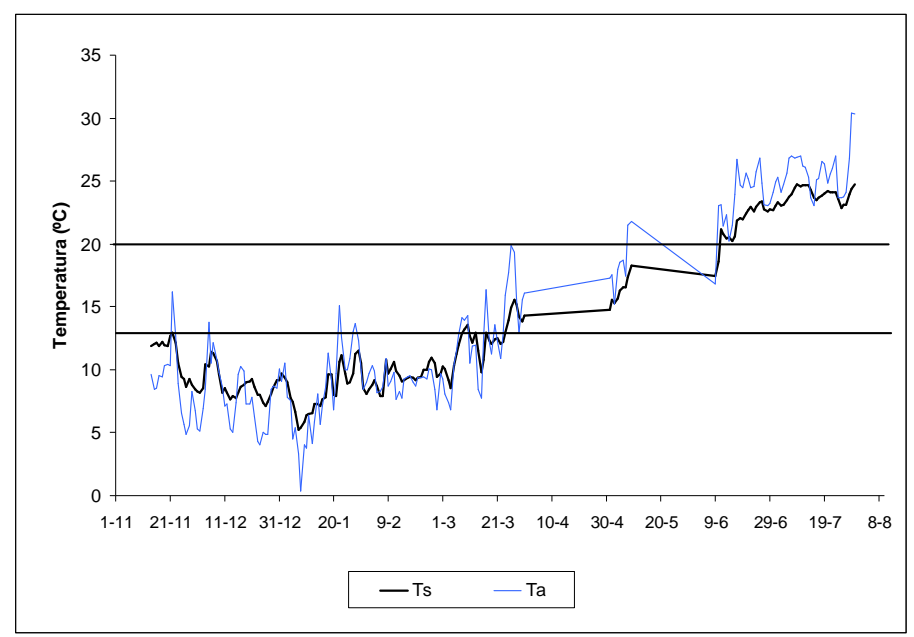

Figura 8. Evolución de la temperatura ambiente (Ta) y del suelo (Ts) a lo largo de la época de maduración del fruto y hasta su reverdecimiento en la localidad de Llíria. Valores para 2008-09. Las líneas horizontales indican $13^{\circ} \mathrm{C}$ y $20^{\circ} \mathrm{C}$.

\subsubsection{Pigmentos en el flavedo}

En los experimentos de España, sobre frutos individuales, la concentración de clorofilas presente en el flavedo de los frutos fue diferente en ambas localidades. En la UPV, la concentración de la clorofila a disminuyó desde $12.5 \mu \mathrm{g} \mathrm{g}^{-1} \mathrm{PF}$ en promedio, al inicio del experimento, hasta $6.8 \mu \mathrm{g} \mathrm{g}^{-1} \mathrm{PF}$, $2.3 \mu \mathrm{g} \mathrm{g}^{-1} \mathrm{PF}$ y $2.1 \mu \mathrm{g} \mathrm{g}{ }^{-1} \mathrm{PF}$ a mediados de enero en los frutos tratados con 
$\mathrm{GA}_{3}, \mathrm{NFZ}$ y sin tratar, respectivamente. En Llíria, la concentración se redujo de $47 \mu \mathrm{g} \mathrm{g}{ }^{-1} \mathrm{PF}$ al inicio, hasta $12.4 \mu \mathrm{g} \mathrm{g}^{-1} \mathrm{PF}$ en los frutos tratados con $\mathrm{GA}_{3}, 6.2 \mu \mathrm{g}$ $\mathrm{g}^{-1} \mathrm{PF}$ en los tratados con NFZ y $3.4 \mu \mathrm{g} \mathrm{g}^{-1} \mathrm{PF}$ en los controles a fines de febrero. El tratamiento con NFZ no afectó la degradación de clorofila a en ninguno de los experimentos, mientras que la aplicación de $\mathrm{GA}_{3}$ inhibió su pérdida partir de los 15 ó 20 días, dependiendo del experimento, de modo que los frutos tratados presentaron mayor concentración que los control y tratados con NFZ (Figura 9).

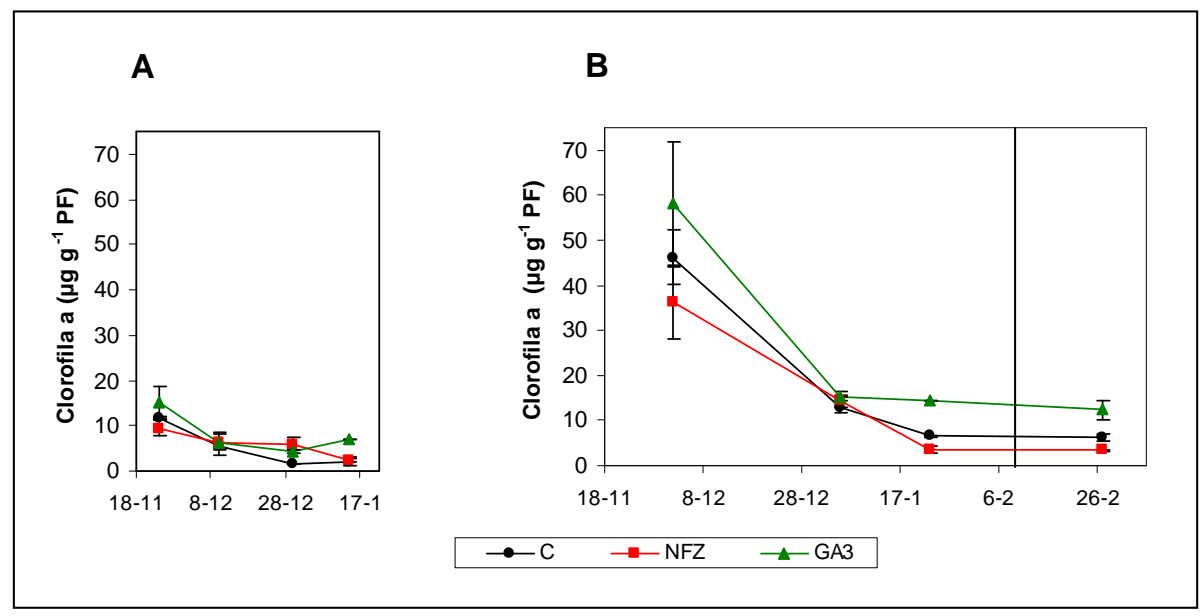

Figura 9. Concentración de clorofila a en el flavedo de frutos de naranjo dulce cv. 'Valencia Late' en las dos localidades de España, UPV (A) y Lliria (B), procedentes de árboles control y tratados con norflurazona (NFZ $1 \mathrm{mM})$ y ácido giberélico $\left(\mathrm{GA}_{3} 10 \mathrm{mg}\right.$ $\mathrm{L}^{-1}$ ) el 3 y el 11 de noviembre, en UPV y Llíria respectivamente. En la Figura $B$, la línea vertical indica el momento en el cual los frutos control de Llíria alcanzaron la misma coloración que en UPV al final del experimento.

La concentración total de carotenoides del flavedo se incrementó en ambos experimentos durante el período estudiado, aunque el efecto de los tratamientos fue diferente entre experimentos. En la UPV aumentó desde $12 \mu \mathrm{g}$ 
$\mathrm{g}^{-1} \mathrm{PF}$ a mediados de noviembre, hasta $50 \mu \mathrm{g} \mathrm{g} \mathrm{g}^{-1} \mathrm{PF}$ a mediados de enero, en los frutos control y tratados con NFZ, y solo hasta $30 \mu \mathrm{g} \mathrm{g}^{-1} \mathrm{PF}$ en los tratados con $\mathrm{GA}_{3}$. En Llíria el incremento en los frutos control y tratados con $\mathrm{GA}_{3}$ fue de $20 \mu \mathrm{g} \mathrm{g}{ }^{-1} \mathrm{PF}$ a $40 \mu \mathrm{g} \mathrm{g}{ }^{-1} \mathrm{PF}$, mientras que en los tratados con NFZ superó los 70

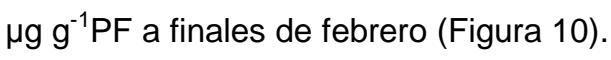

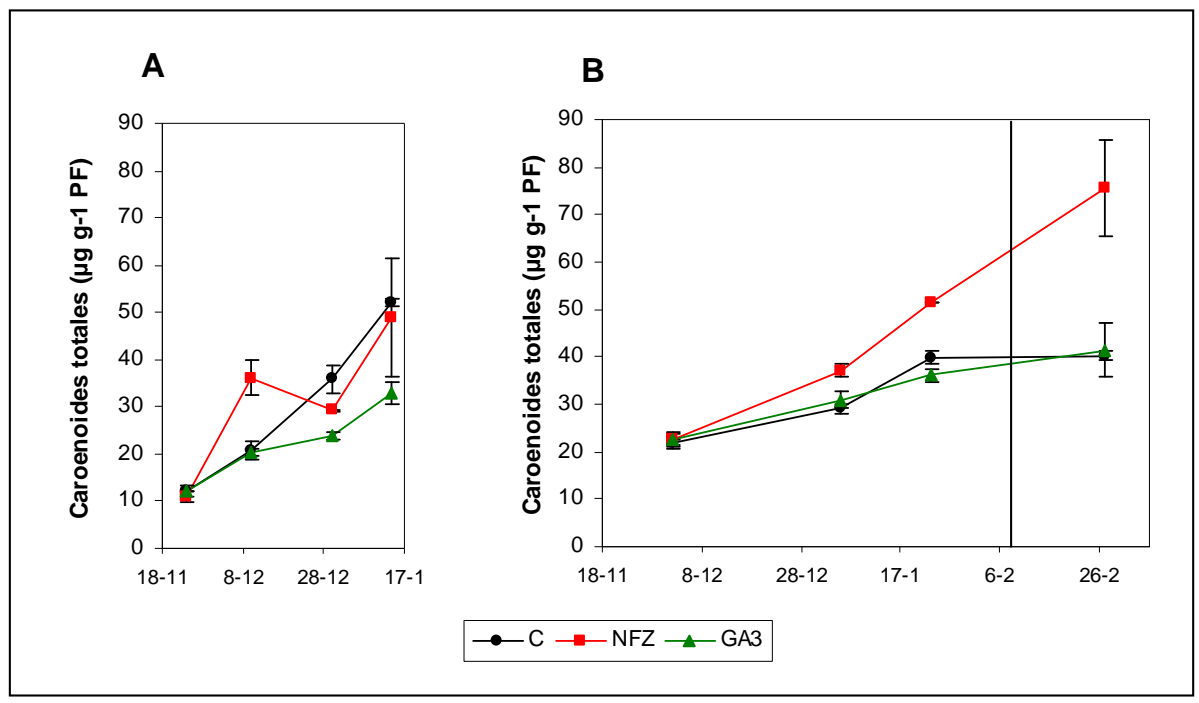

Figura 10. Concentración de carotenoides totales en el flavedo de frutos de naranjo dulce cv. 'Valencia Late' en las dos localidades de España, UPV (A) y Lliria (B), procedentes de árboles control y tratados con norflurazona (NFZ $1 \mathrm{mM}$ ) y ácido giberélico $\left(\mathrm{GA}_{3} 10 \mathrm{mg} \mathrm{L}^{-1}\right)$ el 3 y el 11 de noviembre, en UPV y Llíria respectivamente. En la Figura $B$, la línea vertical indica el momento en el cual los frutos control de Llíria alcanzaron la misma coloración que en UPV al final del experimento.

En Llíria la aplicación de NFZ incrementó la concentración de carotenoides lineales incoloros, fitoeno y fitoflueno, desde $5 \mu \mathrm{g} \mathrm{g}^{-1} \mathrm{PF}$ y $0.3 \mu \mathrm{g}$ $g^{-1} \mathrm{PF}$, respectivamente, a $27 \mu \mathrm{g} \mathrm{g} \mathrm{g}^{-1} \mathrm{PF}$ y $2.5 \mu \mathrm{g} \mathrm{g} \mathrm{g}^{-1} \mathrm{PF}$ al principio y final del experimento (Figura 11). La aplicación de $\mathrm{GA}_{3}$ no alteró significativamente su 
concentración. Una respuesta similar se obtuvo en la UPV, aunque con valores marcadamente inferiores (datos no presentados).

La concentración de $\beta$-caroteno disminuyó con el tiempo desde valores próximos a $0.8 \mu \mathrm{g} \mathrm{g}^{-1} \mathrm{PF}$ a mediados de noviembre hasta desaparecer a finales de febrero (Figura 11). La de luteína varió entre $2.4 \mu \mathrm{g} \mathrm{g}^{-1} \mathrm{PF}$ y $0.5 \mu \mathrm{g} \mathrm{g}^{-1} \mathrm{PF}$ (Figura 11). La aplicación de $\mathrm{GA}_{3}$ consiguió mantener concentraciones de $\beta$ caroteno y luteína significativamente superiores a las del control a lo largo de todo el período en estudio. La NFZ no alteró significativamente su concentración respecto del control (Figura 11). En la UPV los resultados fueron similares, aunque, al igual que en el caso anterior, marcadamente inferiores (datos no presentados).

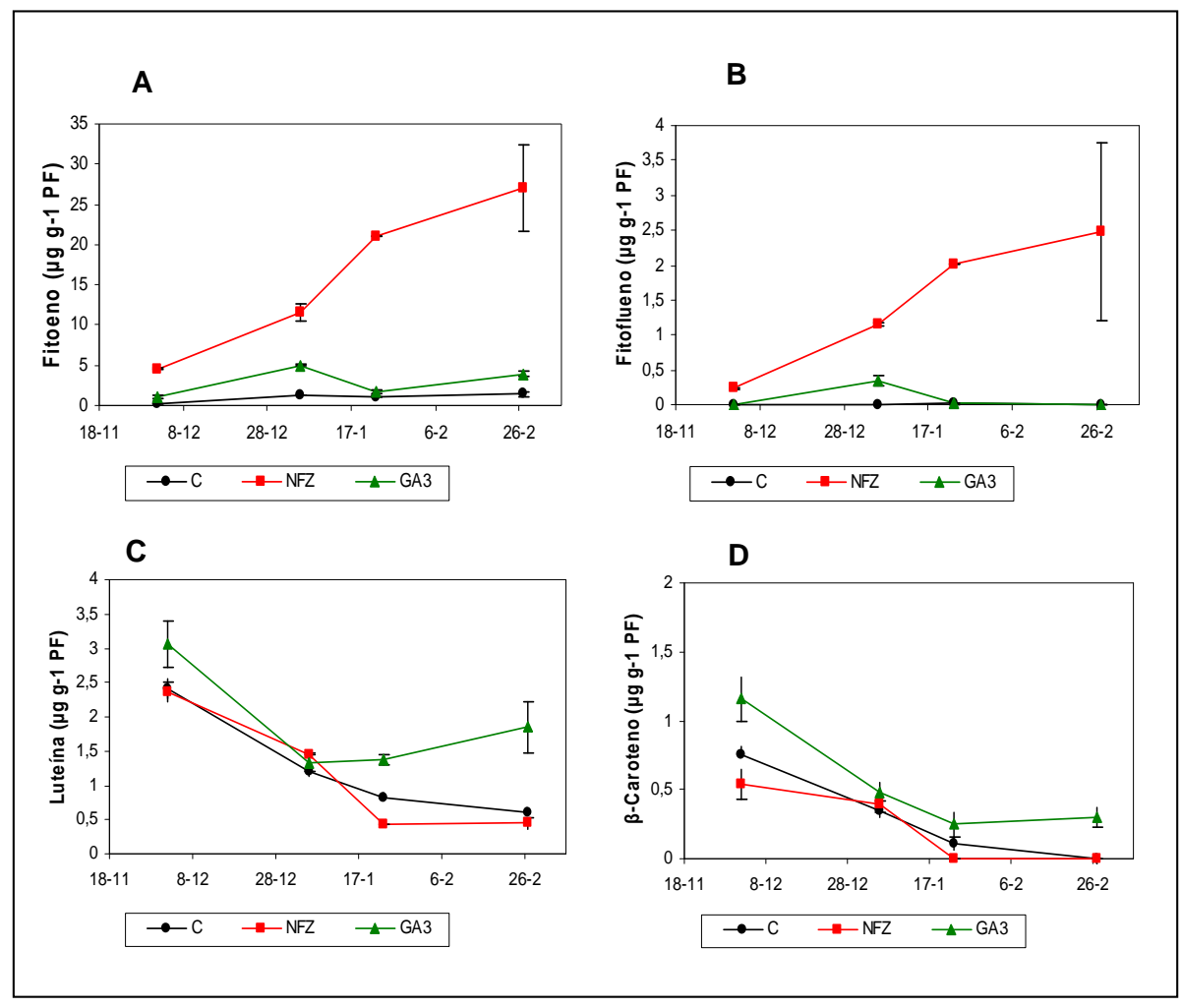

Figura 11. Concentración de fitoeno (A), fitofluoeno (B), luteína (C ) y $\beta$-caroteno (D) en el flavedo de frutos de naranjo dulce cv. 'Valencia Late', procedentes de árboles 
control y tratados con norflurazona (NFZ $1 \mathrm{mM})$ y ácido giberélico $\left(\mathrm{GA}_{3} 10 \mathrm{mg} \mathrm{L}^{-1}\right)$ el 11 de noviembre, Llíria (España).

Los carotenoides responsables de la coloración ( $\beta$-criptoxantina, $\beta$ citraurina y cis-violaxantina), aumentaron con el tiempo en las dos localidades en estudio (Figura 12), en correspondencia con el incremento del ICC (ver Figura 7). En Llíria, donde se dejaron los frutos hasta reverdecer, la concentración de estos pigmentos descendió también de un modo paralelo al descenso del ICC. Los frutos tratados con $\mathrm{GA}_{3}$, presentaron consistentemente una concentración significativamente más baja de $\beta$-criptoxantina, de $\beta$ citraurina y de cis-violaxantina (Figura 12) durante el período de cambio de color de los frutos, con independencia de la localidad. Los frutos tratados con NFZ presentaron en términos generales menor concentración que los control (Figura 12), aunque en Llíria la concentración de estos tres pigmentos siguió creciendo aún cuando la del resto de los tratamientos había iniciado ya su descenso. En estos casos, sin embargo, las concentraciones en la UPV fueron similares a las de Llíria (Figura 12). 

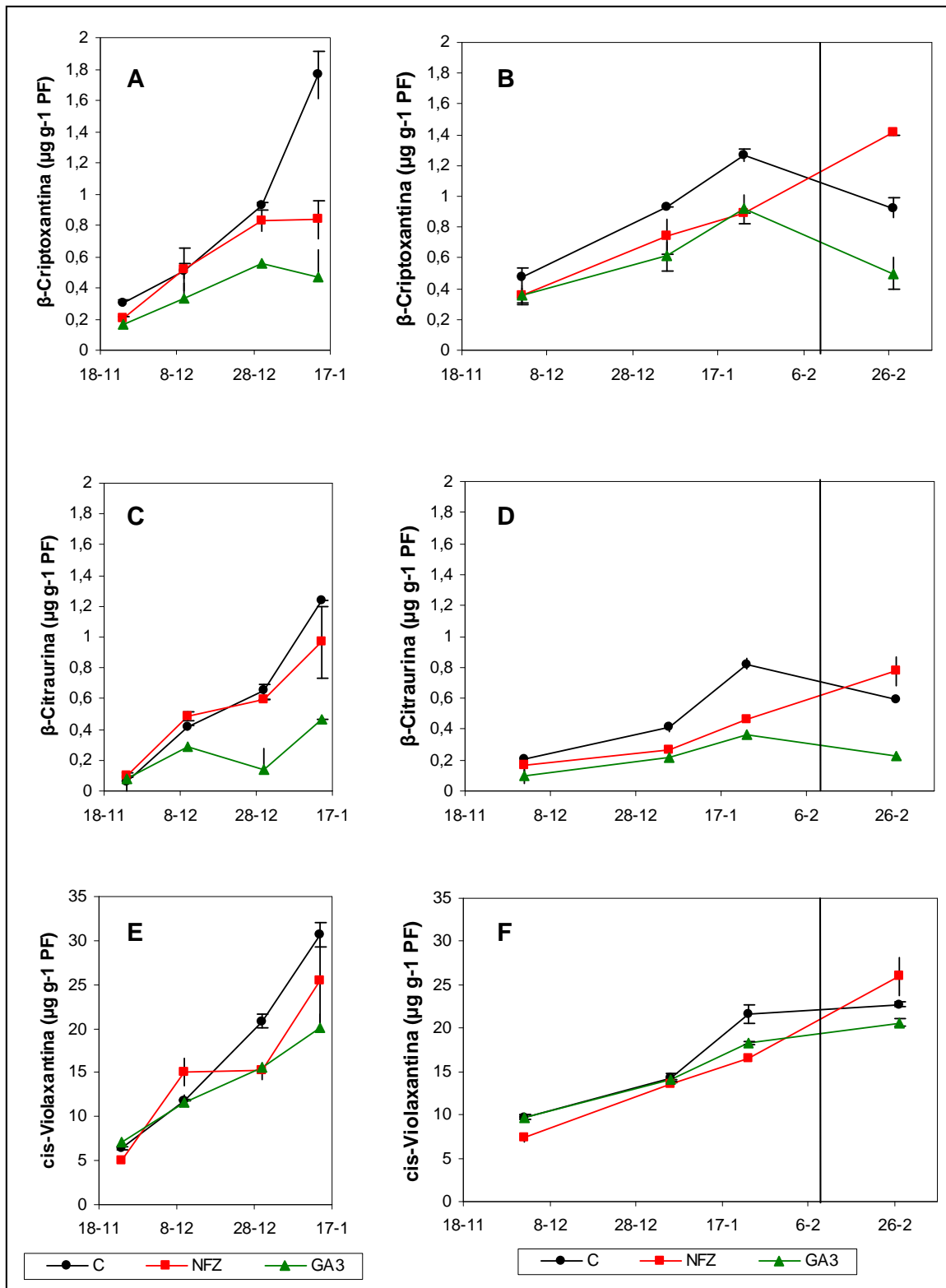

Figura 12. Concentración de carotenoides $\beta$-criptoxantina ( $A$ y $B$ ), $\beta$-citraurina ( $C$ y D) y cis-violaxantina (E y $F$ ) en el flavedo de frutos de naranjo dulce cv. 'Valencia Late', procedentes de árboles control y tratados con norflurazona (NFZ $1 \mathrm{mM}$ ) y ácido giberélico $\left(\mathrm{GA}_{3} 10 \mathrm{mg} \mathrm{L}^{-1}\right)$, en las dos localidades de España, UPV (A, C y E) y Llíria 
(B, D, F). En Llíria la línea vertical indica el momento en el cual los frutos control alcanzaron la misma coloración que en UPV al final del experimento.

\subsubsection{3. Ácido abscísico en el flavedo}

En el experimento de mandarino Satsuma cv. 'Okitsu', realizado a planta entera en Uruguay, se observaron diferencias significativas entre el color de los frutos control y tratados con $\mathrm{GA}_{3}$ a los 45 días del tratamiento, acompañadas de diferencias asimismo significativas, en la concentración de ABA (Tabla 6). En el cv. 'Owari', la concentración de $A B A$ en el flavedo aumentó concomitantemente con el cambio de color. Así, en nuestro experimento, el ICC pasó de $-11.14 \mathrm{a}+6.10$ en 45 días, al mismo tiempo que la concentración de ABA lo hizo de 0.13 a $8.27 \mu \mathrm{g} \mathrm{g}^{-1}$ PS (Tabla 6). Por otra parte la aplicación de $\mathrm{GA}_{3}$ retrasó la coloración, y ésta junto con una menor concentración de $A B A$, alcanzó la significación estadística a partir de los 70 días del tratamiento. La NFZ, por el contrario, no modificó significativamente la coloración ni la concentración de ABA del flavedo (Tabla 6).

En los naranjos dulces cvs. 'Navelina', 'Washington navel' y 'Navelate', la aplicación de $\mathrm{GA}_{3}$ también retardó significativamente la coloración (ICC) del fruto, pero solamente en el cv. 'Navelina' redujo a su vez, la concentración de ABA (Tabla 7). En los otros dos cvs. ésta fue ligeramente más baja, pero no alcanzó la significación estadística. Al igual que para el mandarino Satsuma, la aplicación de NFZ se mostró ineficaz en la alteración del color y de la concentración de ABA (Tabla 7). Es de destacar que los análisis del color y ABA se hicieron en fechas distintas respecto del momento de la aplicación de $\mathrm{GA}_{3}$ ○ NFZ para cada uno de los tres cultivares. 
Tabla 6. Índice de color (ICC) y concentración de ácido abscísico en el flavedo de frutos de Satsuma cvs. 'Okitsu' y 'Owari' procedentes, de árboles control y tratados antes del cambio de color con NFZ $(1 \mathrm{mM})$ y $\mathrm{GA}_{3}\left(10 \mathrm{mg} \mathrm{L}^{-1}\right)$. Cada valor es la media de 3 repeticiones de 10 frutos cada una (año 2005).

\begin{tabular}{llcccccc}
\hline \multirow{2}{*}{ Cultivar } & Trat & \multicolumn{3}{c}{ ICC } & \multicolumn{3}{c}{ ABA $\left(\mu \mathrm{g} \mathrm{g}^{-1} \mathrm{PS}\right)$} \\
\cline { 3 - 8 } & & \multicolumn{3}{c}{ Días post tratamiento } & \multicolumn{3}{c}{ Días post tratamiento } \\
\cline { 3 - 8 } & & 45 & 70 & 90 & 45 & 70 & 90 \\
\hline \multirow{2}{*}{ 'Okitsu' } & Control & $-2.37 \mathrm{a}^{\mathrm{z}}$ & - & - & $0.67 \mathrm{a}$ & - & - \\
& $\mathrm{GA}_{3}$ & $-8.39 \mathrm{~b}$ & - & - & $0.19 \mathrm{~b}$ & - & - \\
\hline \multirow{3}{*}{ 'Owari' } & Control & $-11.14 \mathrm{C}^{\mathrm{y}}$ & $-2.15 \mathrm{a} \mathrm{B}$ & $6.10 \mathrm{a} \mathrm{A}$ & $0.13 \mathrm{C}$ & $6.35 \mathrm{a} \mathrm{B}$ & $8.27 \mathrm{a} \mathrm{A}$ \\
& $\mathrm{NFZ}$ & $-12.36 \mathrm{C}$ & $-2.03 \mathrm{a} \mathrm{B}$ & $5.87 \mathrm{a} \mathrm{A}$ & $0.16 \mathrm{C}$ & $5.25 \mathrm{ab} \mathrm{B}$ & $7.56 \mathrm{a} \mathrm{A}$ \\
& $\mathrm{GA}_{3}$ & $-12.74 \mathrm{C}$ & $-9.89 \mathrm{~b} \mathrm{~B}$ & $-2.55 \mathrm{~b} \mathrm{~A}$ & $0.02 \mathrm{~B}$ & $3.57 \mathrm{~b} \mathrm{~A}$ & $2.84 \mathrm{~b} \mathrm{~A}$ \\
\hline
\end{tabular}

${ }^{z}$ Letras minúsculas diferentes en una misma columna y para un mismo cultivar indican diferencias significativas $\overline{(p \leq 0.05)}$

'Letras mayúsculas diferentes en una misma fila y para una misma variable (ICC o ABA) indican diferencias significativas $(p \leq 0.05)$ 
Tabla 7. Índice de color (ICC) y concentración de ácido abscísico en el flavedo de frutos de naranjo dulce cvs. 'Navelina', 'Washington navel' y 'Navelate' a los 15, 30 y 50 días después del tratamiento (DPT), respectivamente. Cada valor es la media de 3 repeticiones de 5 frutos cada una (año 2005).

\begin{tabular}{|c|c|c|c|c|c|c|}
\hline \multirow{3}{*}{ Tratamiento } & \multicolumn{2}{|c|}{$\begin{array}{c}\text { 'Navelina' } \\
15 \text { DPT (1/04/05) }\end{array}$} & \multicolumn{2}{|c|}{$\begin{array}{l}\text { 'Washington navel' } \\
30 \text { DPT (15/04/05) }\end{array}$} & \multicolumn{2}{|c|}{$\begin{array}{c}\text { 'Navelate' } \\
50 \text { DPT }(20 / 05 / 05)\end{array}$} \\
\hline & & $\mathrm{ABA}$ & & $\mathrm{ABA}$ & & $\mathrm{ABA}$ \\
\hline & ICC & $\left(\mu \mathrm{g} \mathrm{g}^{-1} \mathrm{PS}\right)$ & ICC & $\left(\mu g g^{-1} P S\right)$ & ICC & $\left(\mu \mathrm{g} \mathrm{g}^{-1} \mathrm{PS}\right)$ \\
\hline Control & $-4.27 a^{z}$ & $1.60 \mathrm{a}$ & $-4.42 \mathrm{a}$ & 1.59 & $3.50 \mathrm{a}$ & 2.84 \\
\hline NFZ & $-5.77 a b$ & $1.10 a b$ & $-5.25 a$ & 1.22 & $3.55 \mathrm{a}$ & 2.63 \\
\hline $\mathrm{GA}_{3}$ & $-6.31 b$ & $0.64 \mathrm{~b}$ & $-6.77 b$ & 0.86 & $-0.77 b$ & 2.32 \\
\hline
\end{tabular}

${ }^{\bar{Z}}$ Letras diferentes en una misma columna indican diferencias significativas $(p \leq 0.05)$ 
En los tratamientos realizados en Uruguay a frutos individuales de naranjo dulce cv. 'Washington navel', la aplicación de NFZ, que no modificó el color de los frutos, tampoco alteró significativamente la concentración de ABA en el flavedo (Tabla 8). La aplicación de $\mathrm{GA}_{3}$, que disminuyó el ICC respecto del control, redujo significativamente la concentración de ABA.

Tabla 8. Índice de color (ICC) y concentración de ácido abscísico en el flavedo de frutos de naranjo dulce cv. 'Washington navel' (2006, Uruguay) tratados antes del cambio de color con NFZ (2 mM) ० GA $3\left(10 \mathrm{mg} \mathrm{L}^{-1}\right)$, a los 60 días de efectuados los tratamientos. Cada valor es la media de 3 repeticiones de 5 frutos cada una.

\begin{tabular}{ccc}
\hline Tratamiento & ICC & $\begin{array}{c}\text { ABA } \\
\left(\mu \mathrm{g} \mathrm{g}^{-1} \mathrm{PS}\right)\end{array}$ \\
\hline Control & $4.41 \mathrm{a}^{2}$ & $1.21 \mathrm{a}$ \\
$\mathrm{NFZ}$ & $4.02 \mathrm{a}$ & $1.04 \mathrm{ab}$ \\
$\mathrm{GA}_{3}$ & $0.59 \mathrm{~b}$ & $0.79 \mathrm{~b}$
\end{tabular}

${ }^{2}$ Letras diferentes en una misma columna indican diferencias significativas $(p \leq 0.05)$

En España, la concentración de $A B A$ en el flavedo de frutos maduros de naranjo dulce 'Valencia Late' fue de $0.32 \mu \mathrm{g} \mathrm{g}{ }^{-1} \mathrm{PF}$ y $0.35 \mu \mathrm{g} \mathrm{g} \mathrm{g}^{-1} \mathrm{PF}$ en Llíria y la UPV, respectivamente. Al final del verano, cuando los frutos comenzaron a reverdecer, la concentración en Llíria descendió a niveles de $0.05 \mu \mathrm{g} \mathrm{g}^{-1} \mathrm{PF}$ (Tabla 9). La aplicación de NFZ disminuyó la concentración de ABA del flavedo respecto del control, de un modo paralelo a la acumulación de carotenoides lineales (ver Figura 11) y a las variaciones del ICC (Tabla 9). El tratamiento con $\mathrm{GA}_{3}$, sin embargo, no alteró significativamente la concentración de $A B A$ respecto de los frutos sin tratar, a pesar de haber retrasado el color de los mismos. 
Tabla 9. Índice de color (ICC) y concentración de ácido abscísico en el flavedo de frutos de naranjo dulce cv. 'Valencia Late' (2008-09, España), tratados antes del cambio de color con NFZ $(1 \mathrm{mM}) \circ \mathrm{GA}_{3}\left(10 \mathrm{mg} \mathrm{L}^{-1}\right)$. Cada valor es la media de 3 repeticiones de 5 frutos cada una.

\begin{tabular}{|c|c|c|c|c|c|c|c|}
\hline \multirow[t]{2}{*}{ Localidad } & \multirow[t]{2}{*}{ Tratamiento } & \multicolumn{3}{|c|}{ ICC } & \multicolumn{3}{|c|}{$\begin{array}{c}\text { ABA } \\
\left(\mu g^{-1} P F\right)\end{array}$} \\
\hline & & $24 / 11$ & $10 / 12$ & $30 / 12$ & $24 / 11$ & $10 / 12$ & $30 / 12$ \\
\hline & Control & $-3.90 a^{z} C^{y}$ & 1.62 a B & 4.95 a A & $0.24 \mathrm{~B}$ & 0.27 a B & $0.35 \mathrm{~A}$ \\
\hline \multirow[t]{5}{*}{ UPV } & NFZ & -3.92 a C & $1.13 a b B$ & $3.96 \mathrm{~b} \mathrm{~A}$ & $0.17 \mathrm{~B}$ & $0.03 \mathrm{~b} \mathrm{C}$ & $0.31 \mathrm{~A}$ \\
\hline & $\mathrm{GA}_{3}$ & $-5.37 b \mathrm{C}$ & -1.03 c B & 2.65 c A & $0.26 \mathrm{~A}$ & 0.33 a A & $0.33 \mathrm{~A}$ \\
\hline & & \multicolumn{3}{|c|}{ ICC } & \multicolumn{3}{|c|}{$\begin{array}{c}\text { ABA } \\
\left(\mu g g^{-1} P F\right)\end{array}$} \\
\hline & & $2 / 12$ & $23 / 01$ & $26 / 06$ & $2 / 12$ & $23 / 01$ & $26 / 06$ \\
\hline & Control & $-5.60 a^{\prime} C^{y}$ & 5.37 a $A$ & $0.01 \mathrm{a} \mathrm{B}$ & $0.07 \mathrm{~B}$ & 0.32 a $A$ & $0.05 \mathrm{~B}$ \\
\hline \multirow[t]{2}{*}{ Llíria } & NFZ & -4.39 a C & $4.19 \mathrm{~b} \mathrm{~A}$ & -0.15 b B & $0.04 \mathrm{~B}$ & $0.14 \mathrm{~b} \mathrm{~A}$ & $0.02 \mathrm{~B}$ \\
\hline & $\mathrm{GA}_{3}$ & -6.44 b C & 0.82 c A & -3.72 c B & $0.07 \mathrm{~B}$ & 0.28 a A & $0.07 \mathrm{~B}$ \\
\hline
\end{tabular}

${ }^{z}$ Letras minúsculas diferentes en una misma columna y para una misma localidad indican diferencias significativas $(p \leq 0.05)$

y'Letras mayúsculas diferentes en una misma fila y para una misma variable (ICC ○ ABA) indican diferencias significativas $(p \leq 0.05)$ 


\subsubsection{Carbohidratos y nitrógeno en el flavedo}

\subsection{Carbohidratos}

En todos los experimentos realizados a la planta completa en Uruguay, se estudió la evolución del contenido de fructosa, glucosa y sacarosa en el flavedo de los frutos. Igualmente se analizó la evolución conjunta de los dos azúcares reductores y de los azúcares totales.

La concentración de azúcares solubles totales del flavedo de los frutos aumentó durante el proceso de desverdizado. En todas los cultivares estudiados, los azúcares reductores representaron la mayor proporción del total, explicando el incremento general de los azúcares del flavedo. La concentración de sacarosa del flavedo se incrementó hasta el inicio del cambio de color de los frutos, y posteriormente se mantuvo relativamente estable, con leves variaciones inconsistentes entre cultivares. En la Figura 13 se presentan los datos de los experimentos realizados el segundo año con los tres cultivares de naranjo.

El flavedo de los frutos del cv. 'Navelina' presentó mayor concentración de azúcares reductores y totales que el de 'Washington navel' y 'Navelate' a partir de los 15 días de iniciados los experimentos. Con respecto a la sacarosa, el cv. 'Navelate' presentó siempre menor concentración que los otros dos cultivares.

La comparación de la concentración de carbohidratos en el flavedo de los tres cvs. de naranjo dulce indica que para un índice de color determinado (independientemente de la fecha), el más precoz ('Navelina') posee mayor concentración de azucares totales, que el intermedio ('Washington navel') y tardío ('Navelate') (Tabla 10). En los mandarinos, sin embargo, no se encontró relación alguna entre la precocidad y la concentración de azúcares del flavedo (datos no presentados). Sin embargo, para una fecha dada, el cv. más precoz ('Okitsu') también poseía una concentración mayor de azúcares (Tabla 11). 


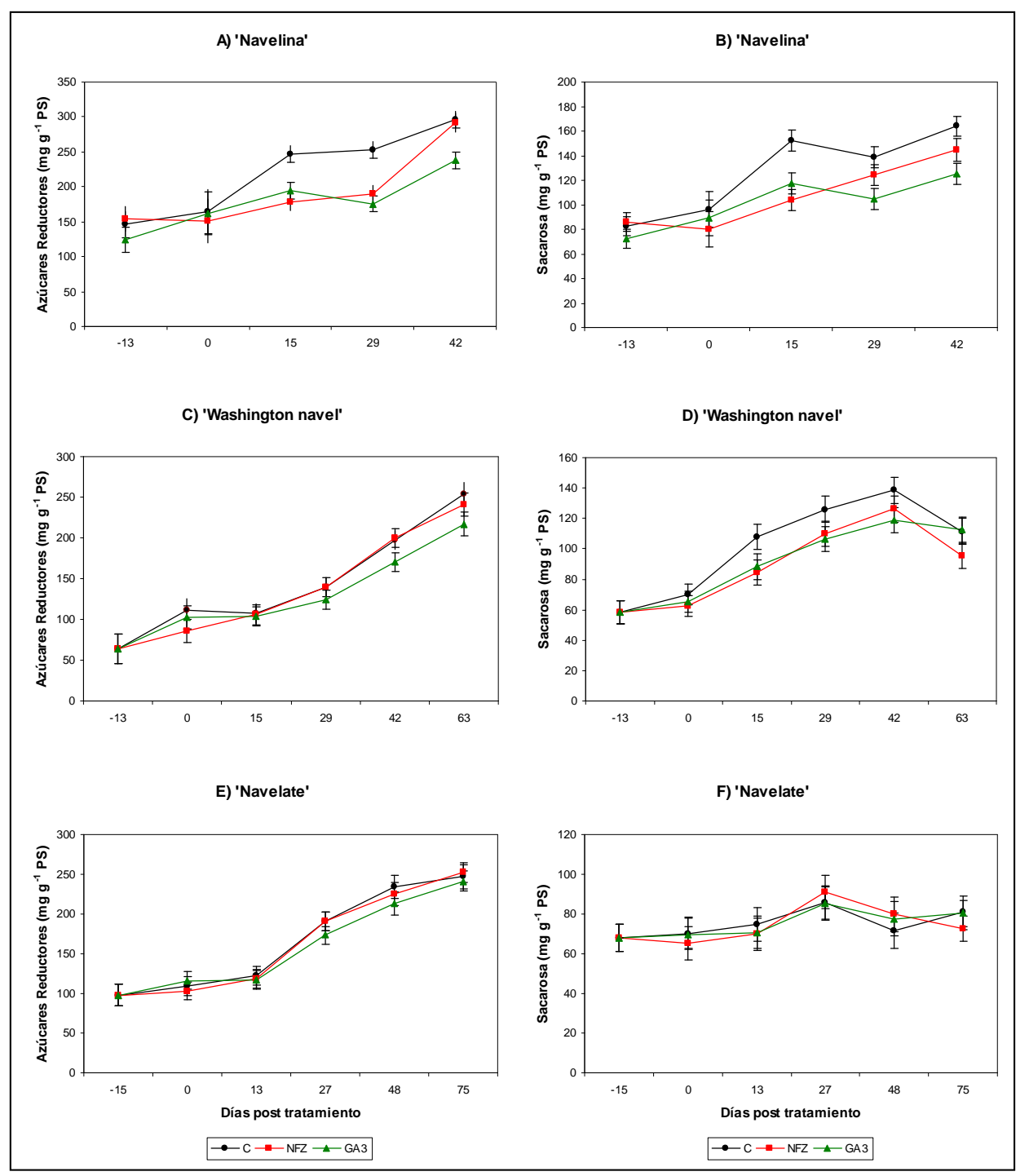

Figura 13. Azúcares reductores (Fructosa+Glucosa) y sacarosa en el flavedo de frutos de naranjo dulce cvs. 'Navelina' de maduración temprana (A, B), 'Washington navel' de maduración intermedia (C, D), y 'Navelate' de maduración tardía (E, F). Influencia de la aplicación previa al cambio de color de norflurazona (NFZ $1 \mathrm{mM}$ ) y ácido giberélico $\left(\mathrm{GA}_{3} 20 \mathrm{mg} \mathrm{L}^{-1}\right)$. Cada valor es la media de 3 repeticiones de 5 frutos cada una (año 2005). En 'Navelina' y 'Washington navel' -13 es 4/03/05; en 'Navelate -15 es $17 / 03 / 05$. 
Tabla 10. Concentración de azúcares reductores (Fructosa+Glucosa, $\mathrm{mg} \mathrm{g}^{-1} \mathrm{PS}$ ) y sacarosa ( $\mathrm{mg} \mathrm{g}^{-1} \mathrm{PS}$ ) en el flavedo de los frutos de naranjo dulce cvs. 'Navelina', de maduración temprana, 'Washington navel', de maduración intermedia y 'Navelate', de maduración tardía. Cada valor es la media de 3 repeticiones de 5 frutos cada una (año 2005).

\begin{tabular}{|c|c|c|c|c|c|c|}
\hline \multirow[b]{2}{*}{ Cultivar } & \multicolumn{3}{|c|}{ Frutos verdes $^{y}$} & \multicolumn{3}{|c|}{ Frutos maduros $^{x}$} \\
\hline & ICC & $\begin{array}{l}\text { Azúcares } \\
\text { reductores }\end{array}$ & Sacarosa & ICC & $\begin{array}{l}\text { Azúcares } \\
\text { reductores }\end{array}$ & Sacarosa \\
\hline 'Navelina' & -4.3 & $247 a^{2}$ & $153 \mathrm{a}$ & 2.4 & $296 a$ & $164 \mathrm{a}$ \\
\hline 'Navel' & -4.4 & $140 \mathrm{~b}$ & $126 \mathrm{~b}$ & 2.5 & $227 \mathrm{~b}$ & $124 \mathrm{~b}$ \\
\hline 'Navelate' & -4.4 & $122 b$ & $75 c$ & 2.1 & $243 b$ & $82 \mathrm{c}$ \\
\hline
\end{tabular}

${ }^{z}$ Letras diferentes en cada columna indican diferencia significativa $(p \leq 0.05)$.

${ }^{y}$ Frutos verdes, corresponden a las siguientes fechas: 'Navelina' 1/04/05; 'Washington navel' y 'Navelate' 15/04/05

${ }^{x}$ Frutos maduros corresponden a las siguientes fechas: 'Navelina' y 'Washington navel' 28/04/05; 'Navelate' 13/05/05

En términos generales, en los naranjos y mandarinos, los frutos tratados con $\mathrm{GA}_{3}$ presentaron menor concentración de todos los azúcares solubles que los controles y tratados con NFZ, que fueron iguales entre sí. La única excepción fue el cv. 'Navelate' en el año 2005, en el que no se registraron diferencias significativas entre tratamientos. Existe, por tanto, una relación entre el retraso en la toma de color de los frutos tratados con $\mathrm{GA}_{3}$ (ver Figura 6 , Tabla 4) y el menor contenido en azúcares del flavedo (Figura 13, Tablas 10 y 11).

Las aplicaciones realizadas en Uruguay a frutos individuales en el cv. 'Washington navel' proporcionaron resultados similares; el tratamiento de NFZ no alteró la concentración de azúcares del flavedo, mientras que la aplicación de $\mathrm{GA}_{3}$ disminuyó levemente, la concentración de azúcares reductores, sin afectar la de sacarosa (Tabla 12). 
Tabla 11. Concentración de azúcares solubles totales (Fructosa+Glucosa+Sacarosa, $\mathrm{mg} \mathrm{g}^{-1} \mathrm{PS}$ ) en el flavedo de frutos de mandarino Satsuma cv. 'Okitsu' de maduración muy temprana y 'Owari' de maduración temprana, procedentes de árboles control y tratados antes del cambio de color con norflurazona (NFZ $1 \mathrm{mM})$ y ácido giberélico $\left(\mathrm{GA}_{3} 10 \mathrm{mg} \mathrm{L}^{-1}\right)$. Cada valor es la media de 3 repeticiones de 5 frutos cada una (año 2005).

\begin{tabular}{llccccccc}
\hline Cultivar & Tratamiento & \multicolumn{7}{c}{ Días Post Tratamiento } \\
\hline & & 0 & 15 & 30 & 45 & 60 & 70 & 90 \\
\hline ‘Okitsu' & $\mathrm{C}$ & - & - & - & $256 \mathrm{a}^{\mathrm{z}} \mathrm{C}^{\mathrm{y}}$ & $301 \mathrm{a} \mathrm{C} \mathrm{\#}$ & $354 \mathrm{a} \mathrm{B} \mathrm{\#}$ & $381 \mathrm{~A}$ \\
& $\mathrm{GA}_{3}$ & - & - & - & $161 \mathrm{~b} \mathrm{C}$ & $164 \mathrm{~b} \mathrm{C}$ & $219 \mathrm{~b} \mathrm{~B}$ & $338 \mathrm{~A}$ \\
\hline \multirow{2}{*}{ Owari' } & $\mathrm{C}$ & $102 \mathrm{E}$ & $129 \mathrm{D}$ & $148 \mathrm{a} \mathrm{D}$ & $209 \mathrm{a} \mathrm{C}$ & $199 \mathrm{C}$ & 287 a B & 364 a A \\
& $\mathrm{NFZ}$ & $99 \mathrm{E}$ & $121 \mathrm{D}$ & $115 \mathrm{~b} \mathrm{D}$ & $171 \mathrm{ab} \mathrm{C}$ & $181 \mathrm{C}$ & $290 \mathrm{a} \mathrm{B}$ & 368 a A \\
& $\mathrm{GA}_{3}$ & $96 \mathrm{E}$ & $121 \mathrm{D}$ & $109 \mathrm{~b} \mathrm{D}$ & $151 \mathrm{~b} \mathrm{C}$ & $149 \mathrm{C}$ & $235 \mathrm{~b} \mathrm{~B}$ & $303 \mathrm{~b} \mathrm{~A}$
\end{tabular}

${ }^{z}$ Letras minúsculas diferentes en una misma columna y para un mismo cultivar indican diferencias significativas $(p \leq 0.05)$

yetras mayúsculas diferentes en una misma fila indican diferencias significativas $(p \leq 0.05)$

\# indica diferencias significativas entre cultivares $(p \leq 0.05)$ 
Tabla 12. Concentración de azúcares reductores (fructosa, glucosa) y sacarosa ( $\mathrm{mg} \mathrm{g}^{-1}$ PS) en el flavedo de frutos de naranjo 'Washington navel' (2006, Uruguay) tratados antes del cambio de color con NFZ $(2 \mathrm{mM}) \circ \mathrm{GA}_{3}\left(10 \mathrm{mg} \mathrm{L}^{-1}\right)$, a los 60 días después del tratamiento. Cada valor resulta del promedio de 3 repeticiones de 5 frutos cada una.

\begin{tabular}{cccc}
\hline Tratamiento & Fructosa & Glucosa & Sacarosa \\
\hline $\mathrm{C}$ & $98.3 \mathrm{a}^{\mathrm{z}}$ & $118.6 \mathrm{a}$ & 93.3 \\
$\mathrm{NFZ}$ & $97.7 \mathrm{a}$ & $121.2 \mathrm{a}$ & 93.1 \\
$\mathrm{GA}_{3}$ & $77.0 \mathrm{~b}$ & $100.7 \mathrm{~b}$ & 89.5 \\
\hline
\end{tabular}

${ }^{z}$ Letras diferentes en una misma columna indican diferencias significativas $(p \leq 0.05)$.

\subsection{Nitrógeno}

En Uruguay, en los experimentos realizados a la planta completa, la concentración de nitrógeno total en el flavedo de los frutos disminuyó en todos los cultivares con el avance del cambio de color. En los mandarinos evolucionó desde $1.0 \%$ del peso seco al inicio del experimento, hasta $0.5 \%$ al final (Tabla 13), y en los naranjos la variación fue de $0.85 \%$ a $0.4 \%$ (datos no presentados). La fracción proteica (N-P) representó entre el 98\% y el 99\% del nitrógeno total (NT), mientras que el porcentaje restante correspondió a la fracción amoniacal $\left(\mathrm{N}-\mathrm{NH}_{4}^{+}\right)$; no se detectaron nitratos ni nitritos en el flavedo.

El efecto de los tratamientos de $\mathrm{GA}_{3}$ y NFZ sobre la concentración de N$P$ y NT en el flavedo no fue consistente. En los experimentos realizados el primer año con naranjos (datos no presentados) y el segundo año con mandarinos (Tabla 13), los frutos tratados con $\mathrm{GA}_{3}$ mantuvieron mayores valores endógenos de NT y N-P que los controles, mientras que los tratados con NFZ no se diferenciaron de los sin tratar. Ambas respuestas se relacionaron con la evolución del color de la piel. Los frutos del cv. 'Okitsu', de maduración más temprana, tratados con $\mathrm{GA}_{3}$ presentaron igual concentración de $\mathrm{N}$ que los frutos sin tratar del cv. 'Owari', en todas las fechas de evaluación. Por el contrario, en los experimentos de naranjos del segundo año, no se 
detectaron diferencias en la concentración de $\mathrm{N}$ entre los frutos tratados y control (datos no presentados).

El N-NH${ }_{4}{ }^{+}$del flavedo de los frutos tratados y sin tratar osciló entre los 20 y $60 \mu \mathrm{g} \mathrm{g}^{-1}$ PS en todos los cultivares. No se observó asociación entre su evolución y la toma de color de los frutos (datos no presentados).

En los experimentos realizados en Uruguay a frutos individuales de naranjo dulce cv. 'Washington navel', la aplicación de NFZ ○ GA 3 , no modificó el contenido de nitrógeno en el flavedo de los frutos a los 60 días después del tratamiento. La concentración de nitrógeno total fue $0.65 \%$ del peso seco, $0.62 \%$ y $0.69 \%$ para los frutos control, tratados con NFZ y con $\mathrm{GA}_{3}$, respectivamente. La fracción amoniacal en el flavedo de los frutos control fue $17.2 \mu \mathrm{g} \mathrm{g}^{-1} \mathrm{PS}$, y en los tratados con NFZ y GA $14.8 \mu \mathrm{g} \mathrm{g}^{-1} \mathrm{PS}$ y $12.3 \mu \mathrm{g} \mathrm{g}^{-1}$ PS, respectivamente. 
Tabla 13. Concentración de nitrógeno total (mg $100 \mathrm{mg}^{-1} \mathrm{PS}$ ) en el flavedo de frutos de mandarino Satsuma cv. 'Okitsu', de maduración muy temprana, y 'Owari', de maduración temprana, procedentes de árboles control y tratados antes del cambio de color con norflurazona (NFZ $1 \mathrm{mM})$ y ácido giberélico $\left(\mathrm{GA}_{3} 10 \mathrm{mg} \mathrm{L}^{-1}\right)$. Cada valor es el promedio de 3 repeticiones de 5 frutos cada una.

\begin{tabular}{llccccccc}
\hline \multirow{2}{*}{ Cultivar } & \multirow{2}{*}{ Tratamiento } & \multicolumn{7}{c}{ Días Post Tratamiento } \\
\cline { 3 - 9 } & & 0 & 15 & 30 & 45 & 60 & 70 & 90 \\
\hline \multirow{2}{*}{ ‘Okitsu’ } & $\mathrm{C}$ & - & - & - & $0.60 \mathrm{~b}^{\mathrm{z}} \mathrm{A}^{\mathrm{y}} \#$ & $0.57 \mathrm{~b} \mathrm{~A} \mathrm{\#}$ & $0.52 \mathrm{~b} \mathrm{~B} \#$ & $0.49 \mathrm{~b} \mathrm{C} \mathrm{\#}$ \\
& $\mathrm{GA}_{3}$ & - & - & - & $0.75 \mathrm{a} \mathrm{A}$ & $0.73 \mathrm{a} \mathrm{A}$ & $0.70 \mathrm{a} \mathrm{B}$ & $0.58 \mathrm{a} \mathrm{C}$ \\
\hline \multirow{2}{*}{ 'Owari’ } & $\mathrm{C}$ & $1.03 \mathrm{~A}$ & $1.07 \mathrm{~A}$ & $0.89 \mathrm{AB}$ & $0.82 \mathrm{~b} \mathrm{~B}$ & $0.81 \mathrm{~b} \mathrm{~B}$ & $0.68 \mathrm{~b} \mathrm{C}$ & $0.61 \mathrm{a} \mathrm{D}$ \\
& $\mathrm{NFZ}$ & $1.03 \mathrm{~A}$ & $0.98 \mathrm{~A}$ & $0.99 \mathrm{AB}$ & $0.84 \mathrm{~b} \mathrm{~B}$ & $0.78 \mathrm{~b} \mathrm{~B}$ & $0.65 \mathrm{~b} \mathrm{C}$ & $0.49 \mathrm{~b} \mathrm{D}$ \\
& $\mathrm{GA}_{3}$ & $1.04 \mathrm{~A}$ & $0.92 \mathrm{~A}$ & $1.02 \mathrm{AB}$ & $0.91 \mathrm{a} \mathrm{B}$ & $0.90 \mathrm{a} \mathrm{B}$ & $0.79 \mathrm{a} \mathrm{C}$ & $0.66 \mathrm{a} \mathrm{D}$
\end{tabular}

${ }^{z}$ Letras minúsculas diferentes en una misma columna y para un mismo cultivar indican diferencias significativas $(p \leq 0.05)$

'Letras mayúsculas diferentes en una misma fila indican diferencias significativas $(p \leq 0.05)$

\# indica diferencias significativas entre cultivares $(p \leq 0.05)$ 


\subsubsection{Interrupción del transporte: anillado del pedúnculo}

\subsubsection{Color del flavedo}

En los tres experimentos, el anillado del pedúnculo (extracción permanente de $0.5 \mathrm{~cm}$ de la corteza del pedúnculo), realizado previo al cambio de color, lo retrasó respecto de los frutos control. Se constataron diferencias significativas en la evolución de todas las variables de color analizadas entre ambos grupos de frutos. En la medida en que no hubo interacción entre tratamientos, se presentan las curvas ajustadas de la evolución del ICC para los dos grupos de frutos, con el pedúnculo anillado y sin anillar, del primer año (2006) en el cv. 'Washington navel' (Figura 14).

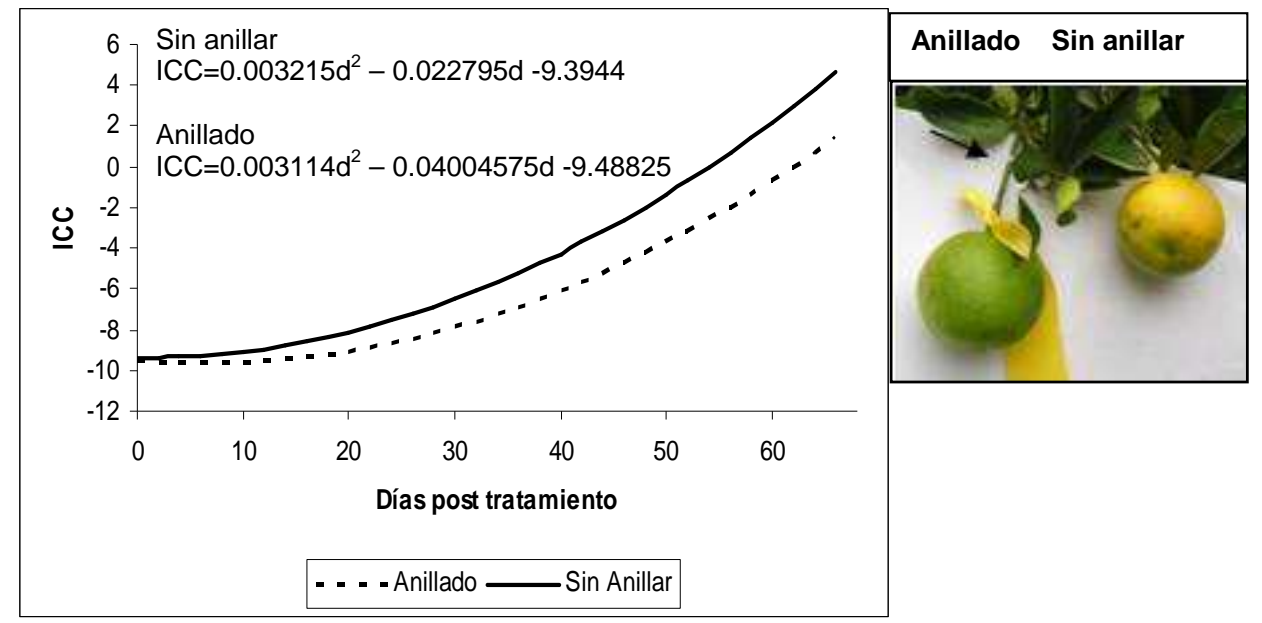

Figura 14. Curvas ajustadas del índice de color (ICC) de frutos de naranjo dulce cv. 'Washington navel' con pedúnculo anillado y sin anillar (2006, Uruguay). Determinaciones realizadas a partir de frutos individuales (número inicial: 100 frutos por grupo y número final: 100 Frutos sin anillar y 60 anillados). d: días post tratamiento. 
En el cv. 'Washington navel' el primer año, las curvas ajustadas de la evolución del ICC de todos los tratamientos con anillado (anillado de la zona media del pedúnculo con hojas: $\mathrm{AMH}$, anillado a $0.5 \mathrm{~cm}$ del fruto: $\mathrm{A}$, o su combinación con nitrato de amonio o ABA: A-N, A-ABA) fueron significativamente diferentes al control. Para todos ellos, el fruto tratado vio retrasada su entrada en color respecto de los frutos sin tratar (Figura 15). Por el contrario, la aplicación de nitrato de amonio $(\mathrm{N})$ no alteró la coloración respecto del control (Figura 15). En el segundo año, el color de los frutos con anillado en la zona media del pedúnculo también se retrasó respecto de los frutos sin anillar. La aplicación de ABA no alteró la coloración como tratamiento individual, ni combinado con el anillado del pedúnculo (Figura 15).

En el experimento del cv. 'Valencia Delta Seedless', la curva de ICC de los frutos control fue diferente a la del resto de los tratamientos. El color de los frutos con anillado próximo a éstos (A) ó en la zona media del pedúnculo manteniendo las hojas (AMH), no se diferenció estadísticamente (Figura 15).

En los tres experimentos, se encontraron diferencias entre los tratamientos anillados y no anillados a partir de los 20 días para las variables $L$, b, ICC y c del color y a partir de los 35 días ('Valencia Delta Seedless') o 40 días ('Washington navel') para a, a/b y HUE.

Considerando los tratamientos en forma individual, en el cv. 'Washington navel', el primer año los frutos con pedúnculo anillado ( $\mathrm{AMH}$ y $\mathrm{A}$ ), y el segundo año con anillado en la zona media del pedúnculo eliminando las hojas entre el anillado y el fruto ( $A M)$, o combinado con $A B A$ ( $A M-A B A$ ), presentaron significativamente menor color que el control a partir de los 40 días del tratamiento. En 'Valencia Delta Seedless', a partir de los 35 días los frutos de todos los tratamientos presentaron menor color que el control (Figura 16), y en la última fecha de muestreo el AM resultó significativamente más verde que el anillado (A) (Tabla 14). 


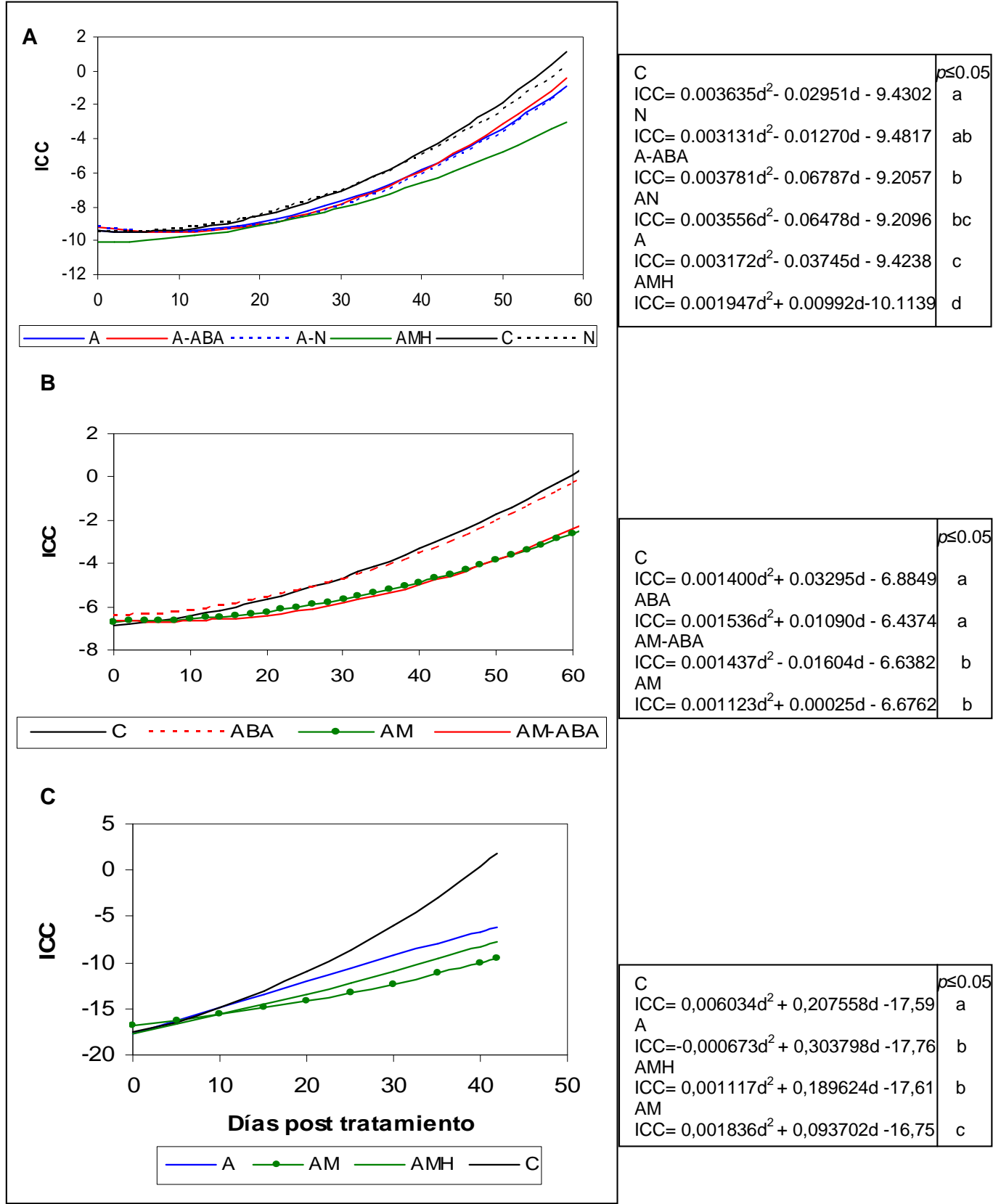

Figura 15. Curvas ajustadas de la evolución del índice de color (ICC) de los frutos de naranjo dulce cv. 'Washington navel', año 2006 (A) y 2008 (B) en Uruguay, y cv. 'Valencia Delta Seedless', 2006 (C), en España. Letras diferentes en un mismo experimento indican diferencias significativas entre curvas $(p \leq 0.05)$. d: días post 
tratamiento. Valores determinados en frutos individuales, número inicial 25-30 frutos por tratamiento (2006) y 100 frutos (2008), y número final 20-30 frutos por tratamiento. Tratamientos: C: control, A: anillado de pedúnculo a $0.5-1 \mathrm{~cm}$ del fruto, $\mathrm{AMH}$ : anillado de pedúnculo a 8-10 $\mathrm{cm}$ del fruto, $\mathrm{AM}$ : anillado de pedúnculo a $8-10 \mathrm{~cm}$ del fruto eliminando las hojas entre el fruto y el anillado, $\mathrm{N}$ : aplicación de $\mathrm{NH}_{4} \mathrm{NO}_{3}\left(20 \mathrm{~g} \cdot \mathrm{L}^{-1}\right), \mathrm{A}$ $\mathrm{N}$ : anillado de pedúnculo a 0.5-1 cm del fruto y aplicación de $\mathrm{NH}_{4} \mathrm{NO}_{3}\left(20 \mathrm{~g} \cdot \mathrm{L}^{-1}\right), A-A B A$ ó AM-ABA: anillado de pedúnculo a $0.5-1 \mathrm{~cm}$ del fruto $(\mathrm{A})$, ó a $8-10 \mathrm{~cm}$ del fruto eliminando las hojas (AM)y aplicación de ABA (250 $\left.\mathrm{mg} \cdot \mathrm{L}^{-1}\right)$.

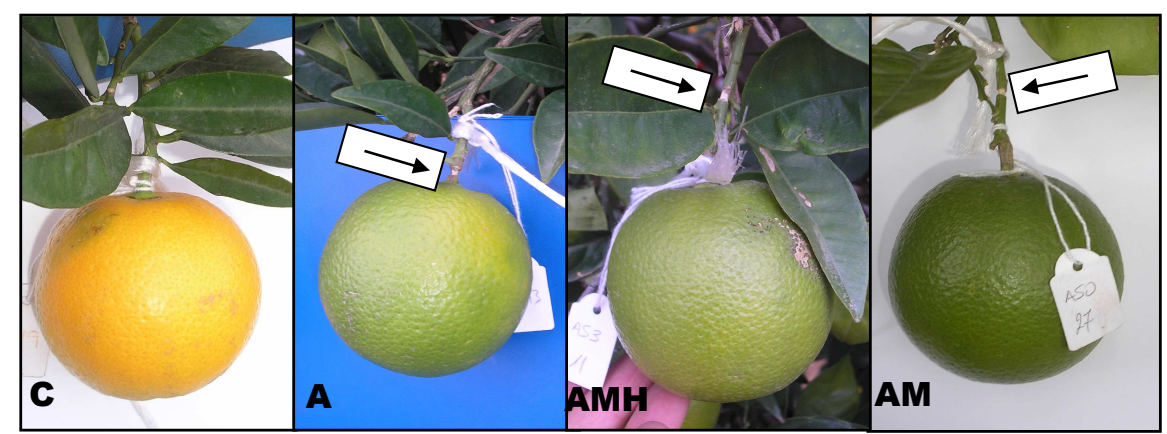

Figura 16. Frutos de naranjo dulce cv. 'Valencia Delta Seedless' a los 35 días de realizados los tratamientos: control $(C)$, anillado de pedúnculo a $0.5-1 \mathrm{~cm}$ del fruto $(A)$, anillado de pedúnculo a 8-10 cm del fruto $(\mathrm{AMH})$ y anillado de pedúnculo a 8-10 cm del fruto eliminando las hojas entre el fruto y el anillado (AM). La flecha señala la posición del anillado.

Tabla 14. Color de los frutos de naranjo dulce cv. 'Valencia Delta Seedless' (2006, España), expresado como relación a/b, croma y ángulo-tono HUE (Hunter Lab) a los 42 días de realizados los tratamientos: control $(C)$, anillado de pedúnculo a $0.5-1 \mathrm{~cm}$ del fruto $(A)$, anillado de pedúnculo a $8-10 \mathrm{~cm}$ del fruto $(\mathrm{AMH})$ y anillado de pedúnculo a 8-10 cm del fruto eliminando las hojas entre el fruto y el anillado (AM).

\begin{tabular}{cccc}
\hline Tratamiento & $\mathrm{a} / \mathrm{b}$ & Croma & Angulo HUE \\
\hline C & $0.103 \mathrm{a}$ & $39.2 \mathrm{a}$ & $84.3^{\circ} \mathrm{c}$ \\
$\mathrm{A}$ & $-0.309 \mathrm{~b}$ & $30.8 \mathrm{~b}$ & $106.6^{\circ} \mathrm{b}$ \\
AMH & $-0.368 \mathrm{bc}$ & $30.5 \mathrm{~b}$ & $109.5^{\circ} \mathrm{ab}$ \\
AM & $-0.477 \mathrm{c}$ & $29.5 \mathrm{~b}$ & $115.3^{\circ} \mathrm{a}$ \\
\hline
\end{tabular}

${ }^{\mathrm{z}}$ Letras diferentes en una misma columna indican diferencias significativas $(p \leq 0.05)$ 


\subsubsection{Tamaño del fruto}

El crecimiento de los frutos se vio fuertemente afectado por el anillado del pedúnculo previo al cambio de color. Analizando conjuntamente todos los frutos cuyos pedúnculos fueron anillados se determinó que éstos crecieron más lentamente y alcanzaron menor tamaño final que los frutos cuyos pedúnculos no fueron anillados (Figura 17). El mismo resultado se encontró al considerar los frutos de cada tratamiento individualmente (Tabla 15).

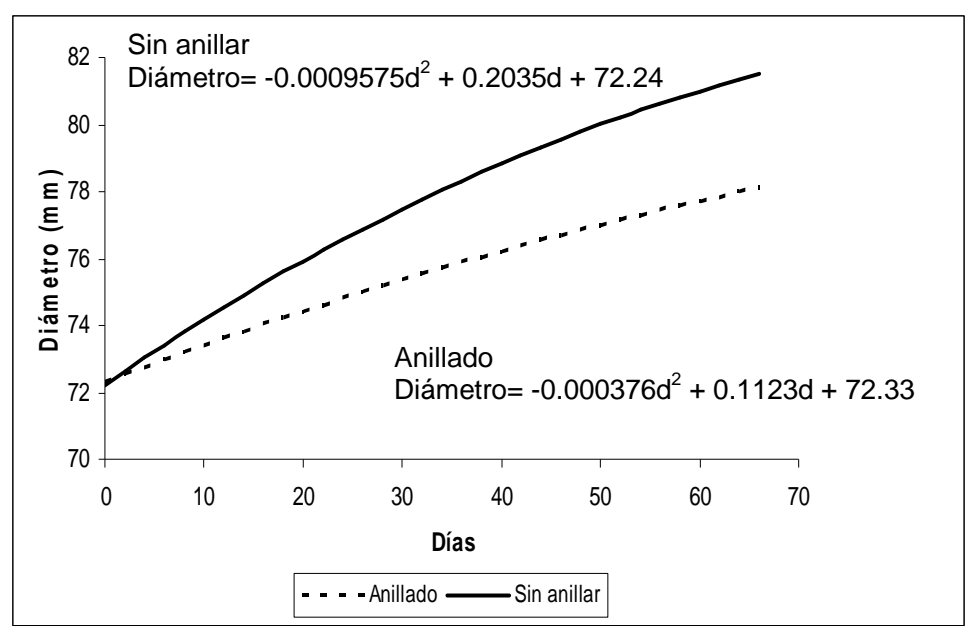

Figura 17. Curvas ajustadas de la evolución del diámetro ecuatorial de los frutos de naranjo dulce cv. 'Washington navel' con el pedúnculo anillado y sin anillar (2008, Uruguay), determinadas a partir de frutos individuales (número inicial: 100 frutos por grupo y número final: 100 sin anillar y 60 anillados). d: días post tratamiento. 
Tabla 15. Diámetro ecuatorial promedio $(\mathrm{mm})$ de frutos de naranjo dulce cv. 'Washington navel' (2006, 2008; Uruguay) y 'Valencia Delta Seedless' (2006; España) al final del experimento. Cada valor es el promedio de 25-30 frutos por tratamiento.

\begin{tabular}{cccccc}
\hline \multicolumn{2}{c}{ 'Washington navel' } & \multicolumn{2}{c}{ 'Washington navel' } & \multicolumn{2}{c}{ 'Valencia Delta Seedless' } \\
\multicolumn{4}{c}{2006} & \multicolumn{2}{c}{2008} \\
\hline Trat & Diámetro & Trat & Diámetro & Trat & Diámetro \\
C $^{z}$ & $77.9 \mathrm{a}^{\mathrm{y}}$ & $\mathrm{C}$ & $76.2 \mathrm{a}$ & $\mathrm{C}$ & $61.5 \mathrm{a}$ \\
$\mathrm{N}$ & $76.8 \mathrm{ab}$ & $\mathrm{ABA}$ & $73.3 \mathrm{a}$ & $\mathrm{AMH}$ & $59.4 \mathrm{~b}$ \\
$\mathrm{~A}-\mathrm{N}$ & $74.6 \mathrm{~b}$ & $\mathrm{AM}$ & $66.2 \mathrm{~b}$ & $\mathrm{AM}$ & $59.2 \mathrm{~b}$ \\
A-ABA & $75.5 \mathrm{~b}$ & AM-ABA & $62.5 \mathrm{~b}$ & $\mathrm{~A}$ & $59.1 \mathrm{~b}$ \\
A & $74.9 \mathrm{bc}$ & & & & \\
AMH & $74.1 \mathrm{c}$ & & & &
\end{tabular}

${ }^{\mathrm{Z}} \mathrm{C}$ : control, $\mathrm{A}$ : anillado de pedúnculo a $0.5-1 \mathrm{~cm}$ del fruto, $\mathrm{AMH}$ : anillado de pedúnculo a 8-10 cm del fruto, AM: anillado de pedúnculo a $8-10 \mathrm{~cm}$ del fruto eliminando las hojas entre el fruto y el anillado, $\mathrm{N}$ : aplicación de $\mathrm{NH}_{4} \mathrm{NO}_{3}\left(20 \mathrm{~g} \cdot \mathrm{L}^{-1}\right), \mathrm{A}-\mathrm{N}$ : anillado de pedúnculo a $0.5-1 \mathrm{~cm}$ del fruto y aplicación de $\mathrm{NH}_{4} \mathrm{NO}_{3}\left(20 \mathrm{~g} \cdot \mathrm{L}^{-1}\right), A-A B A$ ó AM-ABA: anillado de pedúnculo a $0.5-1 \mathrm{~cm}$ del fruto $(A)$, ó a $8-10 \mathrm{~cm}$ del fruto eliminando las hojas (AM)y aplicación de ABA (250 mg. $\left.\mathrm{L}^{-1}\right)$.

${ }^{y}$ Letras diferentes en un mismo experimento (cultivar) indican diferencias significativas $(p \leq 0.05)$.

\subsubsection{Etileno, ácido abscísico y giberelinas}

\subsection{Etileno}

En ninguno de los experimentos se detectó producción de etileno medida en los frutos enteros, con independencia de los tratamientos. Tampoco se detectó actividad ACS (ácido 1-aminociclopropano-1-carboxílico sintasa) en el flavedo.

\subsubsection{2. Ácido Abscísico}

\section{Flavedo}

La concentración de $\mathrm{ABA}$ en el flavedo de los frutos anillados fue, en términos generales, mayor que la de los frutos sin anillar, contrariamente a lo ocurrido con el color en ambos grupos de frutos ('Washington navel', 2006, 
Uruguay, y 'Valencia Delta Seedless', 2006, España). Sin embargo, de todos los tratamientos evaluados el único que en forma consistente incrementó significativamente la concentración de $\mathrm{ABA}$ fue el anillado realizado en la zona media del pedúnculo con hojas (AMH) (Tabla 16).

En el naranjo dulce cv. 'Washington navel', el agregado exógeno de ABA a los frutos con el pedúnculo anillado no provocó un incremento en su concentración endógena respecto de los frutos control, ni de los frutos a los que solo se les anilló el pedúnculo. Considerando estos resultados, la aplicación, a frutos individualmente, de una concentración de $250 \mathrm{mg} \mathrm{L}^{-1}$ de ABA no se relacionó directamente con su coloración ni con su concentración endógena.

Tabla 16. Índice de color (ICC) y concentración de ácido abscísico en el flavedo de frutos de naranjo dulce cv. 'Washington navel' (2006, Uruguay) y 'Valencia Delta Seedless' (2006, España) a los 60 y 40 días de efectuados los tratamientos (DPT), respectivamente. Cada valor es la media de 3 repeticiones de 5 frutos cada una.

\begin{tabular}{|c|c|c|c|c|c|}
\hline \multicolumn{6}{|c|}{ Flavedo de frutos } \\
\hline \multirow{2}{*}{\multicolumn{3}{|c|}{$\begin{array}{c}\text { 'Washington navel' } \\
60 \text { DPT }\end{array}$}} & \multicolumn{3}{|c|}{ 'Valencia Delta Seedless' } \\
\hline & & & & $40 \mathrm{DPT}$ & \\
\hline Tratamiento & ICC & $\begin{array}{c}\text { ABA } \\
\left(\mu g g^{-1} P S\right)\end{array}$ & Tratamiento & ICC & $\begin{array}{c}\text { ABA } \\
\left(\mu g g^{-1} P S\right)\end{array}$ \\
\hline $\mathrm{C}^{\mathrm{z}}$ & $4.41 \mathrm{a}^{\mathrm{y}}$ & $1.21 \mathrm{~b}$ & $\mathrm{C}$ & $1.12 \mathrm{a}$ & $3.15 b$ \\
\hline $\mathrm{N}$ & $3.26 \mathrm{a}$ & $1.16 \mathrm{~b}$ & $A$ & $-5.04 b$ & $4.56 \mathrm{~b}$ \\
\hline $\mathrm{A}-\mathrm{N}$ & $1.97 a b$ & $1.04 \mathrm{~b}$ & $\mathrm{AMH}$ & $-6.55 b c$ & $6.46 \mathrm{a}$ \\
\hline A-ABA & $2.70 a b$ & $1.15 b$ & AM & $-9.22 c$ & $4.11 \mathrm{~b}$ \\
\hline$A$ & $1.83 \mathrm{bc}$ & $1.80 \mathrm{ab}$ & & & \\
\hline $\mathrm{AMH}$ & $-1.03 c$ & $2.31 \mathrm{a}$ & & & \\
\hline \multicolumn{6}{|c|}{$\begin{array}{l}{ }^{\mathrm{z}} \mathrm{C} \text { : control, } \mathrm{A} \text { : anillado de pedúnculo a } 0.5-1 \mathrm{~cm} \text { del fruto, } \mathrm{AMH} \text { : anillado de pedúnculo } \\
\text { a 8-10 cm del fruto, AM: anillado de pedúnculo a } 8-10 \mathrm{~cm} \text { del fruto eliminando las hojas } \\
\text { entre el fruto y el anillado, } \mathrm{N} \text { : aplicación de } \mathrm{NH}_{4} \mathrm{NO}_{3}\left(20 \mathrm{~g} \cdot \mathrm{L}^{-1}\right), \mathrm{A}-\mathrm{N} \text { : anillado de } \\
\text { pedúnculo a } 0.5-1 \mathrm{~cm} \text { del fruto y aplicación de } \mathrm{NH}_{4} \mathrm{NO}_{3}\left(20 \mathrm{~g} \cdot \mathrm{L}^{-1}\right), \mathrm{A}-\mathrm{ABA} \text { : anillado de } \\
\text { pedúnculo a } 0.5-1 \mathrm{~cm} \text { del fruto y aplicación de } \mathrm{ABA}\left(250 \mathrm{mg} \cdot \mathrm{L}^{-1}\right) \text {. } \\
\text { y Letras diferentes en una misma columna indican diferencias significativas }(p \leq 0.05) \text {. }\end{array}$} \\
\hline
\end{tabular}




\section{Corteza del pedúnculo}

El tratamiento de anillado provocó un incremento en la concentración de ABA en la zona apical del pedúnculo (próximo al fruto) en ambos experimentos. En la zona basal (desconectada del fruto por el anillado), la tendencia fue similar, aunque sin alcanzar significación estadística (Tabla 17).

Tabla 17. Concentración de ácido abscísico ( $\mu \mathrm{g} \mathrm{g}^{-1} P e s o$ Seco) en la corteza del pedúnculo de frutos de naranjo dulce cv. 'Washington navel' (2006, Uruguay) y 'Valencia Delta Seedless' (2006, España) a los 60 y 40 días del tratamiento (DPT), respectivamente. Cada valor es la media de 3 repeticiones de 10 pedúnculos cada una.

\begin{tabular}{|c|c|c|c|c|}
\hline \multirow[b]{2}{*}{ Tratamiento } & \multicolumn{4}{|c|}{ Corteza del pedúnculo } \\
\hline & \multicolumn{2}{|c|}{ 'Washington navel' } & \multicolumn{2}{|c|}{ 'Valencia Delta Seedless' } \\
\hline \multirow[t]{2}{*}{$C^{2}$} & \multicolumn{2}{|c|}{$0.40 b^{y}$} & \multicolumn{2}{|c|}{$0.89 \mathrm{~b}$} \\
\hline & Zona basal $^{\mathrm{x}}$ & Zona apical & Zona basal & Zona apical \\
\hline A & $0.82 a b$ & - & $1.07 \mathrm{~b}$ & - \\
\hline $\mathrm{AMH}$ & $0.58 \mathrm{~b}$ & $1.24 \mathrm{a}$ & $1.49 \mathrm{~b}$ & $2.36 \mathrm{a}$ \\
\hline AM & - & - & $1.49 \mathrm{~b}$ & $2.86 \mathrm{a}$ \\
\hline
\end{tabular}

${ }^{z} \mathrm{C}$ : control, $\mathrm{A}$ : anillado de pedúnculo a $0.5-1 \mathrm{~cm}$ del fruto, $\mathrm{AMH}$ : anillado de pedúnculo a $8-10 \mathrm{~cm}$ del fruto y $\mathrm{AM}$ : anillado de pedúnculo a $8-10 \mathrm{~cm}$ del fruto eliminando las hojas entre el fruto y el anillado.

${ }^{y}$ Letras diferentes en un mismo experimento (cultivar) indican diferencias significativas $(p \leq 0.05)$.

'Zona basal: desconectada del fruto por el anillado. Zona apical: próxima al fruto y desconectada de la planta por el anillado.

\section{Hojas}

En el naranjo 'Valencia Delta Seedless' la concentración de ABA en las hojas del brote próximas al fruto aumentó de $0.02 \mu \mathrm{g} \mathrm{g}^{-1} \mathrm{PS}$ al inicio del experimento hasta $0.98 \mu \mathrm{g} \mathrm{g}{ }^{-1} \mathrm{PS}$ al final. A los 40 días del anillado, la concentración de $\mathrm{ABA}$ en las hojas de los frutos control fue aproximadamente el doble $\left(0.98 \mu \mathrm{g} \mathrm{g}^{-1} \mathrm{PS}\right)$ que en las hojas de brotes anillados $(0.57$ y $0.45 \mu \mathrm{g} \mathrm{g}$ ${ }^{1} \mathrm{PS}$ en $\mathrm{A}$ y $\mathrm{AMH}$, respectivamente), independientemente de su posición en relación al corte. Estas diferencias, sin embargo, no alcanzaron la significación estadística entre tratamientos. 


\subsection{Giberelinas}

\section{Flavedo}

En el naranjo dulce cv. 'Washington navel' (2008, Uruguay), la concentración de $\mathrm{GA}_{1}$ y $\mathrm{GA}_{4}$ en el flavedo de los frutos control aumentó desde marzo (cuando el ICC era de -5.66) hasta abril (cuando era -3.52), disminuyendo en la última fecha de evaluación (mayo, cuando el ICC era 1.74) asociado al inicio del cambio de color. En los frutos anillados (AM), sin embargo, ambas GAs incrementaron su concentración entre la primera y la última fecha de evaluación (Figura 18).
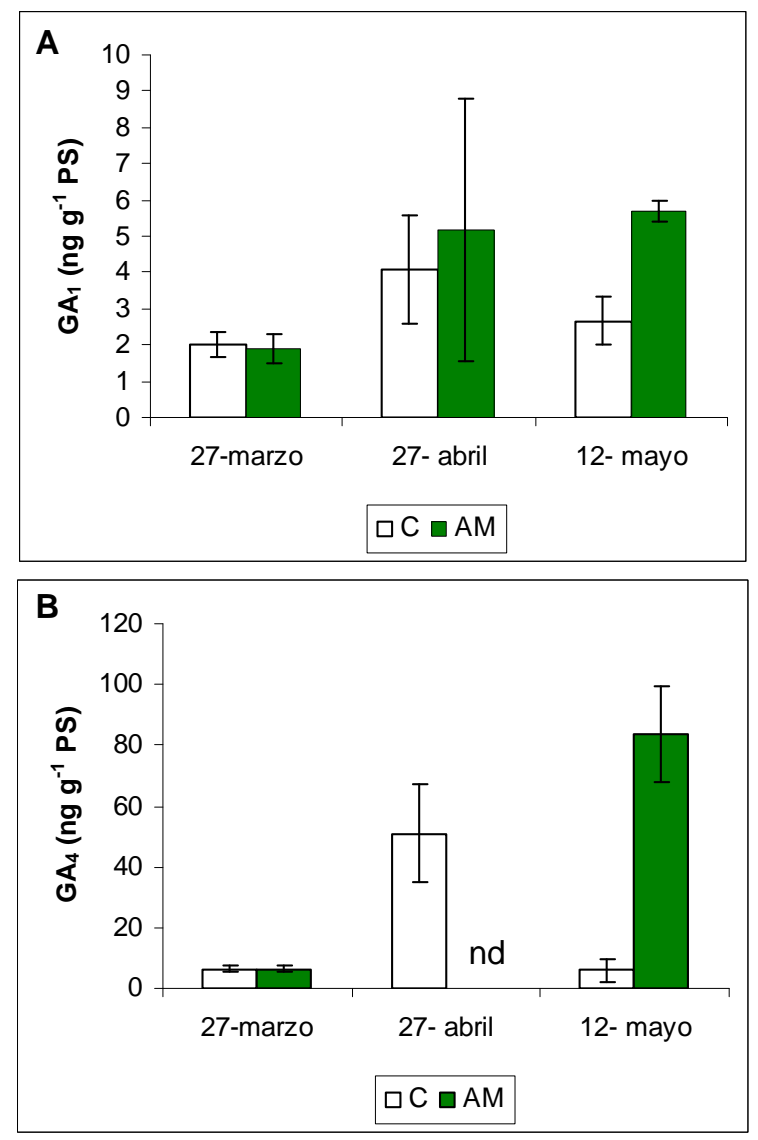

Figura 18. Concentración de $\mathrm{GA}_{1}(\mathrm{~A})$ y $\mathrm{GA}_{4}$ (B) en el flavedo de frutos de naranjo dulce cv. 'Washington navel', con el pedúnculo anillado a $8-10 \mathrm{~cm}$ del fruto, eliminando las 
hojas entre el fruto y el anillado (AM) y frutos control sin anillar (C), (2008, Uruguay). Cada valor es la media de 3 repeticiones de 5 frutos cada una. nd: no determinado.

En todas las fechas, y tanto para los controles como para los frutos con el pedúnculo anillado, la concentración de $\mathrm{GA}_{4}$ en el flavedo fue superior a la de $\mathrm{GA}_{1}$. Considerando la primera (fruto totalmente verde) y última fecha de análisis (frutos control cambiando de color), la relación $\mathrm{GA}_{1}: \mathrm{GA}_{4}$ en los frutos control permaneció constante, mientras que en los anillados disminuyó notablemente (Tabla 18).

Tabla 18. Índice de color (ICC) y relación $\mathrm{GA}_{1}: \mathrm{GA}_{4}$ en el flavedo de frutos y en la corteza de pedúnculos anillados a $8-10 \mathrm{~cm}$ del fruto, eliminando las hojas entre el fruto y el anillado (AM) y frutos sin anillar (control), de naranjo 'Washington navel' (2008, Uruguay). Cada valor es la media de 3 repeticiones de 5 frutos ó 10 pedúnculos cada una.

\begin{tabular}{|c|c|c|}
\hline Tratamiento / Fecha & 27-marzo & nayo \\
\hline & \multicolumn{2}{|c|}{ ICC } \\
\hline $\begin{array}{l}\text { Control } \\
\text { AM }\end{array}$ & $\begin{array}{l}-5.66 \\
-5.89\end{array}$ & $\begin{array}{r}1.74 a^{z} \\
-2.09 b\end{array}$ \\
\hline Flavedo de frutos & \multicolumn{2}{|c|}{$\mathrm{GA}_{1}: \mathrm{GA}_{4}$} \\
\hline Control & 0,31 & $0,45 a$ \\
\hline AM & 0,29 & $0,07 \mathrm{~b}$ \\
\hline Corteza de pedúnculos & \multicolumn{2}{|c|}{$\mathbf{G A}_{1}: \mathbf{G A}_{4}$} \\
\hline Control & 1.55 & $0.46 \mathrm{c}$ \\
\hline AM-zona apicaly & 1,43 & $4.76 \mathrm{a}$ \\
\hline AM-zona basal & 1,53 & $2.25 \mathrm{~b}$ \\
\hline
\end{tabular}

${ }^{z}$ Letras diferentes en una misma columna (fecha) y para una misma variable (ICC, $\mathrm{GA}_{1}: \mathrm{GA}_{4}$ en el flavedo de los frutos ó $\mathrm{GA}_{1}: \mathrm{GA}_{4}$ en la corteza de los pedúnculos) indican diferencias significativas $(p \leq 0.05)$

'Zona apical: próxima al fruto y desconectada de la planta por el anillado. Zona basal: desconectada del fruto por el anillado.

\section{Corteza de pedúnculo}

En la corteza del pedúnculo de los frutos control, la concentración de ambas giberelinas aumentó durante el cambio de color (período marzo-mayo), particularmente la de la $\mathrm{GA}_{4}$ (Figura 19). En los anillados, la concentración de 
ambas GAs también aumentó significativamente entre marzo y mayo, sobre todo la de la $\mathrm{GA}_{1}$ (Figura 19). A los 45 días del anillado (12 de mayo) la concentración de $\mathrm{GA}_{1}$ en la corteza de la zona apical del pedúnculo, próxima al fruto, fue significativamente mayor que en el control sin anillar, mientras que la de $\mathrm{GA}_{4}$ fue significativamente menor. Para la misma fecha, en la zona basal, desconectada del fruto por el anillado, la concentración de $\mathrm{GA}_{1}$ también fue significativamente mayor que la del control, mientras que la de la $\mathrm{GA}_{4}$, si bien fue significativamente superior a la de la zona apical, descendió ligeramente respecto del control, sin alcanzar diferencias significativas (Figura 19).
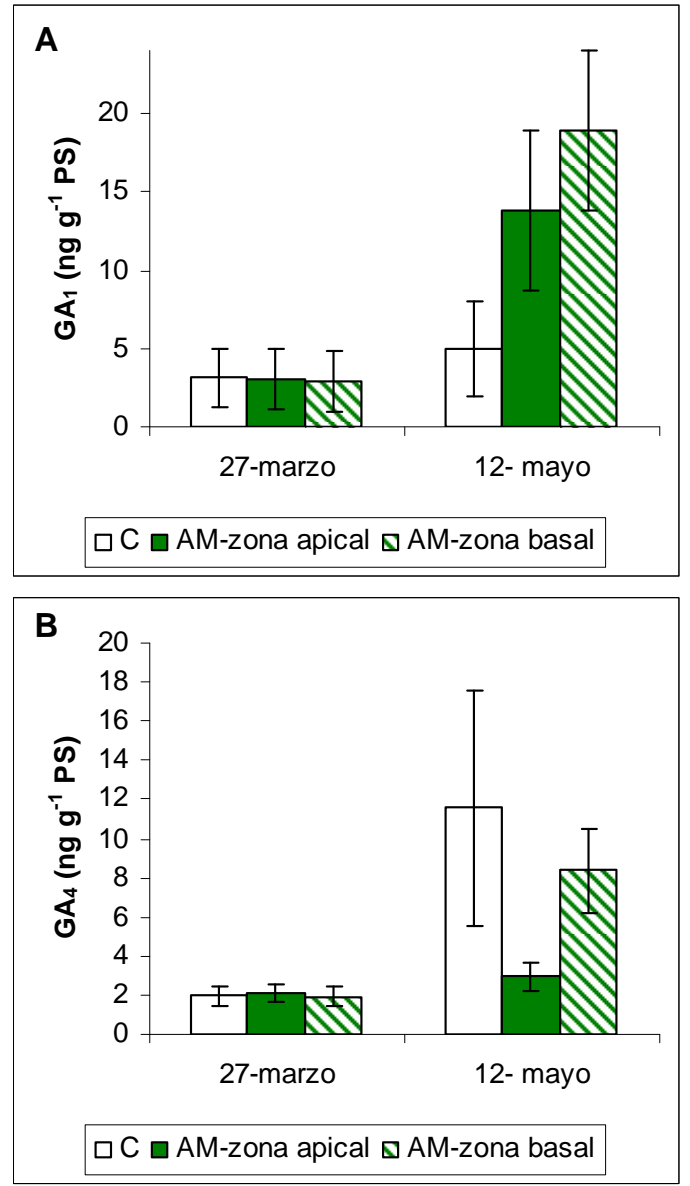

Figura 19. Concentración de $\mathrm{GA}_{1}(\mathrm{~A})$ y $\mathrm{GA}_{4}$ (B) en la corteza de pedúnculos anillados a 8-10 cm del fruto, eliminando las hojas entre el fruto y el anillado (AM) y frutos control sin anillar (C) de naranjo dulce cv. 'Washington navel' (2008, Uruguay). Análisis 
correspondientes a la zona apical del pedúnculo (próxima al fruto y desconectada del resto de la rama por el anillado), y zona basal (desconectada del fruto por el anillado). Cada valor es la media de 3 repeticiones de 10 pedúnculos cada una.

La relación $\mathrm{GA}_{1}: \mathrm{GA}_{4}$ en la corteza evolucionó de modo diferente según el tratamiento y la zona del pedúnculo analizada; en el control disminuyó de 1.55 a 0.46 , mientras que en los anillados aumentó de 1.43 a 4.76 en la zona apical y de 1.53 a 2.25 en la basal. (Tabla 18).

\subsubsection{Carbohidratos y nitrógeno}

\subsection{Carbohidratos}

\section{Flavedo}

En términos generales, la concentración de fructosa, glucosa y sacarosa en el flavedo de los frutos anillados fue menor que en los sin anillar a los 40 días ('Valencia Delta Seedless') y 60 días ('Washington navel') del tratamiento (DPT). En el cv. 'Valencia Delta Seedless' todos los tratamientos mantuvieron este comportamiento, mientras que en el cv. 'Washington navel' solamente el AMH alcanzó la significación estadística en relación con el control (Tabla 19). Las aplicaciones de N o ABA tampoco afectaron la concentración de azúcares del flavedo. 
Tabla 19. Concentración de azúcares reductores (fructosa, glucosa) y sacarosa ( $\mathrm{mg} \mathrm{g}^{-1} \mathrm{PS}$ ) en el flavedo de frutos de naranjo 'Washington navel' (2006, Uruguay) y 'Valencia Delta Seedless' (2006, España) 60 y 40 días después del tratamiento (DPT), respectivamente. Cada valor es la media de 3 repeticiones de 5 frutos cada una.

\begin{tabular}{|c|c|c|c|c|c|c|c|}
\hline \multirow[b]{2}{*}{ Tratamiento } & \multicolumn{3}{|c|}{$\begin{array}{l}\text { 'Washington navel' } \\
60 \text { DPT }\end{array}$} & \multicolumn{3}{|c|}{$\begin{array}{c}\text { 'Valencia Delta Seedless' } \\
40 \mathrm{DPT}\end{array}$} & \multirow[b]{2}{*}{ Sacarosa } \\
\hline & Fructosa & Glucosa & Sacarosa & Tratamiento & Fructosa & Glucosa & \\
\hline$C^{2}$ & $98.3 a^{y}$ & $118.6 \mathrm{a}$ & $93.3 \mathrm{a}$ & C & $76.7 \mathrm{a}$ & $97.3 \mathrm{a}$ & $82.19 \mathrm{a}$ \\
\hline $\mathrm{N}$ & $92.6 \mathrm{a}$ & $113.3 \mathrm{ab}$ & $92.0 \mathrm{a}$ & A & $46.5 \mathrm{~b}$ & $57.6 \mathrm{~b}$ & $25.32 b$ \\
\hline $\mathrm{A}-\mathrm{N}$ & $78.4 \mathrm{ab}$ & $95.1 \mathrm{ab}$ & $58.9 \mathrm{ab}$ & $\mathrm{AMH}$ & $47.1 \mathrm{~b}$ & $58.6 \mathrm{~b}$ & $24.04 b$ \\
\hline A-ABA & $90.5 a b$ & $109.9 a b$ & $91.4 \mathrm{a}$ & AM & $41.7 \mathrm{~b}$ & $51.6 \mathrm{~b}$ & $24.61 \mathrm{~b}$ \\
\hline A & $74.4 \mathrm{ab}$ & $94.5 a b$ & $76.8 \mathrm{a}$ & & & & \\
\hline $\mathrm{AMH}$ & $48.8 \mathrm{~b}$ & $63.6 \mathrm{~b}$ & $27.3 b$ & & & & \\
\hline
\end{tabular}

${ }^{z} \mathrm{C}$ : control, A: anillado de pedúnculo a 0.5-1 cm del fruto, AMH: anillado de pedúnculo a 8-10 cm del fruto, AM: anillado de pedúnculo a 8-10 $\mathrm{cm}$ del fruto eliminando las hojas entre el fruto y el anillado, $\mathrm{N}$ : aplicación de $\mathrm{NH}_{4} \mathrm{NO}_{3}\left(20 \mathrm{~g} \cdot \mathrm{L}^{-1}\right), \mathrm{A}-\mathrm{N}$ : anillado de pedúnculo a $0.5-1 \mathrm{~cm}$ del fruto y aplicación de $\mathrm{NH}_{4} \mathrm{NO}_{3}\left(20 \mathrm{~g} \cdot \mathrm{L}^{-1}\right)$, A-ABA: anillado de pedúnculo a $0.5-1 \mathrm{~cm}$ del fruto y aplicación de $\mathrm{ABA}\left(250 \mathrm{mg} . \mathrm{L}^{-1}\right)$.

y Letras diferentes en una misma columna y experimento (cultivar) indican diferencias significativas $(p \leq 0.05)$ 


\section{Corteza de pedúnculo}

En los tratamientos de anillado en la zona media del pedúnculo (AM y $\mathrm{AMH})$ se encontró menor concentración de azúcares solubles totales en la corteza de la zona apical del pedúnculo en relación a la basal y al control (Tabla 20). En el cv. 'Washington navel' dicha reducción se debió solamente a un menor contenido de sacarosa, dado que no se modificó la concentración de los azúcares reductores (datos no presentados). Sin embargo en 'Valencia Delta Seedless', con AM y AMH se redujo significativamente la concentración de fructosa y glucosa en la zona apical, mientras que la sacarosa solamente disminuyó en el tratamiento que se retiraron las hojas (AM).

Tabla 20. Concentración de fructosa, glucosa, sacarosa y azúcares solubles totales (Total) en la corteza de pedúnculos anillados y sin anillar de frutos de naranjo dulce cv. 'Valencia Delta Seedless' (2006, España) a los 40 días del tratamiento. Cada valor es la media de 3 repeticiones de 5 frutos cada una.

\begin{tabular}{cccccc}
\hline Trat & $\begin{array}{c}\text { Zona del } \\
\text { pedúnculo }\end{array}$ & $\begin{array}{c}\text { Fructosa } \\
\left(\mathrm{mg} \mathrm{g}^{-1} \mathrm{PS}\right)\end{array}$ & $\begin{array}{c}\text { Glucosa } \\
\left(\mathrm{mg} \mathrm{g}^{-1} \mathrm{PS}\right)\end{array}$ & $\begin{array}{c}\text { Sacarosa } \\
\left(\mathrm{mg} \mathrm{g}^{-1} \mathrm{PS}\right)\end{array}$ & $\begin{array}{c}\text { Total } \\
\left(\mathrm{mg} \mathrm{g}^{-1} \mathrm{PS}\right)\end{array}$ \\
\hline $\mathrm{C}^{\mathrm{z}}$ & - & $12.8 \mathrm{a}^{\mathrm{x}}$ & $14.3 \mathrm{a}$ & $26.0 \mathrm{a}$ & $53.1 \mathrm{a}$ \\
$\mathrm{A}$ & Basal & $11.5 \mathrm{a}$ & $13.4 \mathrm{a}$ & $31.3 \mathrm{a}$ & $56.2 \mathrm{a}$ \\
\multirow{2}{*}{$\mathrm{AMH}$} & Basal & $13.1 \mathrm{a}$ & $14.7 \mathrm{a}$ & $29.5 \mathrm{a}$ & $57.3 \mathrm{a}$ \\
& Apical & $4.9 \mathrm{~b}$ & $4.8 \mathrm{~b}$ & $20.4 \mathrm{ab}$ & $30.1 \mathrm{~b}$ \\
\multirow{2}{*}{$\mathrm{AM}$} & Basal & $13.1 \mathrm{a}$ & $15.3 \mathrm{a}$ & $30.3 \mathrm{a}$ & $58.7 \mathrm{a}$ \\
& Apical & $4.1 \mathrm{~b}$ & $4.2 \mathrm{~b}$ & $9.1 \mathrm{~b}$ & $17.4 \mathrm{~b}$ \\
\hline
\end{tabular}

${ }^{\bar{z}} \mathrm{C}$ : control, $\mathrm{A}$ : anillado de pedúnculo a $0.5-1 \mathrm{~cm}$ del fruto, $\mathrm{AMH}$ : anillado de pedúnculo a $8-10 \mathrm{~cm}$ del fruto y $\mathrm{AM}$ : anillado de pedúnculo a $8-10 \mathrm{~cm}$ del fruto eliminando las hojas entre el fruto y el anillado.

'Zona basal: desconectada del fruto por el anillado. Zona apical: próxima al fruto y desconectada de la planta por el anillado.

${ }^{x}$ Letras diferentes en una misma columna indican diferencias significativas ( $\left.p \leq 0.05\right)$.

\section{Hojas}

El contenido de azúcares solubles en las hojas no fue afectado por los tratamientos de anillado de pedúnculo en el naranjo dulce cv. 'Valencia Delta Seedless'. A los 40 días, la concentración promedio de fructosa, glucosa y 
sacarosa fue de $12.7 \quad \mathrm{mg}^{-1} \mathrm{PS}, \quad 14.4 \quad \mathrm{mg}^{-1} \mathrm{PS}$ y $8.7 \quad \mathrm{mg}^{-1} \mathrm{PS}$ respectivamente, con una relación promedio de 1:3, similar en todos los tratamientos.

\subsection{Nitrógeno}

\section{Flavedo}

En términos generales la concentración de nitrógeno en el flavedo de los frutos fue de $0.60-0.75 \%$ del PS en el naranjo dulce cv. 'Washington navel', y de $0.80-0.98 \%$ en el cv. 'Valencia Delta Seedless'. Considerando los frutos con pedúnculo anillado y sin anillar, se determinó una mayor concentración de nitrógeno proteico y total en los que tenían anillado de ambos cultivares. En el naranjo dulce cv. 'Washington navel' se obtuvo, asimismo, mayor concentración de la fracción amoniacal (23 $\mu \mathrm{g} \mathrm{g}^{-1} \mathrm{PS}$ y $15 \mu \mathrm{g} \mathrm{g} \mathrm{g}^{-1} \mathrm{PS}$ en frutos con pedúnculo anillado y sin anillar, respectivamente). Al analizar los tratamientos individualmente, en el cv. 'Washington navel' se mantuvieron las tendencias (datos no presentados), y en 'Valencia Delta Seedless' se evidenciaron diferencias significativas en la concentración de nitrógeno proteico y total en el flavedo de los frutos con pedúnculo anillado respecto de los frutos control (Tabla 21).

Tabla 21. Concentración de nitrógeno proteico $(\mathrm{N}-\mathrm{P})$, amoniacal $\left(\mathrm{N}-\mathrm{NH}_{4}{ }^{+}\right)$y total $(\mathrm{NT})$ en el flavedo de frutos de naranjo dulce cv. 'Valencia Delta Seedless' (2006, España) con pedúnculo anillado y sin anillar, a los 40 días del tratamiento. Cada valor es la media de tres repeticiones de 5 frutos cada una.

\begin{tabular}{|c|c|c|c|}
\hline Tratamiento & $\begin{array}{c}\mathrm{N}-\mathrm{P} \\
\left(\mathrm{mg} 100 \mathrm{mg}^{-1} \mathrm{PS}\right)\end{array}$ & $\begin{array}{c}{\mathrm{N}-\mathrm{NH}_{4}^{+}}^{+} \\
\left(\mu \mathrm{g} \mathrm{g}^{-1} \mathrm{PS}\right)\end{array}$ & $\begin{array}{c}\mathrm{NT} \\
\left(\mathrm{mg} 100 \mathrm{mg}^{-1} \mathrm{PS}\right)\end{array}$ \\
\hline $\mathrm{AMH}^{\mathrm{z}}$ & $0.98 \mathrm{a}^{\mathrm{y}}$ & 13.03 & $0.982 \mathrm{a}$ \\
\hline AM & $0.95 \mathrm{a}$ & 15.65 & $0.953 a$ \\
\hline A & $0.92 \mathrm{a}$ & 13.51 & $0.916 a b$ \\
\hline C & $0.81 \mathrm{~b}$ & 17.82 & $0.814 \mathrm{~b}$ \\
\hline
\end{tabular}

${ }^{z} \mathrm{C}$ : control, $\mathrm{A}$ : anillado de pedúnculo a $0.5-1 \mathrm{~cm}$ del fruto, $\mathrm{AMH}$ : anillado de pedúnculo a $8-10 \mathrm{~cm}$ del fruto y $\mathrm{AM}$ : anillado de pedúnculo a $8-10 \mathrm{~cm}$ del fruto eliminando las hojas entre el fruto y el anillado.

${ }^{y}$ Letras diferentes en una misma columna indican diferencias significativas ( $\left.p \leq 0.05\right)$. 


\section{Hojas}

La concentración de nitrógeno en las hojas del pedúnculo no fue afectada por los tratamientos de anillado en el naranjo dulce cv. 'Valencia Delta Seedless' a los 40 días de efectuado éste, presentando en promedio $1.58 \%$ del PS de N-P y $24 \mu \mathrm{g} \mathrm{g}{ }^{-1}$ PS de N-NH${ }_{4}^{+}$.

\subsection{Factores exógenos relacionados con la coloración del flavedo}

Para la presentación de los resultados se consideró 'inicio del cambio de color' cuando al menos el $5 \%$ de los frutos evaluados en el árbol comenzó a virar, determinado por el cambio de negativo a positivo de la coordenada 'a' de CIE lab, y consecuentemente de la relación a/b y del ICC (ICC $\geq 0)$. Se definió 'cambio de color' cuando por lo menos el $50 \%$ de los frutos lo había alcanzado. Los experimentos se desarrollaron durante cuatro años consecutivos en España (2005 a 2008) y dos años en Uruguay (2007 y 2008), utilizando la mandarina Clementina. En España se usó el cv. 'Clemenpons', y en Uruguay el cv. 'Clemenules'.

En los dos primeros meses del experimento, el color de los frutos apenas se alteró, con valores de ICC entre - 6 y -4 (CIELab) en Uruguay (Figura 20), y entre -20 y -24 (HunterLab) en España (Figura 21) y sin diferencias entre los tratamientos de cobertura del suelo y el control en ambos países. El 'inicio del cambio de color' se dio la primera semana de mayo en Uruguay, registrándose entre un $7 \%$ y un $11 \%$ de frutos con ICC $\geq 0$ en las plantas control. El 'cambio de color' se alcanzó en los 9-11 días posteriores. En España, el 'cambio de color' se dio a mediados de noviembre para los frutos de los árboles control, mientras que los que poseían la cubierta del suelo presentaban en dicha fecha un ICC significativamente mayor (4.6 y 1.7 con tratamiento de suelo y control, respectivamente), y habían anticipado en 15 días el 'cambio de color' de sus frutos (Figura 21). Resultados similares se obtuvieron en los años

2005, 2006 y 2008, aunque con ligeras diferencias en las fechas (datos no presentados). En Uruguay, en el año 2008, con mediciones más frecuentes dentro de ese período, se observó un aumento del porcentaje de frutos con 
ICC $\geq 0$ del $7 \%$ al $30 \%$ en los primeros siete días, y del $30 \%$ al $60 \%$ en los siguientes cuatro días (Tabla 22).

En Uruguay, el tratamiento de cal presentó mayor porcentaje de frutos con ICC $\geq 0$ que el control y la malla al 'inicio de cambio de color' en 2007 y en el 'cambio de color' en 2008 (Tabla 22).

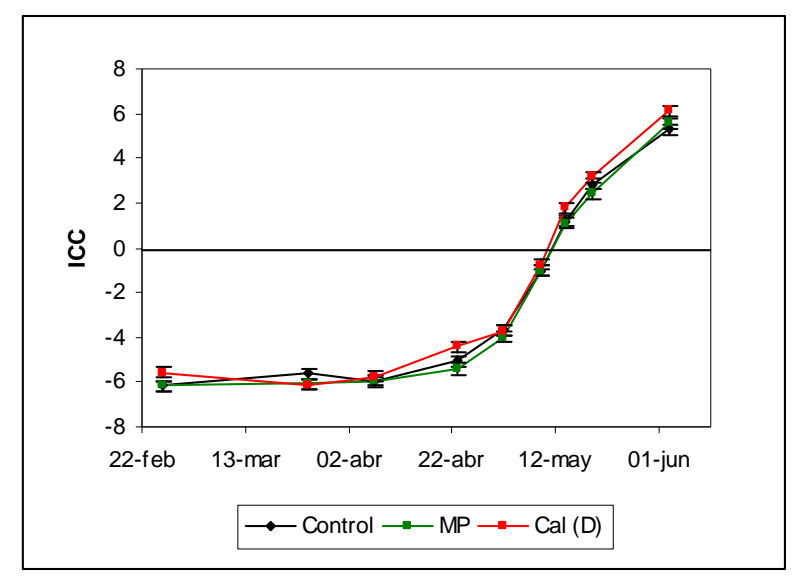

Figura 20. Índice de color de frutos (ICC) de plantas de mandarino Clementino cv. 'Clemenules', control y con cobertura de suelo: malla plateada (MP) y cal (D: Dolomita), durante los meses previos a la recolección. La línea horizontal indica el cambio de color $(I C C=0)$. Cada valor es la media de 3 repeticiones de 30 frutos cada una. Valores correspondientes al año 2008, Uruguay. 


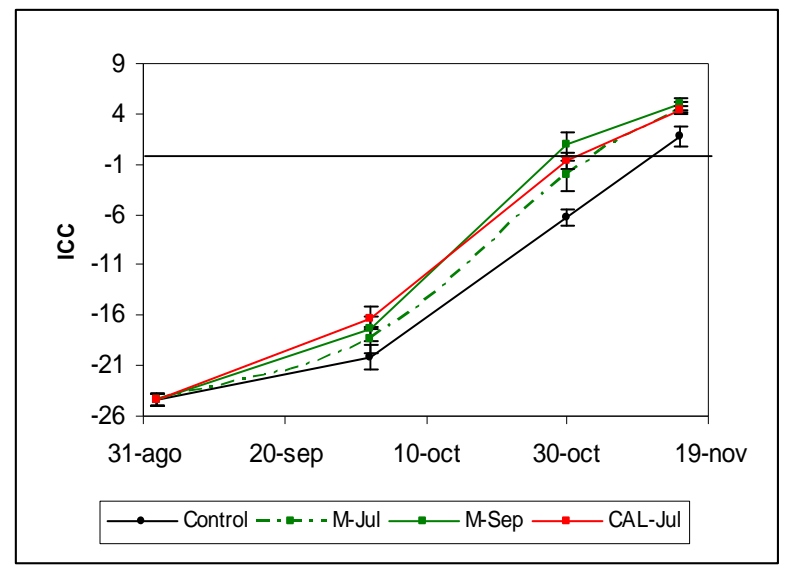

Figura 21. Índice de color de los frutos (ICC) de plantas de mandarino Clementino cv. 'Clemenpons' control y con cobertura de suelo, malla colocada en julio (M-Jul) ó septiembre (M-Sep) y cal aplicada en julio (CAL-Jul), durante los meses previos a la recolección. La línea horizontal indica el cambio de color $(\mathrm{ICC}=0)$. Cada valor es la media de 10 repeticiones de 20 frutos cada una. Valores correspondientes al año 2007, España.

Tabla 22. Porcentaje de frutos con $I C C \geq 0$ (CIELab) de plantas de mandarino Clementino, cv. 'Clemenules' control (C) y con cobertura de suelo, malla plateada (MP) ó cal (CAL: $\mathrm{CaOH}_{2}$; D: Dolomita), durante los meses previos a la recolección. Valores correspondientes a Uruguay.

\begin{tabular}{cccccccc}
\hline 2007 & \multicolumn{3}{c}{ Frutos con ICC $\geq 0$ (\%) } & \multicolumn{2}{c}{ 2008 } & \multicolumn{2}{c}{ Frutos con ICC $\geq 0$ (\%) } \\
\hline 6-Marzo & C & MP & CAL & & C & MP & D \\
28-Marzo & 0 & 0 & 0 & 26-Feb & 0 & 0 & 0 \\
12-Abril & 0 & 0 & 0 & 25-Marzo & 0 & 0 & 0 \\
26-Abril & 0 & 0 & 0 & 23-Abril & 0 & 0 & 0 \\
- & - & - & - & 2-Mayo & 7 & 4 & 4 \\
8-Mayo & $11 \mathrm{~b}^{z}$ & $5 \mathrm{~b}$ & $19 \mathrm{a}$ & 9-Mayo & 30 & 31 & 31 \\
- & - & - & - & 13-Mayo & $60 \mathrm{~b}$ & $60 \mathrm{~b}$ & $69 \mathrm{a}$ \\
17-Mayo & $54 \mathrm{ab}$ & $45 \mathrm{~b}$ & $60 \mathrm{a}$ & 19-Mayo & 83 & 76 & 86 \\
31-Mayo & 99 & 97 & 96 & 3-Junio & 99 & 99 & 100
\end{tabular}

"Letras diferentes en una misma fila y experimento (2007 ó 2008) indican diferencias significativas $(p \leq 0.05)$. 
En España, la cobertura con cal también presentó los mejores resultados con un valor medio de 11.2 de coordenada 'a' (HunterLab) frente a 4.4 en los controles (Tabla 23). Los valores para la cobertura de malla, instalada en julio o en septiembre, fueron significativamente más elevados $(7.1$ y 9.1 , respectivamente) que los de los frutos control, y no difirieron significativamente de los de la cubierta de cal. Resultados similares se obtuvieron para las variables 'b' y 'L' y para la relación 'a/b' (Tabla 23).

El peso medio del fruto y los parámetros de maduración interna (SST y acidez) no fueron modificados por los tratamientos, tanto en España (Tabla 23) como en Uruguay (datos no presentados).

Tabla 23. Influencia de la cubierta de suelo con cal o mallas instaladas en julio (M-Jul) o en septiembre (M-Sep) sobre el peso medio del fruto, el color y la maduración interna (sólidos solubles totales -SST- y acidez titulable) de la mandarina Clementina cv. 'Clemenpons' en el momento de la recolección. Los valores son la media de 3 árboles y 12 frutos por árbol, correspondientes al año 2006, España.

\begin{tabular}{ccccc}
\hline & Control & Cal-Sep & M-Jul & M-Sep \\
\hline Peso fruto (g) & $83.6 \mathrm{a}^{\mathrm{z}}$ & $84.0 \mathrm{a}$ & $88.5 \mathrm{a}$ & $85.1 \mathrm{a}$ \\
& & & & \\
\hline Color (HunterLab) & Control & Cal-Sep & M-Jul & M-Sep \\
\hline $\mathrm{L}$ & $59.1 \mathrm{~b}$ & $61.5 \mathrm{a}$ & $60.7 \mathrm{ab}$ & $61.2 \mathrm{a}$ \\
$\mathrm{a}$ & $4.4 \mathrm{~b}$ & $11.2 \mathrm{a}$ & $7.1 \mathrm{a}$ & $9.1 \mathrm{a}$ \\
$\mathrm{b}$ & $33.0 \mathrm{~b}$ & $35.6 \mathrm{a}$ & $35.3 \mathrm{a}$ & $35.3 \mathrm{a}$ \\
$\mathrm{a} / \mathrm{b}$ & $0.12 \mathrm{c}$ & $0.31 \mathrm{a}$ & $0.25 \mathrm{ab}$ & $0.21 \mathrm{bc}$ \\
ICC & $2.3 \mathrm{~b}$ & $5.1 \mathrm{a}$ & $3.3 \mathrm{ab}$ & $4.2 \mathrm{a}$ \\
\hline Maduración interna & & & & \\
SST (oBrix) & 13.8 & 14.0 & 13.4 & 12.9 \\
Acidez titulable (\%) & 1.0 & 1.1 & 1.0 & 1.0 \\
\hline
\end{tabular}

${ }^{z}$ Letras diferentes en una misma fila indican diferencias significativas $(p \leq 0.05)$

El cambio de color de los frutos se relacionó con la disminución de la temperatura del aire y del suelo. Durante el período de estudio en Uruguay, la temperatura media del aire estuvo por debajo de los $22^{\circ} \mathrm{C}$. Sin embargo, la media de las máximas fue superior a $25^{\circ} \mathrm{C}$ hasta la primera (2007) o segunda (2008) quincena de abril. 
Durante el mes de abril, mes previo al 'inicio de cambio de color' del fruto, el porcentaje de horas con temperaturas de aire superiores a $25^{\circ} \mathrm{C}$ se sitúo entre el $3 \%$ y el $11 \%$ en 2007 y el $18 \%$ en 2008 , mientras que el porcentaje por debajo de $22^{\circ} \mathrm{C}$ estuvo entre el $72 \%$ y el $93 \%$ en ambos años (Tabla 24). A su vez, la temperatura permaneció por debajo de $18^{\circ} \mathrm{C}$ entre el $43 \%$ y el $70 \%$ de las horas y se registraron temperaturas por debajo de $13^{\circ} \mathrm{C}$ (cero biológico de los cítricos) en un rango del 13\% al 31\% de las horas totales (Tabla 24). A partir del 'inicio de cambio de color' (primera semana de mayo) y hasta el 'cambio de color' (segunda semana de mayo), el porcentaje de horas con temperaturas menores a $22^{\circ} \mathrm{C}$ superó el $89 \%$, determinado en más del $70 \%$ por temperaturas inferiores a $18^{\circ} \mathrm{C}$ y en más del $60 \%$ por temperaturas menores a $13^{\circ} \mathrm{C}$ (Tabla 24). Finalmente, en ese período se registraron temperaturas inferiores a $7^{\circ} \mathrm{C}$ durante el $23 \%-27 \%$ de las horas, y se extendieron por encima del $50 \%$ a partir de la segunda quincena de mayo (2007), cuando el resto de los frutos había cambiado de color (Tabla 22).

Con respecto a la amplitud térmica diaria, en ambos años se registró una diferencia de, al menos, $10^{\circ} \mathrm{C}$ durante por lo menos el $60 \%$ de los días de todo el período evaluado (Tabla 24). En marzo, dicha amplitud, se logró con rangos de temperatura diurna/nocturna de $28^{\circ} \mathrm{C}-40^{\circ} \mathrm{C} / 10^{\circ} \mathrm{C}-19^{\circ} \mathrm{C}$, mientras que la misma magnitud registrada los quince días previos al 'cambio de color' (primera quincena de mayo), se logró con rangos de temperatura diurna/nocturna de $17^{\circ} \mathrm{C}-26^{\circ} \mathrm{C} / 2^{\circ} \mathrm{C}-11^{\circ} \mathrm{C}$ (Tabla 24$)$.

En relación con los tratamientos, la malla provocó un leve incremento de la temperatura en la copa de los árboles respecto al control, que nunca superó el $2 \%$ de las horas registradas (datos no presentados). 
Tabla 24. Porcentaje de horas con temperatura del aire superior a $2^{\circ} \mathrm{C}$ e inferior a $22^{\circ} \mathrm{C}, 18^{\circ} \mathrm{C}, 13^{\circ} \mathrm{C}$ y $7^{\circ} \mathrm{C}$; porcentaje de días con amplitud térmica (AT) $\geq 10^{\circ} \mathrm{C}$, y temperaturas máximas y mínimas diarias $\left({ }^{\circ} \mathrm{C}\right)$ con $\mathrm{AT} \geq 10^{\circ} \mathrm{C}$, durante los años 2007 y 2008 , Kiyú (Uruguay). El 'inicio de cambio de color' (al menos $5 \%$ de los frutos con ICC $\geq 0$ ) tuvo lugar el 8 y el 2 de mayo en 2007 y 2008 , respectivamente, y el 'cambio de color' (al menos $50 \%$ de los frutos con ICC $\geq 0$ ) se produjo el 17 y 13 de mayo de 2007 y 2008 , respectivamente.

\begin{tabular}{|c|c|c|c|c|c|c|c|c|}
\hline \multirow{2}{*}{$\begin{array}{l}\text { Año } 2007 \\
\text { Período }\end{array}$} & \multicolumn{5}{|c|}{ Porcentaje de horas con temperatura del aire } & \multirow[t]{2}{*}{$\begin{array}{l}\text { Porcentaje de días con } \\
\qquad \mathrm{AT} \geq 10^{\circ} \mathrm{C}\end{array}$} & \multicolumn{2}{|c|}{$\begin{array}{c}\text { Temperturas }\left({ }^{\circ} \mathrm{C}\right) \text { con } \\
\text { AT } \geq 10^{\circ} \mathrm{C}\end{array}$} \\
\hline & $\geq 25^{\circ} \mathrm{C}$ & $\leq 22^{\circ} \mathrm{C}$ & $\leq 18^{\circ} \mathrm{C}$ & $\leq 13^{\circ} \mathrm{C}$ & $\leq 7^{\circ} \mathrm{C}$ & & máxima & mínima \\
\hline 1-15 Marzo & 25 & 62 & 30 & 1 & 0 & 80 & \multirow{2}{*}{$28-32$} & \multirow{2}{*}{$15-19$} \\
\hline 16-30 Marzo & 17 & 73 & 26 & 5 & 0 & 60 & & \\
\hline 1-15 Abril & 11 & 74 & 43 & 13 & 1 & 67 & \multirow{2}{*}{$21-32$} & \multirow{2}{*}{$8-11$} \\
\hline 16-30 Abril & 3 & 93 & 70 & 22 & 2 & 60 & & \\
\hline 1-15 Mayo & 1 & 96 & 88 & 69 & 23 & 87 & $17-22$ & $5-9$ \\
\hline 16-30 Mayo & 0 & 100 & 97 & 85 & 44 & 60 & $16-22$ & $4-9$ \\
\hline \multirow{2}{*}{$\begin{array}{l}\text { Año } 2008 \\
\text { Período }\end{array}$} & \multicolumn{5}{|c|}{ Porcentaje de horas con temperatura del aire } & $\begin{array}{c}\text { Porcentaje de días con } \\
\text { AT } \geq 10^{\circ} \mathrm{C}\end{array}$ & \multicolumn{2}{|c|}{$\begin{array}{c}\text { Temperturas }\left({ }^{\circ} \mathrm{C}\right) \text { con } \\
\text { AT } \geq 10^{\circ} \mathrm{C}\end{array}$} \\
\hline & $\geq 25^{\circ} \mathrm{C}$ & $\leq 22^{\circ} \mathrm{C}$ & $\leq 18^{\circ} \mathrm{C}$ & $\leq 13^{\circ} \mathrm{C}$ & $\leq 7^{\circ} \mathrm{C}$ & & máxima & mínima \\
\hline 1-15 Marzo & 21 & 62 & 17 & 7 & 0 & 61 & \multirow{2}{*}{$29-40$} & \multirow{2}{*}{$10-18$} \\
\hline 16-30 Marzo & 30 & 58 & 36 & 6 & 0 & 93 & & \\
\hline 1-15 Abril & 18 & 74 & 56 & 21 & 6 & 87 & $26-32$ & $8-14$ \\
\hline 16-30 Abril & 18 & 72 & 64 & 31 & 4 & 93 & $22-35$ & $3-12$ \\
\hline 1-15 Mayo & 3 & 89 & 70 & 60 & 27 & 100 & $21-26$ & $2-11$ \\
\hline
\end{tabular}


Los tratamientos de cobertura del suelo disminuyeron la temperatura del mismo, aumentado el porcentaje de horas por debajo de $21^{\circ} \mathrm{C}$, con relación al control, durante el mes de marzo. En abril, en todos los casos la temperatura del suelo estuvo la mayor parte del tiempo por debajo de $21^{\circ} \mathrm{C}$ (Tabla 25). El primer año (2007), del 3 al 30 de este mes, el porcentaje de horas por debajo de $18^{\circ} \mathrm{C}$ se incrementó del $17 \%$ al $100 \%$ en el tratamiento de cal, mientras que bajo malla y en el control se situó entre 0 y $90 \%$, y 0 y $83 \%$, respectivamente, sin que se registraran frutos con ICC $\geq 0$ (Tabla 25). Al 'inicio del cambio de color' (primera semana de mayo) el porcentaje de horas por debajo de $18^{\circ} \mathrm{C}$ superó el $93 \%$ en todos los tratamientos, con diferencias entre ellos en el número de frutos con ICC $\geq 0$ (Tabla 25). En el segundo año (2008) la diferencia entre tratamientos fue menor, y en las tres semanas previas al 'inicio de cambio de color' (10 al 30 de abril), el porcentaje de horas con temperaturas menores a $18^{\circ} \mathrm{C}$ superó el $58 \%$ en todos los tratamientos (Tabla 25). Con el umbral situado en $15^{\circ} \mathrm{C}$ se encontraron las principales diferencias entre tratamientos. Así, el primer año (2007), las dos semanas previas al 'inicio de cambio de color' (24 de abril al 7 de mayo), el porcentaje de horas por debajo de esta temperatura osciló entre el $23 \%$ y el $57 \%$ en el tratamiento de cal, mientras que en la malla y el control osciló entre el $5 \%$ y el $20 \%$ y el $5 \%$ y el $19 \%$, respectivamente (Tabla 25 ). El segundo año (2008), se verificó un bajo porcentaje de horas con temperaturas inferiores a $15^{\circ} \mathrm{C}$ en las tres semanas previas al 'inicio de cambio de color' (10 al 30 de abril), y las diferencias entre tratamientos fueron menores (15\% a $32 \%$ con la cubierta de cal; $7 \%$ a $24 \%$ con la malla y $2 \%$ a $19 \%$ en el control) (Tabla 25). Desde el 'inicio de cambio' de color (4\%-7\% de frutos con ICC $\geq 0$ ), hasta que un 30\%-31\% de los frutos alcanzó valores de $I C C \geq 0$ (1-7 de mayo), en los tres tratamientos se registraron temperaturas por debajo de $15^{\circ} \mathrm{C}$ durante más del $95 \%$ de las horas. Finalmente, no se registraron temperaturas inferiores a $13^{\circ} \mathrm{C}$ en ninguno de los dos años hasta el 'cambio de color' (Tabla 25). Considerando toda la información, el adelanto en el cambio de color alcanzado con el tratamiento de cal, se relacionó con el mayor tiempo de exposición de las raíces a temperaturas inferiores a $18^{\circ} \mathrm{C}$ en las $3-4$ semanas previas al 'inicio de cambio de color' y a $15^{\circ} \mathrm{C}$ en las $2-3$ semanas previas. 
Tabla 25. Porcentaje de horas con temperatura de suelo inferior a $21^{\circ} \mathrm{C}, 18^{\circ} \mathrm{C}, 15^{\circ} \mathrm{C}$ y $13^{\circ} \mathrm{C}$ en el control y con dos tipos de cobertura de suelo, malla plateada (MP) y cal (CAL: $\mathrm{CaOH}_{2}$; D: Dolomita), durante los años 2007 y 2008, Kiyú (Uruguay). El 'inicio de cambio de color' (al menos $5 \%$ de los frutos con ICC $\geq 0$ ) tuvo lugar el 8 y el 2 de mayo en 2007 y 2008, respectivamente, y el 'cambio de color' (al menos $50 \%$ de los frutos con ICC $\geq 0$ ) se produjo el 17 y 13 de mayo de 2007 y 2008 , respectivamente.

\begin{tabular}{|c|c|c|c|c|c|c|c|c|c|c|c|c|}
\hline \multirow{3}{*}{$\begin{array}{c}\text { Año } 2007 \\
\text { Período }\end{array}$} & \multicolumn{12}{|c|}{ Porcentaje de horas con la temperatura de la zona radicular } \\
\hline & \multicolumn{3}{|c|}{$\leq 21^{\circ} \mathrm{C}$} & \multicolumn{3}{|c|}{$\leq 18^{\circ} \mathrm{C}$} & \multicolumn{3}{|c|}{$\leq 15^{\circ} \mathrm{C}$} & \multicolumn{3}{|c|}{$\leq 13^{\circ} \mathrm{C}$} \\
\hline & Control & MP & Cal & Control & MP & Cal & Control & MP & Cal & Control & MP & Cal \\
\hline 6-12 Marzo & 38 & 53 & 66 & 0 & 0 & 0 & 0 & 0 & 0 & 0 & 0 & 0 \\
\hline 13-19 Marzo & 21 & 57 & 85 & 0 & 0 & 0 & 0 & 0 & 0 & 0 & 0 & 0 \\
\hline 20-26 Marzo & 18 & 88 & 100 & 0 & 0 & 1 & 0 & 0 & 0 & 0 & 0 & 0 \\
\hline 27/3-2 Abril & 27 & 100 & 100 & 0 & 0 & 0 & 0 & 0 & 0 & 0 & 0 & 0 \\
\hline 3-9 Abril & 89 & 100 & 100 & 0 & 0 & 17 & 0 & 0 & 0 & 0 & 0 & 0 \\
\hline 10-16- abril & 100 & 100 & 100 & 33 & 60 & 96 & 0 & 0 & 7 & 0 & 0 & 0 \\
\hline 17-23 Abril & 75 & 91 & 96 & 7 & 12 & 44 & 0 & 0 & 0 & 0 & 0 & 0 \\
\hline 24-30 Abril & 100 & 100 & 100 & 83 & 90 & 100 & 19 & 20 & 57 & 0 & 0 & 0 \\
\hline 1-7 Mayo & 100 & 100 & 100 & 93 & 100 & 100 & 5 & 5 & 23 & 0 & 0 & 0 \\
\hline 8-14 Mayo & 100 & 100 & 100 & 100 & 100 & 100 & 100 & 100 & 100 & 64 & 55 & 99 \\
\hline 15-21 Mayo & 100 & 100 & 100 & 100 & 100 & 100 & 100 & 100 & 100 & 83 & 86 & 100 \\
\hline 22-28 Mayo & 100 & 100 & 100 & 100 & 100 & 100 & 100 & 100 & 100 & 100 & 100 & 100 \\
\hline
\end{tabular}




\begin{tabular}{|c|c|c|c|c|c|c|c|c|c|c|c|c|}
\hline \multirow{3}{*}{$\begin{array}{l}\text { Año } 2008 \\
\text { Período }\end{array}$} & \multicolumn{12}{|c|}{ Porcentaje de horas con la temperatura de la zona radicular } \\
\hline & \multicolumn{3}{|c|}{$\leq 21^{\circ} \mathrm{C}$} & \multicolumn{3}{|c|}{$\leq 18^{\circ} \mathrm{C}$} & \multicolumn{3}{|c|}{$\leq 15^{\circ} \mathrm{C}$} & \multicolumn{3}{|c|}{$\leq 13^{\circ} \mathrm{C}$} \\
\hline & Control & MP & Cal (D) & Control & MP & Cal (D) & Control & MP & Cal (D) & Control & MP & Cal (D) \\
\hline 29/2-6 Marzo & 13 & 13 & 20 & 0 & 0 & 0 & 0 & 0 & 0 & 0 & 0 & 0 \\
\hline 7-13 Marzo & 78 & 78 & 78 & 0 & 0 & 10 & 0 & 0 & 0 & 0 & 0 & 0 \\
\hline 14-20 Marzo & 75 & 75 & 67 & 0 & 0 & 2 & 0 & 0 & 0 & 0 & 0 & 0 \\
\hline 21-27 Marzo & 89 & 89 & 91 & 0 & 0 & 27 & 0 & 0 & 0 & 0 & 0 & 0 \\
\hline 28/3-2 Abril & 100 & 100 & 100 & 0 & 3 & 8 & 0 & 0 & 0 & 0 & 0 & 0 \\
\hline 3-9 Abril & 100 & 100 & 100 & 24 & 35 & 40 & 0 & 0 & 0 & 0 & 0 & 0 \\
\hline 10-16 Abril & 100 & 100 & 100 & 60 & 63 & 68 & 9 & 12 & 31 & 0 & 0 & 0 \\
\hline 17-23 Abril & 96 & 96 & 96 & 58 & 86 & 83 & 2 & 7 & 15 & 0 & 0 & 0 \\
\hline 24-30 Abril & 99 & 99 & 99 & 80 & 93 & 91 & 19 & 24 & 32 & 0 & 0 & 0 \\
\hline 1-7 Mayo & 100 & 100 & 100 & 100 & 100 & 100 & 95 & 100 & 100 & 2 & 4 & 36 \\
\hline 8-14 Mayo & 100 & 100 & 100 & 100 & 100 & 100 & 100 & 100 & 100 & 32 & 44 & 85 \\
\hline
\end{tabular}


Los tratamientos de cobertura del suelo también modificaron la luz reflejada hacia la copa. En la Figura 22 se presenta la evolución de la radiación total y PAR incidente y reflejada desde el suelo. Los tratamientos incrementaron la luz reflejada desde el suelo medida a $1.20 \mathrm{~m}$ de altura respecto del control, particularmente en el mes de abril. Durante el mes de mayo, solamente el tratamiento de malla mostró una radiación reflejada destacable. Estos resultados de luz reflejada no evidencian ninguna asociación entre el color de la fruta y el tratamiento, sugiriendo que la luz incidente no era limitante para el cambio de color.

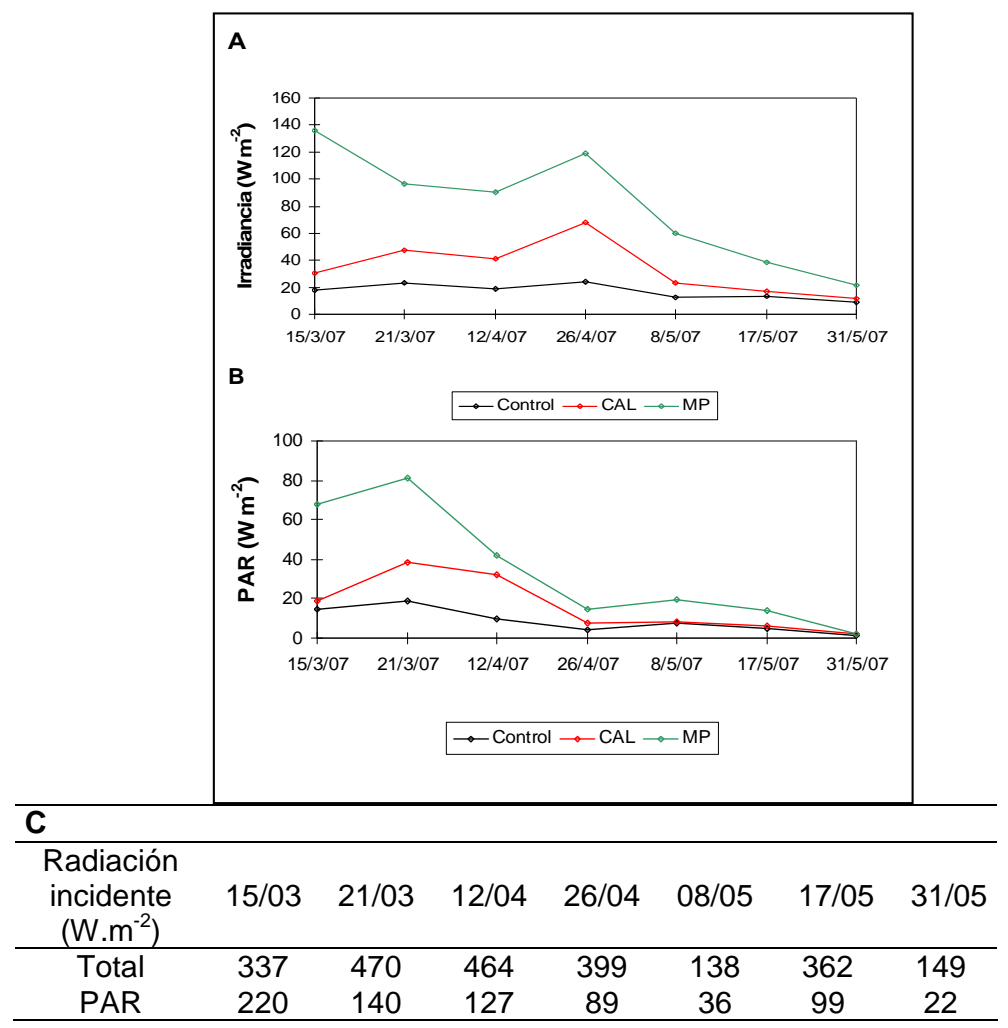

Figura 22. Intensidad de radiación (A), Radiación Fotosintéticamente Activa -PAR- $(B)$ reflejada desde el suelo (Control) o desde la cobertura utilizada: malla plateada (MP) o Cal, instaladas en marzo, e Intensidad de radiación total y PAR incidente (C), a 1.2 $\mathrm{m}$ de altura. Valores correspondientes al año 2007, Uruguay. 
En España, desde el mes de julio al mes de octubre la temperatura media del aire $(\mathrm{Ta})$ se redujo progresivamente desde $25.5^{\circ} \mathrm{C} \pm 0.4$ a $18.3^{\circ} \mathrm{C} \pm$ 0.4; la HR mensual media se incrementó de $46.5 \% \pm 1.4$ a $70.5 \% \pm 2.2$, la $\mathrm{ET}_{0}$ mensual media se redujo de $7.0 \pm 0.1$ a $2.5 \pm 0.1 \mathrm{~mm}$ día $^{-1}$ y la precipitación media se incrementó de $2.8 \pm 2.0 \mathrm{~mm} \mathrm{mes}^{-1}$ en julio a $49.2 \pm 20.1 \mathrm{~mm} \mathrm{mes}^{-1}$ en octubre, registrándose diferencias notables entre años (de $16 \mathrm{~mm}$ en 2005 a 142 mm en 2008 a lo largo del periodo estudiado). En el año 2006 se registró la temperatura media más alta. Las diferencias entre años para la $H R$ y la $E T_{0}$ fueron, prácticamente, inexistentes (datos no presentados). Durante el verano (julio-agosto) la temperatura media del aire estuvo por encima de los $25{ }^{\circ} \mathrm{C}$ durante por lo menos el $70 \%$ de los días. A partir de la segunda quincena de septiembre, un mes previo al inicio de cambio de color de los frutos, la temperatura permaneció por debajo de los $22^{\circ} \mathrm{C}$ durante más del $70 \%$ de los días. Se registró una amplitud térmica diaria mayor a $10^{\circ} \mathrm{C}$ durante todo el verano y hasta el $80 \%$ de los días de la primera quincena de octubre; posteriormente, durante las semanas previas al cambio de color, solo se registró entre el 20 y $50 \%$ de los días.

Los cambios estacionales de la temperatura del suelo (Ts), a $30 \mathrm{~cm}$ de profundidad, provocados por los tratamientos, de cal o malla, durante el año 2007, se presentan en la figura 23. Las mayores diferencias entre tratamientos se establecieron a partir del mes de septiembre. Se destaca una reducción significativa de la temperatura diaria del suelo y de la amplitud (Ts max - Ts min) con los tratamientos de cobertura. El principal efecto de los tratamientos de cobertura con relación al control fue la reducción de la Ts máxima, en un $3.2 \%$, para la cobertura de cal, y en un $1 \%$, para la de malla, durante el periodo julio-agosto, y en un $4.2 \%$, para la cobertura de cal, y un $2 \%$, para la de malla, durante el periodo septiembre-octubre. La Ts mínima no se modificó con la cobertura utilizada, y como consecuencia de ambas variables, la amplitud diaria de la temperatura del suelo se redujo, por término medio, de $2.2^{\circ} \mathrm{C}$ (control) a $1.5^{\circ} \mathrm{C}$ (cobertura de cal) ó 1.6\% (cobertura de malla) durante los meses de julio-agosto, y de $1.4^{\circ} \mathrm{C}$ (control) a $0.9^{\circ} \mathrm{C}$ (cobertura de cal) ó $1.0^{\circ} \mathrm{C}$ (cobertura de malla) durante los meses de septiembre-octubre (Figura 23). Durante septiembre, octubre y noviembre se redujo significativamente el tiempo de permanencia de la temperatura del suelo entre $21^{\circ} \mathrm{C}$ y $25^{\circ} \mathrm{C}$, en un $35 \%, 17 \%$ y 
$19 \%$ para la cobertura de cal, malla instalada en julio y malla instalada en septiembre, respectivamente, respecto de los controles sin cobertura (Figura 24). Resultados similares fueron registrados en los años 2005, 2006 y 2008 (datos no presentados).

Dado que los tratamientos adelantaron significativamente la coloración del fruto sin alterar su maduración interna, la recolección de frutos se anticipó significativamente respecto de los controles. En Uruguay, el tratamiento de cal, el primer año, incrementó significativamente el porcentaje de frutos recolectados por color en la primera fecha (8/05), y un efecto similar se logró el segundo año, aunque sin alcanzar la significación estadística. La cobertura de malla no logró anticipar significativamente la recolección en ninguno de los dos años, coincidentemente con los resultados de temperatura de suelo y evolución del color de los frutos (Figura 20, Tablas 22 y 25). En España, sin embargo, el porcentaje de frutos cosechados en la primera recolección aumentó, en todos los experimentos (2005-2008), entre un 5\%-11\% con la cobertura de malla y un $8 \%-13 \%$ con la de cal, dependiendo del año (Tabla 26). 


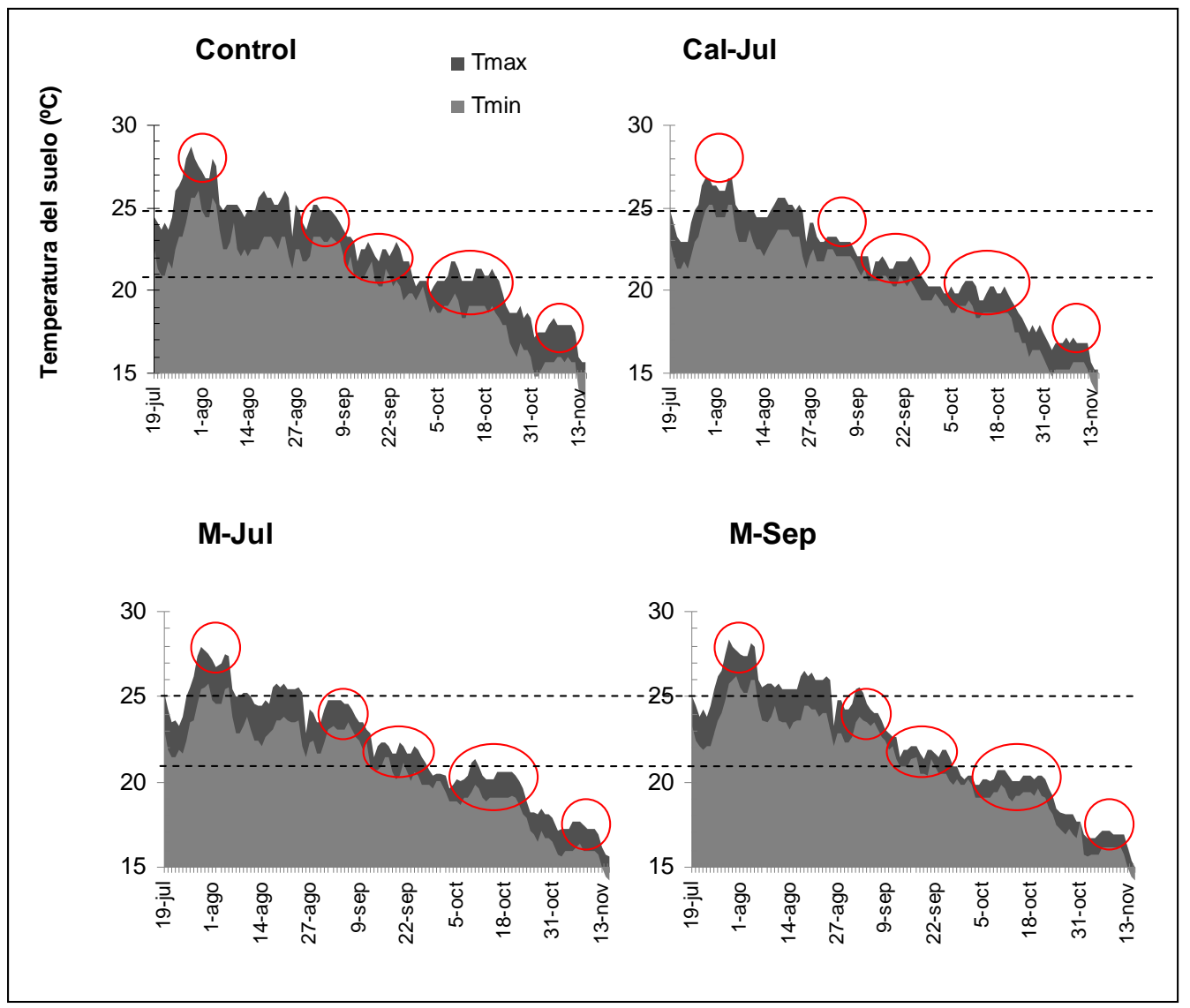

Figura 23. Cambios estacionales de los valores máximos y mínimos de la temperatura del suelo provocados por la cobertura de cal instalada en julio (Cal-Jul), o de mallas instaladas en julio (M-Jul) o en septiembre (M-Sep). Valores correspondientes al año 2007, España. 


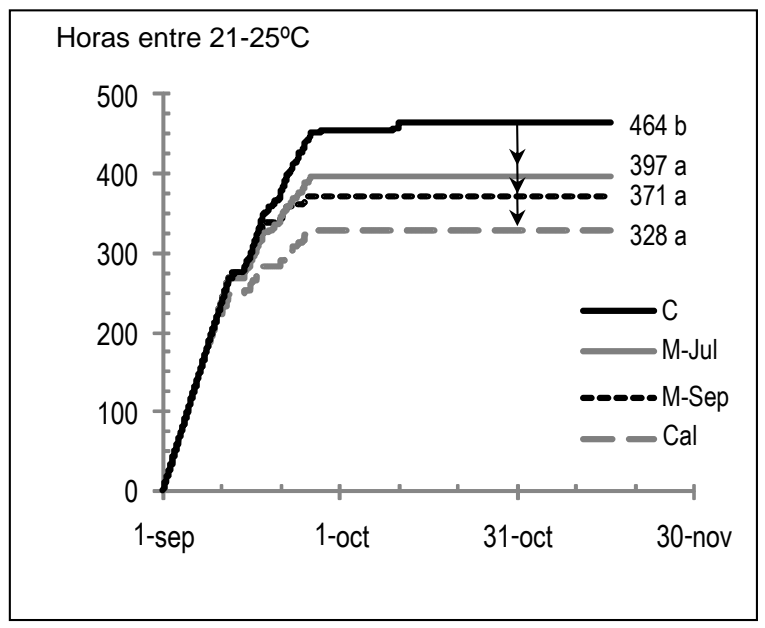

Figura 24. Tiempo de permanencia en horas de la temperatura del suelo entre $21^{\circ} \mathrm{C}$ y $25^{\circ} \mathrm{C}$, provocados por la cobertura de cal instalada en julio, o de mallas instaladas en julio (M-Jul) o en septiembre (M-Sep). Las flechas indican la primera fecha de recolección de frutos. Valores correspondientes al año 2007, España. Letras distintas indican diferencia significativa $(p \leq 0.05)$.

Tabla 26. Influencia del tipo de cobertura del suelo sobre el porcentaje de frutos de mandarina Clementina cv. 'Clemenpons' cosechados en la primera fecha de recolección. Los valores son la media de 10-30 árboles por tratamiento, correspondientes a lo experimentos de España.

\begin{tabular}{|c|c|c|c|c|c|c|}
\hline \multirow[t]{2}{*}{ Año } & \multirow{2}{*}{$\begin{array}{l}\text { Fecha de } \\
\text { cobertura }\end{array}$} & \multirow{2}{*}{$\begin{array}{l}\text { Días con } \\
\text { cobertura }\end{array}$} & \multirow{2}{*}{$\begin{array}{l}1^{\text {a }} \text { fecha } \\
\text { recolección }\end{array}$} & \multicolumn{3}{|c|}{$\begin{array}{c}\text { Frutos cosechados en la } 1^{\mathrm{a}} \text { fecha } \\
(\%)\end{array}$} \\
\hline & & & & Control & Cal & Malla \\
\hline 2005 & $\begin{array}{l}\text { Julio } \\
\text { Sept }\end{array}$ & $\begin{array}{l}95 \\
53\end{array}$ & 28-Oct & $9.6 b^{z}$ & - & $\begin{array}{l}18.6 \mathrm{a} \\
20.3 \mathrm{a}\end{array}$ \\
\hline 2006 & $\begin{array}{l}\text { Julio } \\
\text { Sept }\end{array}$ & $\begin{array}{c}104 \\
56\end{array}$ & 31-Oct & $8.0 \mathrm{~b}$ & $\begin{array}{c}21.0 \mathrm{a} \\
-\end{array}$ & $\begin{array}{l}17.4 \mathrm{a} \\
15.0 \mathrm{a}\end{array}$ \\
\hline 2007 & $\begin{array}{l}\text { Julio } \\
\text { Sept }\end{array}$ & $\begin{array}{c}119 \\
56\end{array}$ & 30-Oct & $3.6 \mathrm{~b}$ & $\begin{array}{c}13.5 \mathrm{a} \\
-\end{array}$ & $\begin{array}{r}8.3 a \\
11.8 a\end{array}$ \\
\hline 2008 & Julio & 102 & 4-Nov & $13.5 \mathrm{~b}$ & $21.7 \mathrm{a}$ & - \\
\hline
\end{tabular}

${ }^{\mathrm{Z}}$ Letras distintas en un mismo año indican diferencia significativa $(p \leq 0.05)$. 
De acuerdo con estos resultados, el sombreado del suelo a lo largo de los dos últimos meses previos a la recolección fue suficiente para avanzar el cambio de color del fruto y anticipar su recolección. Cuanto menor fue el tiempo en que el suelo permaneció con temperaturas superiores a $21^{\circ} \mathrm{C}$, mayor fue el porcentaje de frutos cosechados en la primera fecha de recolección respecto del control. 




\section{Discusión}



El cambio de color de los frutos cítricos es un proceso complejo que involucra modificaciones fisiológicas y bioquímicas asociados a factores endógenos (varietales, hormonales y nutricionales) y exógenos (luz y temperatura). El proceso de desverdizado natural se puede modificar con aplicaciones exógenas de reguladores de crecimiento, tales como ácido giberélico (Goldschmidt y Eilati, 1970, Kuraoka et al., 1977) y etileno (Pons et al., 1992; Goldschmidt et al., 1993); sustancias nitrogenadas (Jones y Embleton, 1959; Sala et al., 1992; Quiñones et al., 2004) y carbohidratos (Iglesias et al., 2001).

Con respecto a las características varietales, en nuestros experimentos, al comparar frutos del naranjo 'Washington navel' y sus mutantes 'Navelina' y 'Navelate', se comprobó que para un mismo valor de ICC el cultivar más temprano posee mayor concentración de todos los azúcares, que su parental 'Washington navel' y su mutante más tardío. Asimismo, la magnitud del retraso de color provocada por la aplicación exógena de $\mathrm{GA}_{3}$ estuvo asociada al genotipo, oscilando entre 15-20 días en cultivares de ciclo corto y medio ('Satsumas', 'Navelina' y 'Washington navel') y hasta 60 días en el naranjo 'Navelate' de ciclo largo.

En todos los cultivares estudiados la concentración de azúcares solubles totales del flavedo aumentó durante el proceso de desverdizado, lo que coincide con estudios previos (Huff, 1984, Sala et al., 1992, Holland et al., 1999). Este incremento se debió fundamentalmente al aumento de los azúcares reductores, al igual que lo encontrado por Huff (1984) y Fidelibus et al. (2008). La sacarosa se incrementó hasta el inicio del cambio de color de los frutos $y$, posteriormente, se mantuvo relativamente estable, con pequeñas variaciones entre cultivares, lo que sugiere que a partir de ese momento el aumento de los restantes azúcares es producto de su hidrólisis. Se ha señalado que el suplemento de sacarosa in vitro (Huff, 1983) o in vivo (Iglesias et al., 2001) promueve el desverdizado del flavedo de los cítricos. Adicionalmente, la aplicación de etileno, que promueve la coloración, estimula los genes involucrados en el transporte de sacarosa y de invertasa ácida (Fujii et al., 2007). En los experimentos realizados en esta tesis, la aplicación de $\mathrm{GA}_{3}$ previo al cambio de color retrasó el desverdizado, y el flavedo de los frutos presentó menor concentración de todos los azúcares solubles en relación a los 
controles. La relación SAC: $\mathrm{FRU}+\mathrm{GLU}$ en los frutos control y los tratados con $\mathrm{GA}_{3}$ fue similar durante el período de desverdizado; solamente en una fecha en cada cultivar (que se situó a los 35 y 60 días del tratamiento) se observó una mayor relación SAC: FRU+GLU en los tratados. Con estos resultados no se pudieron verificar cambios consistentes en la relación sacarosa: azúcares reductores, esperables como consecuencia de la aplicación de $\mathrm{GA}_{3}$, que de acuerdo con Fujii et al. (2008) reprime la transcripción del gen CitINV1, asociado a la hidrólisis de sacarosa en hexosas durante la maduración.

Nuestros resultados comprueban que con la aplicación de $\mathrm{GA}_{3}$ se reduce el aporte de sacarosa al fruto, no propuesto previamente, sin modificaciones de importancia en las proporciones SAC: FRU+GLU. Consecuentemente, la menor disponibilidad de azúcares reductores limita la toma de color de los frutos cítricos tratados con $\mathrm{GA}_{3}$, confirmando lo propuesto por Fidelibus et al. (2008) de que al menos parcialmente, el retraso en la toma de color de los frutos de estas especies está mediado por la disminución de las hexosas del flavedo.

Al igual que los tratados con $\mathrm{GA}_{3}$, los frutos cuyo pedúnculo fue anillado permanecieron más verdes, presentando una menor concentración de todos los azúcares solubles debido a la interrupción del flujo provocada por la eliminación permanente de $0.5 \mathrm{~cm}$ de la corteza del pedúnculo. En este caso, además, con una importante reducción de la sacarosa, que se explica por su hidrólisis en hexosas, provocando un cambio en las proporciones SAC: $\mathrm{FRU}+\mathrm{GLU}$.

El metabolismo del nitrógeno también parece estar involucrado en el proceso de maduración de los frutos cítricos, ya que aplicaciones tardías (Jones y Embleton, 1959; Sala et al., 1992; Quiñones et al., 2004) ó abundantes de este elemento (Jones y Embleton, 1959; Lee y Chapman, 1988), retrasan el cambio de color ó promueven el reverdecimiento de los frutos (Jones y Embleton, 1959). En condiciones in vitro, Huff (1983) demostró que el nitrógeno es el único elemento mineral necesario para el reverdecimiento de discos de epicarpio.

En todos los cultivares evaluados, la concentración de nitrógeno total y la fracción proteica, que representó entre el $98 \%$ y el $99 \%$ del nitrógeno total del flavedo, disminuyeron junto con el cambio de color, lo que coincide con lo 
propuesto por Iglesias et al. (2001) y Sala et al. (1992). Sin embargo, otros investigadores no encontraron cambios en el contenido de proteínas totales (Lewis et al., 1967) o $\mathrm{N}$ total (Huff, 1984, Win et al., 2006) durante la maduración. En nuestros experimentos no se detectaron nitratos ni nitritos en el flavedo de los frutos y no encontramos una correlación significativa entre la concentración de $\mathrm{N}-\mathrm{NH}_{4}{ }^{+}$endógena y la toma de color de los frutos.

La aplicación de nitrato amónico a los frutos no afectó la evolución de su color ni la concentración de nitrógeno del flavedo. Estos resultados, no esperados, podrían explicarse por la fuente de nitrógeno utilizada; de acuerdo con Sala et al. (1992) el nitrógeno amoniacal es menos eficiente que los nitratos. Antecedentes recientes revelan que la aplicación de nitratos previa a la maduración, disminuye la pérdida de clorofilas y altera la composición y el contenido total de carotenoides en el flavedo (Alós et al., 2006). Huff (1984), propone que el nitrógeno tiene un papel protector estabilizando los cloroplastos, pero que no promueve su formación. Considerando los antecedentes y nuestros resultados, proponemos que el nitrógeno, a pesar de ser un metabolito importante modulando la toma de color de los frutos cítricos (Jones y Embleton, 1959; Huff, 1983; Lee y Chapman, 1988; Quiñones et al., 2004; Alós et al. 2006), no es un factor desencadenante del proceso.

En el experimento de anillado en la zona media del pedúnculo del fruto, las 3-4 hojas próximas al fruto no tuvieron un papel determinante en la toma de color del mismo, en la medida que los frutos con pedúnculo anillado, con o sin hojas próximas, no presentaron diferencias en la evolución del color, ni en la concentración de azúcares reductores o nitrógeno en el flavedo ni en la corteza del pedúnculo. Las únicas diferencias fueron la mayor concentración de ABA en el flavedo y de sacarosa en la zona apical del pedúnculo de los anillados con hojas. Las hojas próximas a los frutos y aisladas del resto de la rama por el anillado, no presentaron diferencias en contenidos endógenos de ABA, azúcares solubles y nitrógeno respecto de las hojas próximas a los frutos control. Estos resultados difieren de los de Iglesias et al. (2001), en los que los frutos de plantas defoliadas no logran madurar externamente. Los autores relacionan el bloqueo de la acumulación de sacarosa y de la reducción del nitrógeno en el flavedo de los frutos, con la inhibición de la pérdida de clorofila de los mismos. Probablemente las diferencias se deban a que en nuestro 
experimento el pedúnculo de los frutos se encuentra anillado (extracción de 0.5 cm de corteza), y se quitan las 3-4 hojas cercanas al fruto, pero no se realiza una defoliación completa de las plantas, como en el trabajo de Iglesias et al. (2001), en el que, probablemente, se afecte otros procesos y no solo la maduración de los frutos.

Con respecto a los factores hormonales estudiados en esta tesis, en el mandarino Satsuma 'Owari' y en el naranjo dulce 'Valencia Late', la concentración de $\mathrm{ABA}$ en el flavedo de los frutos aumentó en relación directa con el cambio de color de los mismos, lo que coincide con resultados previos en otras especies de cítricos (Goldschmidt, 1976; Aung et al., 1991; Lafuente et al., 1997, Rodrigo et al., 2003, Agustí et al., 2007). Es más, nuestros resultados demuestran que cuando los frutos se mantuvieron en el árbol hasta reverdecer, la concentración de ABA disminuyó paralelamente al descenso del ICC. La aplicación de $\mathrm{GA}_{3}$, que retrasó la toma de color, estuvo asociada a una disminución de la concentración de ABA en Satsuma cvs. 'Okitsu' y 'Owari', y naranjos dulces cvs. 'Navelina' y 'Washington navel', de maduración precoz. Por el contrario, en los naranjos dulces cvs. 'Navelate' y 'Valencia Late', de maduración tardía, no se encontró relación significativa entre el color de los frutos tratados con $\mathrm{GA}_{3}$ y la concentración de $\mathrm{ABA}$. Estos resultados confirman el efecto del $\mathrm{GA}_{3}$ probado en el mandarino 'Clementino', en el que los frutos tratados mantienen por más tiempo los carotenoides típicos de frutos verdes (luteína, $\alpha$-caroteno, $\beta$-caroteno, todos los $E$-violaxantinas y neoxantina), y reducen la acumulación de fitoeno y 9-Cis-violaxantina (Alós et al., 2006), precursor directo del ABA (Rodrigo et al., 2003), como ocurre en nuestros experimentos con el naranjo dulce cv. 'Valencia Late', con la excepción del fitoeno, que también se acumula en los frutos tratados respecto del control. Se ha sugerido que el $\mathrm{GA}_{3}$ contrarresta el efecto estimulador de la biosíntesis de carotenoides que presenta el etileno, reprimiendo la transcripción de genes relacionados, lo que resulta en la represión de la conversión de carotenoides en ABA (Rodrigo y Zacarías, 2007; Fujii et al., 2008). Adicionalmente, se ha probado en Arabidopsis que las GAs regulan positivamente la expresión del gen CYP707A3 (Saito et al., 2004), que codifica la enzima que promueve el primer paso en la inactivación del ABA (Nambara y Marion-Poll, 2005). Sin embargo, en 'Navelate' no se modificó la concentración endógena de ABA en 
frutos tratados con $\mathrm{GA}_{3}$ de coloración más verde que los control. Adicionalmente, la aplicación exógena de ABA a frutos con o sin anillado de pedúnculo no mejoró el color, ni modificó el contenido endógeno de esta hormona en el flavedo de los frutos con pedúnculo anillado. Por otro lado, los frutos con el pedúnculo anillado permanecieron más verdes y presentaron mayores niveles de $A B A$ en el flavedo que los control, al igual que la corteza del pedúnculo de la zona conectada al fruto (zona apical). La mayor concentración de $\mathrm{N}$ encontrada en los frutos anillados parece no haber afectado la ruta de biosíntesis de ABA, propuesta por Alós et al. (2006), frente al agregado exógeno de nitratos.

Nuestros resultados demuestran que también en los cítricos la NFZ bloquea la ruta de síntesis de carotenoides, aumentando la concentración de los lineales (fitoeno y fitoflueno), probado en otras especies, Narcissus pseudonarcisus y Hordeum vulgare, (Deane-Drummond y Johnson, 1980; Beyer et al., 1994). Este efecto, a su vez, explica la menor intensidad de color de los frutos tratados con NFZ que, sin embargo, iniciaron el cambio de color simultáneamente con los controles sin tratar. Es decir, que a medida que los carotenoides incoloros se acumulan, el fruto ve retrasado su color. Como consecuencia de ello, los frutos tratados con NFZ presentaron menor concentración de $\beta$-criptoxantina, cis-violaxantina y $\beta$-citraurina (responsables de la coloración) que los frutos control. Este efecto es claro en nuestro experimento de la UPV, en el que los frutos con menor intensidad de color son los que presentan concentraciones más bajas de $\beta$-criptoxantina, cisviolaxantina y $\beta$-citraurina. En el experimento de Lliria, los resultados son similares para las mismas fechas de la UPV, pero el incremento final de su concentración se explica por el retraso en la acumulación de estos pigmentos en los frutos tratados, que alcanzaron valores similares a los de los controles para valores, a su vez, similares de ICC, pero con un retraso aproximado de un mes.

Los cambios en la coloración de los frutos están regulados hormonalmente. En nuestros experimentos se encontró un aumento de la concentración de $\mathrm{GA}_{1}$ y $\mathrm{GA}_{4}$ en el flavedo, previo al inicio de la toma de color (entre las 20 y 24 semanas después de la caída de pétalos), que disminuyó durante las dos semanas siguientes junto con el cambio de color. Esta 
disminución en el flavedo se vio acompañada por un incremento de ambas GAs, especialmente de la $\mathrm{GA}_{4}$, en la corteza del pedúnculo. En el flavedo de los frutos con pedúnculo anillado, como consecuencia de la interrupción vascular, las GAs no son exportadas desde el fruto, incrementando su concentración en el tiempo y en relación al control $\left(G_{1}\right.$ dos veces y $G_{4} 14$ veces), lo que explica el color verde de estos frutos. Sin embargo, en ambas zonas del pedúnculo, la $\mathrm{GA}_{1}$ presentó concentraciones superiores al control, mientras que la $\mathrm{GA}_{4}$, tuvo una concentración menor en la zona apical, conectada con el fruto y desconectada del resto de la planta por el anillado, y no se diferenció en la zona basal, desconectada floemáticamente del fruto, respecto del control. Para el aumento de la concentrtación de $\mathrm{GA}_{1}$ en la zona basal no tenemos una explicación convincente.

Esta es la primera información sobre contenidos endógenos de $G_{1}$ y $\mathrm{GA}_{4}$ durante el período comprendido entre el final de la fase II de crecimiento del fruto y la fase III. Hasta hoy, toda la información disponible está relacionada con la concentración endógena de GAs en la fase de floración y cuajado de frutos (Ali-Dinar et al., 1988; Talón et al., 1992). En trabajos en los que se estudió la actividad GAs, se ha señalado un incremento desde la antesis hasta 14-16 semanas después de la caída de pétalos (Hofman, 1990), o hasta el comienzo de la pérdida de clorofilas (García-Luis et al., 1985), y una disminución cuando el fruto está próximo a la madurez (Kuraoka et al., 1977). Los resultados obtenidos a partir de frutos con pedúnculo anillado y sin anillar, en relación con la concentración endógena de $\mathrm{GA}_{1}, \mathrm{GA}_{4}$ y $\mathrm{ABA}$, sugieren que el balance entre ambos reguladores es uno de los factores centrales en la regulación del desverdizado de los frutos. Las GAs deben ser exportadas de los frutos para permitir el cambio de color, mientras que el aumento en la concentración de $A B A$, que también acompaña el cambio de color, no es suficiente para disparar el proceso de maduración. Su incremento en frutos con pedúnculo anillado, que no tomaron color, podría explicarse como respuesta al estrés provocado por el tratamiento, pero no confirma una relación causaefecto.

Con respecto a los factores exógenos, el cambio de color de los frutos de plantas adultas de mandarino 'Clementino', evaluado en dos condiciones ambientales diferentes (suroeste de España y sur de Uruguay), se asoció a la 
disminución de la temperatura del suelo, reflejo de la temperatura del aire, y fue promovido por la reducción artificial de la primera.

En las condiciones de nuestros experimentos, la luz natural incidente no fue un factor limitante en la toma de color de los frutos. En España se encontró una correlación muy baja entre la luz reflejada desde el suelo por las mallas y el color de los frutos, y en Uruguay, el tratamiento de mallas incrementó significativamente la luz reflejada hacia la copa en relación al control, sin adelantar el cambio de color.

En España, donde se utilizó citrange 'Carrizo' como portainjerto, el umbral de la temperatura del aire para que se iniciara el cambio de color se situó en los $21^{\circ} \mathrm{C}$. En Uruguay, con un portainjerto caducifolio ( $P$. trifoliata), este umbral se situó en $15^{\circ} \mathrm{C}-18^{\circ} \mathrm{C}$. Con relación a la amplitud térmica diaria, previamente citada como necesaria para promover el cambio de color, nuestros experimentos confirman que una diferencia de al menos $10^{\circ} \mathrm{C}$ durante por lo menos el $60 \%$ de los días no es suficiente para ello, y es el régimen térmico día/noche el que se ha de situar por debajo de ciertos umbrales $\left(17^{\circ} \mathrm{C}-26^{\circ} \mathrm{C} /\right.$ $\left.2^{\circ} \mathrm{C}-11^{\circ} \mathrm{C}\right)$. Nuestros resultados en Uruguay con el mandarino Clementino 'Clemenules' coinciden con los de Manera et al. (2008) en plantas adultas de limonero, para los que los umbrales de $12^{\circ} \mathrm{C}$ y $14^{\circ} \mathrm{C}$, se correlacionaron significativamente con la pérdida del tono verde y el aumento de la coloración amarilla de los frutos, respectivamente.

La reducción de la temperatura de la zona radicular lograda en España con la cobertura con mallas o cal, que aumentó la exposición de las raíces a temperaturas inferiores a $21^{\circ} \mathrm{C}$, provocó un adelanto del cambio de color respecto del control. En Uruguay, sin embargo, sólo el tratamiento de cal logró adelantar el proceso, asociado al mayor tiempo de exposición de las raíces a temperaturas inferiores a $18^{\circ} \mathrm{C}$, en las $3-4$ semanas previas al 'inicio de cambio de color' y a $15^{\circ} \mathrm{C}$ en las $2-3$ semanas previas. A su vez, en las plantas control el 'inicio de cambio de color' se dio tras permanecer una semana con el $80 \%$ de sus horas por debajo de $18^{\circ} \mathrm{C}$, y el número de frutos maduros se incrementó notablemente después de permanecer, por lo menos, el $60 \%$ de las horas por debajo de $15^{\circ} \mathrm{C}$. En la medida que los tratamientos de cobertura de suelo no afectaron la temperatura y humedad del aire, y que la luz reflejada aumentó con el tratamiento de malla sin adelantar el cambio de color, el resultado se 
atribuye exclusivamente a la disminución de la temperatura del suelo. El efecto de las bajas temperaturas sobre la reducción de la actividad radicular ha sido estudiado únicamente en plantas jóvenes (12-16 meses) y en general en condiciones controladas. De los antecedentes se desprende que, el crecimiento radicular comienza por encima de $13^{\circ} \mathrm{C}$ (Castle, 1978), y que éste se correlaciona positiva y linealmente con temperaturas entre $18^{\circ} \mathrm{C}$ y $28^{\circ} \mathrm{C}$, pero que es muy reducido por debajo de $22^{\circ} \mathrm{C}$ (Bevington y Castle, 1985). De igual manera, la respiración de las raíces de naranjo amargo se reduce exponencialmente con temperaturas del suelo por debajo de 25ㄷ (Bryla et al., 2001). Por otra parte, en plantas jóvenes de limonero 'Eureka' y de naranjo dulce 'Valencia' se observó que la absorción y el transporte de nitrógeno aumenta entre $9^{\circ} \mathrm{C}$ y $23^{\circ} \mathrm{C}$, y disminuye a partir de $27^{\circ} \mathrm{C}$ (Wallace, 1953).

Las diferencias de respuesta encontradas en nuestros experimentos, pueden explicarse, al menos parcialmente, por el portainjertos utilizado. El crecimiento radicular de plantas jóvenes de citrange 'Carrizo' (utilizado en España) se limita con temperaturas de suelo inferiores a $22^{\circ} \mathrm{C}$ (Bevington y Castle, 1985), y ello explica por qué la malla colocada en julio, que si bien redujo la temperatura del suelo durante el verano (julio-agosto), no lo hizo por debajo de $22^{\circ} \mathrm{C}$, y no aceleró el cambio de color respecto de la colocada en septiembre. En este mes disminuyó la temperatura media del aire y del suelo por debajo de los $22^{\circ} \mathrm{C}$, lo que fue potenciado por los tratamientos, promoviendo el cambio de color. Sin embargo, en Uruguay, donde se utilizó como portainjertos el P.trifoliata, fue necesario que la temperatura se redujera por debajo de $15^{\circ} \mathrm{C}-18^{\circ} \mathrm{C}$ para disparar el proceso, umbral para el que se ha encontrado el cese del desarrollo y de la actividad radicular de este portainjertos (Poerwanto et al., 1989). Nuestros resultados, apoyados en estas diferencias de los umbrales térmicos de desarrollo y actividad radiculares de los dos portainjertos utilizados, $P$. trifoliata y citrange 'Carrizo', permiten relacionar la disminución del metabolismo radicular con el cambio de color de los frutos cítricos en plantas adultas.

Adicionalmente, existen evidencias, aunque en condiciones controladas, que relacionan la disminución de la temperatura de las raíces con el cambio de color del fruto; así en 'Calamondín' (Citrus madurensis Lour.) y mandarino Satsuma el contenido de carotenoides del flavedo se duplica con una 
disminución de la temperatura de $30^{\circ} \mathrm{C}$ a $14^{\circ} \mathrm{C}$ (Soonen et al., 1979). En el mismo sentido, Young y Erickson (1961) encuentran la menor concentración de clorofilas y la mayor concentración de xantofilas en el flavedo de frutos de naranjo dulce 'Valencia' con una amplitud térmica diurna/nocturna de $20^{\circ} \mathrm{C} / 7^{\circ} \mathrm{C}$ y temperaturas del suelo de $12^{\circ} \mathrm{C}$.

El inicio de la coloración en respuesta a las bajas temperaturas se ha atribuido fundamentalmente a la inhibición de la translocación de sustancias con actividad giberelinas desde las raíces (Eilati et al., 1969a) y a la reducción de la absorción de nitrógeno (Chapman y Parker, 1942) y translocación de este mineral hacia la parte aérea (Wallace, 1953). Estudios recientes realizados en plantas jóvenes de citrange 'Carrizo' indican que con temperaturas diurnas/nocturnas de $32^{\circ} \mathrm{C} / 27^{\circ} \mathrm{C}$ se incrementa el contenido endógeno de $\mathrm{GA}_{1}$ en la parte aérea, respecto a las temperaturas de $17^{\circ} \mathrm{C} / 12^{\circ} \mathrm{C}$, como consecuencia del aumento de la expresión del gen CsGA20ox1 (Vidal et al., 2004). Una reducción en el metabolismo de las GAs, con la subsiguiente disminución del contenido de $\mathrm{GA}_{1}$ en la parte aérea y por lo tanto también en el fruto, podría estar ocurriendo naturalmente en el otoño-invierno al disminuir la temperatura del suelo por debajo de $15^{\circ} \mathrm{C}-18^{\circ} \mathrm{C}$ y $21^{\circ} \mathrm{C}$ (en Uruguay y España, respectivamente, de acuerdo con los patrones utilizados) y provocar el inicio del cambio de color de los frutos. El proceso se aceleraría al disminuir artificialmente la temperatura de la zona radicular, logrando incrementar la integral térmica por debajo de dichos umbrales. Adicionalmente este descenso disminuiría la absorción y el transporte de nitrógeno. Con la disminución de la temperatura del aire disminuye la actividad vegetativa y sólo queda el fruto como órgano sumidero de carbohidratos (Agustí, 2003), al mismo tiempo que aumenta la actividad invertasa (Purvis and Rice, 1983), incrementando la concentración de azúcares reductores en el flavedo de los frutos (Purvis and Grierson, 1982). La reducción de la competencia por carbohidratos entre el fruto y otros órganos de la planta (hojas y raíces), y la disminución del flujo de nitrógeno desde las raíces y su relación con el desverdizado de los frutos cítricos es una hipótesis nutricional propuesta por Huff (1984), que demostró cultivando in vitro pericarpio de naranja dulce. Nuestros resultados aportan evidencias sobre el efecto de la disminución de la temperatura del aire y del suelo en la promoción del cambio de color de los frutos cítricos en plantaciones 
adultas, bajo condiciones no-controladas de temperatura del aire y reduciendo la temperatura del suelo.

Considerando la relación entre los factores endógenos y exógenos se propone que el inicio del cambio de color de los frutos cítricos es consecuencia del descenso de la temperatura del suelo, mediada por la temperatura del aire, que provoca el cese del desarrollo vegetativo y de la raíz. Como consecuencia de ello, se reduce la síntesis y el transporte de giberelinas desde las raíces, al mismo tiempo que se inicia su exportación desde los frutos. Adicionalmente, disminuye la absorción de $\mathrm{N}$ y su concentración y aumenta la de azúcares reductores y de $\mathrm{ABA}$ en el flavedo. 


5. Conclusiones 

$>\quad$ Las giberelinas $\mathrm{GA}_{1}$ y $\mathrm{GA}_{4}$ deben exportarse desde el flavedo de los frutos para permitir el cambio de color.

> La aplicación de $\mathrm{GA}_{3}$ no solo retarda la pérdida de clorofilas, sino que reduce la concentración de pigmentos carotenoides coloreados ( $\beta$ criptoxantina, cis-violaxantina y $\beta$-citraurina) y aumenta la concentración de los propios de frutos verdes ( $\beta$-caroteno y luteína) a lo largo de todo el periodo de maduración.

$>\quad$ Con el cambio de color se incrementa la concentración de ABA en el flavedo, pero su papel no es el de promotor del proceso.

Se verifica una relación inversa entre el color y la concentración de nitrógeno en el flavedo en condiciones in vivo. Las evidencias de que el incremento de GAs es, por una parte, la señal endógena primaria que limita el cambio de color y promueve, por otra, el incremento del $\mathrm{N}$ endógeno, permiten postular un papel subsidiario de éste en el proceso de la maduración externa de los frutos cítricos.

$>\quad$ El cambio de color de los frutos de mandarino 'Clementino' es promovido por el descenso de la temperatura del suelo por debajo de un umbral crítico asociado al portainjertos. En las condiciones de España y Uruguay, con los portainjertos citrange 'Carrizo' y P. trifoliata, el cambio de color de los frutos se correlaciona con temperaturas de la zona radicular menores de $21^{\circ} \mathrm{C}$ y de $15^{\circ} \mathrm{C}-18^{\circ} \mathrm{C}$, respectivamente.

> La disminución de la temperatura de la zona radicular lograda con el sombreado del suelo con cobertura de malla blanca o de cal, durante los dos meses previos al cambio de color, permite adelantar el inicio de éste en frutos de mandarino 'Clementino', incrementando el porcentaje de frutos cosechados en la primera fecha de recolección. 

6. Referencias

Bibliográficas 

Acaster, M.A. and Kende, H. 1983. Properties and Partial Purification of 1Aminocyclopropane - 1carboxylate Synthase. Plant Physiol., 72: 139145.

Agustí, M. 2003. Citricultura. $2^{\mathrm{a}}$ edición, España. Mundiprensa. 422p

Agustí, M; Almela, V. y Guardiola, J.L. 1981. The regualtion of fruit cropping in mandarins through the use of growth regulators. Proc. Int. Soc. Citriculture: 216-220.

Agustí, M; Almela, V. y Guardiola, J.L. 1988. Aplicaciones de ácido giberélico para el control de alteraciones de la corteza de las mandarinas asociadas a la maduración. Invest. Agr. Prot. Veg., 3 (2): 125-137.

Agustí, M.; Juan, M.; Martínez-Fuentes, A.; Mesejo, C.; Reig, C. and Almela, V. 2006. Application of 2,4-dichlorophenoxypropionic acid and acid 2-ethylhexyl ester reduces mature fruit abscission in Citrus navel cultivars. J. Hort. Sci. \& Biotech., 81 (3): 532-536.

Agustí, J.; Zapater, M.; Iglesias, D.J.; Cercós, M.; Tadeo, F.M. and Talón, M. 2007. Differential expression of putative 9-cis-epoxycarotene dioxygenases and abscisic acid accumulation in water stressed vegetative and reproductive tissues of citrus. Plant Sci., 172: 85-94.

Aharoni, Y. 1968. Respiration of oranges and grapefruit harvested at different stages of development. Plant Physiol., 43: 99-102.

Ahmed, S.A. and Higazi, A.M. 1983. Effect of orchard density on yield and quality in Amoun oranges (Citrus sinensis). Minufiya J. Agric. Res., 6: 227-239.

Albert, A. 1973. Influencia de diferentes patrones sobre las variedades de Satsuma y Valencia en la posterior comercialización. Congreso Mundial de Citricultura (I, Murcia, 1973), 3: 213-211.

Alexander, L. and Grierson, D. 2002. Ethylene biosynthesis and action in tomato: a model for climacteric fruit ripening. J. Exp. Bot., 53 (377):20392055.

Ali-Dinar, H.M.; Krezdorn, A.H. and Wheaton, T.A. 1988. The sexualhormonal relation in citrus during fruit set. Acta Hortic., 218: 159-174. 
Allen, R.G.; Pereira, L.S.; Raes, D. and Smith, M. 1998. Crop evapotranspiration (guidelines for computing crop water requirements). FAO Irrigation and Drainage Paper № 56, FAO, Rome.

Alonso, J.M.; Chamarro, J. and Granell, A. 1995. Evidence for the involvement of ethylene in the expression of the specific RNAs during maturation of the orange, a non-climacteric fruit. Plant Mol. Biol., 29: 385390.

Alós, E.; Cercós, M.; Rodrigo, M.J.; Zacarías, L. and Talón, M. 2006. Regulation of color break in Citrus fruits. Changes in pigment profiling and gene expression induced by gibberellins and nitrate, two ripening retardants. J. Agric. Food Chem., 54 (13): 4888 -4895.

Andersen, S.; Bastola, R.D. and Minocha, S.C. 1998. Metabolism of polyamines in transgenic cells of carrot expressing a mouse ornithine descarboxylas cDNA. Plant Physiol., 116: 299- 307.

Anthony, F.E. and Coggins, C.W. $\mathbf{J}_{\mathbf{R}}$. 2001. NAA and 3,5,6-TPA control mature fruit drop in California citrus. HortScience, 36: 1296-1299.

Apelbaum, A. Goldschmidt, E.E. and Ben-Yehoshua, S. 1976. Involvement of endogenous ethylene in the induction of colour change in Shamouti oranges. Plant Physiol., 57:836-838.

Aranda, M.A. 1986. Influencia de la posición de las naranjas W.navel en el árbol sobre el color y el contenido de pigmentos de las mismas. Tesina Fac. Biol. Univ. Valencia.

Arellano-Gómez, L.A.; Saucedo-Veloz, C. and Arévalo-Galarza, L. 2005. Biochemical and physiological changes during ripening of black sapote fruit (Diospyros digyna Jack.). Agrociencia, 39 (002): 173-181.

Arias, M.; Carbonell, J. and Agustí, M. 2005. Endogenous free polyamines and their role in fruit set of low and high parthenocarpic ability citrus cultivars. J.Plant Physiol., 162: 845-853.

Aung, L.H.; Houck, L.G. and Norman, S.M. 1991. The abscisic acid content of Citrus with special reference to lemmons. J. Exp. Bot., 42: 1083-1088.

Bain, J. M. 1958. Morphological, anatomical and physiological changes in the developing fruit of the Valencia orange Citrus sinensis (L) Osbeck. Aust. J. Bot., 6: 1-24. 
Baker, J.E.; Anderson, J.D. and Hruschka, W.R. 1985. Protein synthesis in tomato fruit pericarp tissue during ripening. Characteristics of aminoacid incorporation. J. Plant Physiol., 120: 167-179.

Bañuls, J; Quiñones, A.; Primo-Millo, E. and Legaz, F. 2004. Complemetary effect of foliar spray of $\mathrm{KNO}_{3}$ on mineral status, yield and fruit quality in citrus orchard. Proc. Int. Citriculture, 2: 686-687.

Barry, G.H. and le Roux, S. 2008. Preharvest manipulation of chlorochromoplast transformation in Citrus rinds by gibberellin-biosynthesis inhibitor Prohexadione-calcium. Proc. Int. Soc. Citriculture, Abs № 164: 83

Barry, G.H. and van Wyk, A.A. 2004. Novel approaches to rind colour enhancement of citrus. Proc. Int. Soc. Citriculture, 3: 1076-1079.

Barry, G.H. and van Wyk, A.A. 2006. Low-temperature cold shock may induce rind colour development of 'Nules Clementine' mandarin (Citrus reticulata Blanco) fruit. Postharvest Biol. \& Technol., 40: 82-88.

Bevington, K.B. and Castle, W.S. 1985. Annual root growth pattern of young trees in relation to shoot growth, soil temperature and water content. J. Amer. Soc. Hort. Sci., 110: 840-845.

Beyer, P.; Nievelstein, V.; Albabili, S.; Bonk, M. and Kleinig, H. 1994. Biochemical aspects of carotene desaturation and cyclization in chromoplast membranes from Narcissus pseudonarcissus. Pure and Appl. Chem., 66 (5): 1047-1056.

Biale, J.B.; Young, R.E. and Olmstead, A.J. 1954. Fruit respiration and ethylene production. Plant Physiol., 29: 168-174.

Bitters, W.P. 1961. Physical characteristics and chemical composition as affected by scion and rootstock. En: The orange. Its biochemistry and physiology. W.B.Sinclair ed. Univ. Clif.Div. Agric. Sci. Berkeley: 56-95.

Beljaars, P.R.; van Dijk, R. and van Der Horst, G.M. 1994. Determination of Nitrate in Vegetables by Continuous Flow:.Interlaborator.Study.Journal of AOAC International Vol.77.Boswell, S.B.; Lewis, L.N.; McCarty, C.D. and Hench, K.W. 1970. Tree spacing of Washington navel orange. J. Amer. Hort. Sci., 95: 523-528. 
Boswell, S.B.; Nauer, E.M. and Atkin, D.R. 1982. Effect of tree density of fruit quality, temperature, light penetration, growth and productionof old-line 'Atwood' navel orange trees. J. Amer. Soc. Hort. Sci., 107: 60-65.

Bowden, R.P. 1968. Processing quality of oranges grown in the near north coast of Queensland. Queensl. J. Agric. Anim. Sci., 25: 93-119.

Bryla, D.R.; Bouma, T.J.; Hartmond, U. and Eissenstat, D.M. 2001. Influence of temperature and soil drying on respiration of individual roots in citrus: integrating greenhouse observations into a predictive model for the field. Plant, Cell and Environment, 24: 781-790.

Brady, C.J.; Palmer, J.K.; O'connell, P.B.H. and Smillie, R.M. 1970. An increase in protein synthesis during ripening of the banana fruit. Phytochemestry, 9: 1037-1047.

Burdon, J.N. and Sexton, R. 1990. Fruit abscission and ethylene production of red raspberry cultivars. Sci. Hort., 43: 95-102.

Castle, W.S. 1978. Citrus root system: their structure, function, growth and relationship to tree performance. Proc. Int. Soc. Citriculture, 62-69.

Castle, W.S. 1980. Citrus rootstocksfor tree-size-control in Florida. Proc. Flo. State Hortic. Sci., 93: 24-27.

Cercós, M.; Soler, G.; Iglesias, D.J.; Gadea, J.; Forment, J. and Talón, M. 2006. Global analysis of gene expression during development and ripening of citrus fruit flesh. A proposed mechanism for citric acid utilization. Plant Mol. Biol., 62:513-527.

Coggins, C.W. and Hall, A.E. 1975. Effects of light, temperature, and 2',4'Dichloro-1-Cyanoethanesulphonanilide on degreening of regreened 'Valencia' oranges. J. Amer. Soc. Hort. Sci., 100 (5): 484-487.

Coggins, C.W. and Lewis, L.N. 1962. Regreening of Valencia orange as influenced by potassium gibberellate. Plant Physiol., 37:625-627.

Coggins, C.W.; Hall, A.E. and Jones, W.W. 1981.The influence of temperature on regreening and carotenoid content of the 'Valencia' orange rind. J. Amer. Soc. Hort. Sci., 106: 251-254.

Coggins, C.W.JR; Hield, H.Z. and Boswell, S.B. 1960a. The influence of potassium gibberellate on Lisbon lemon trees and fruit. Proc. Amer. Soc. Hort. Sci., 76: 199-207. 
Coggins, C.W. JR; Hield, H.Z. and Garber, M.J. 1960b. The influence of potassium gibberellate on Valencia orange trees and fruit. Proc. Amer. Soc. Hort. Sci., 76: 193-198.

Cohen, E. and Kende, H. 1987. In Vivo 1-Aminocyclopropane-1-Carboxylate Synthase Activity in Internodes of Deepwater Rice. Enhancement by submergence and low oxygen levels. Plant Physiol., 84: 282-286.

Cohen, E.; Shalom, Y. and Rosenberger, I. 1990. Post-harvest behaviour of 'Ortanique' ('Topaz') tangor citrus fruit during long-term storage at various temperatures. Sci. Hort, 44: 235-240.

Collado, M., Sala, J.M. and Iñarrea, P. 1996. Influence of nitrogenous fertilization on the protein content of flavedo of 'Navelina' oranges and its relationship with rind colour. J. Hort. Sci., 71 (6): 971-976.

Cooper, W. C.; Rasmussen, G. K.; Rogers, B. J.; Reece, P. C. and Henry, W. H. 1968. Control of Abscission in Agricultural Crops and Its Physiological Basis. Plant Physiol., 43: 1560-1576.

Chapman H.D. and Parker, E. R. 1942. Weekly absorption of nitrate by young bearing orange trees growing out of doors in solution cultures. Plant Physiol., 17: 336-376.

Chapman, H.D. and Reyner, D.S. 1951. Effects of various levels of phosphate on the growth, yield, composition and quality of Washington navel oranges. Hilgardia, 20: 325-358.

Chiwocha, S.D.S; Abrams, S.R.; Ambrose, S.J.; Cutler, A.J.; Loewen, M.; Ross, A.R.S. and Kermode, A.R. 2003. A method for profiling classes for plant hormones and their metabolites using liquid chromatographyelectrospray ionization tandem mass spectrometry:and analysis of hormones regulation of thermodormancy of lettuce (Lactuca sativa L.) seeds. The Plant Journal, 35: 405-417.

Davies, BH. 1976. Carotenoids. In: Goodwin TW, ed. Chemistry and biochemistry of plant pigments, Vol. II. New York: Academic Press, 38165.

Deane-Drummond, C. E. and Johnson, C. B. 1980. Absence of nitrate reductase activity in San 9789 bleached leaves of barley seedlings (Hordeum vulgare cv. Midas). Plant, Cell and Environment, 3 (5): 303308. 
Eaks, I.L. 1970. Respiratory response, ethylene production, and response to ethylene on citrus fruit during ontogeny. Plant Physiol., 45: 334-338.

Eilati, S.K.; Goldschmidt, E.E. and Monselise, S.P. 1969a. Hormonal control of colour change in orange peel. Experientia, 25: 209-210.

Eilati, S.K.; Monselise, S.P. and Budowski, P. 1969b. Seasonal development of external color and carotenoid content in the peel of ripening 'Shamuti' oranges. J. Amer. Soc. Hort. Sci., 94 (4): 346-348.

Eisenreich, W.; Bacher, A.; Arigoni, D. and Rohdich, F. 2004. Biosynthesis of isoprenoids via the non-mevalonate pathway. Cell. Mol. Life Sci., 61:1401-1426.

Embleton, T.W.; Jones, W.W. and Coggins, C. W. 1973. Aggregate effects of nutrients and gibberellic acid on Valencia orange crop value. J. Amer. Soc. Hort. Sci., 98:281-285.

Embleton, T.W.; Jones, W.W. and Labanaukas, C.K. 1971. Leaf analysis and phosphorous fertiliation of oranges. Calif. Citrogr., 56: 101-104.

Embleton, T.W.; Jones, W.W. and Page, A.L. 1967. Potassium and phosphorous effects on deficient Eureka lemon trees and some salinity problems. Proc. Amer. Soc. Hort. Sci. 91: 120-127.

Erickson, L.C. 1960. Colour development in Valencia oranges. Proc. Amer. Soc. Hort. Sci., 75: 257-261.

Erner, Y.; Goren, R. and Monselise, S.P. 1976. The rough fruit condition of the 'Shamouti' orange connections with the endogenous hormonal balance. J. Hort. Sci., 51:367-374.

Evans, T.E. and Malmberg, R.L. 1989. Do Polyamines have roles in plant developments? Annu. Rev. Plant Physiol. \& Plant Mol. Biol., 40: 235.

Faust, M. 1989. Physiology of temperate zone fruit trees, John Wiley \& Sons, Inc, Nueva York, EEUU.

Fidelibus, M.W.; Koch, K.E.; Davies, F.S. 2008. Gibberellic acid alters sucrose, hexoses, and their gradients in peel tissues during color break delay in 'Hamlin' orange J. Amer. Soc. Hortic. Sci., 133 (6): 706-767.

Fraser, P.D. and Bramley, P.M. 2004. The biosynthesis and nutritional uses of carotenoids. Prog. Lipid Res., 43: 228-265.

Frenkel, C. and Dick, R. 1973. Auxin inhibition of ripening in Bartlett pears. Plant Physiol., 51: 6-9. 
Frenkel, C.; Klein, I. and Dilley, D. R. 1968. Protein synthesis in relation to ripening of pome fruits. Plant Physiol., 155: 52-57.

Fujii, H.; Shimada, T; Sugiyama, A.; Endo, T.; Nishikawa, F.; Nakano, M.; Ikoma, Y.; Shimizu, T. and Omura, M. 2008. Profiling gibberellin $\left(\mathrm{GA}_{3}\right)$ responsive genes in mature mandarin fruit using a citrus $22 \mathrm{~K}$ oligoarray. Scientia Hort., 116 (3): 291-298.

Fujii, H.; Shimada,T.; Sugiyama,A.; Nishikawa, F.; Endo, T.; Nakano,M.; Ikoma, Y.; Shimizu, T. and Omura, M. 2007. Profiling ethyleneresponsive genes in mature mandarin fruit using a citrus $22 \mathrm{~K}$ oligoarray. Plant Science, 173: 340-348.

García-Luis, A.; Agustí, M.; Almela, V.; Romero, V. and Guardiola, J.L. 1985. Effect of gibberellic acid on ripening and peel puffing in 'Satsum' mandarin. Scientia Hort., 27: 75-86.

García-Luis, A.; Fornés, F. and Guardiola, J.L. 1986. Effects of gibberellin $A_{3}$ and citoquinins on natural and post-harvest, ethylene-induced pigmentation of Satsuma mandarin peel. Physiol. Plant., 68: 271-274.

García Petillo, M. and Castel, J.R. 2007. Water balance and crop coefficient (Kc) estimation of a citrus orchard in Uruguay. Spanish Journal of Agricultural Research. 5(2): 232-243.

Gardner, E.E. 1941. Practical application of plant growth substances in Hortulture. Proc. Flo. State Hort. Soc., 54:20-26.

Galston, A.W. 1983. Polyamines as modulators of plant development. Bioscience, 33: 382-388.

Giovannoni, J.J. 2004. Genetic regulation of fruit development and ripening. The Plant Cell, 16: 170-180.

Goodner, K.L.; Rouseff, R.L. and Hofsommer, H.J. 2001. Orange, mandarin, and hybrid classification using multivariate statistics based on carotenoid profiles. J. Agric. Food Chem., 49: 1146-1150.

Goldschmidt, E.E. 1976. Endogenus growth substances of Citrus tissues. HortScience, 11, 95-99.

Goldschmidt, E.E. 1988. Regulatory aspects of chloro-chromoplast interconversions in senescing Citrus fruit peel. Israel J. Bot., 37: 123-130.

Goldschmidt, E.E. 1997. Ripening of citrus and other non-climacteric fruits: a role for ethylene. Acta Hortic., 463: 335-340. 
Goldschmidt, E.E. 2000. Maturation of citrus fruit: hormonal and molecular regulation of chlorophyll breakdown and other processes. Proc. Int. Soc., Citriculture, 1: 364-366

Goldschmidt, E.E. and Eilati, S.K. 1970. Gibberellin-treated Shamouti oranges: Effects on coloration and translocation within peel of fruits attached to or detached from the tree. Bot. Gaz., 131 (2), 116-122.

Goldschmidt, E.E.; Goren, G.; Even-Chen, Z. and Bittner, S. 1973. Increase in free and bound abscisic acid during natural and ethylene-induced senescence of citrus fruit peel. Plant Physiol., 51, 879-882.

Goldschmidt E.E.; Huberman, M. and Goren, R. 1993. Probing the role of endogenous ethylene in the degreening of citrus fruit with ethylene antagonist. Plant Growth Reg., 12: 325-329.

Goldschmidt, E.E.; Aharoni, Y.; Eilati, S.K.; Riov, J.W. and Monselise, S.P. 1977. Differential counteraction of ethylene effects by gibberellin $A_{3}$ and $\mathrm{N}_{6}$-Benzyladenine in senescing citrus peel. Plant Physiol., 59: 193-195.

Gomez-Cadenas, A.; Mehouachi, J.; Tadeo, F.R.; Primo-Millo, E. and Talon, M. 2000. Hormonal regulation of fruitlet abscission induced by carbohydrate shortage in citrus. Planta, 210: 636-643.

Goren, R. 1993. Anatomical, physiological and hormonal aspects on abscission in citrus. Hort. Rev., 15: 145-182.

Gravina, A.; Arbiza, H.; Telias, A.; Benzano, F.; D’OliveiraFlores, V.; Cassanova, S. and Gambetta, G. 2004. Harvest date effect on fruit quality and return bloom in three Citrus cultivars. Proc. Int. Soc. Citriculture, I: 284-290.

Gross, J. 1977. Carotenoid pigments in citrus. En: Citrus Science and technology. Nagy, S. et al., (Eds.). A VI Westpost Ct., Vol I: pp 302-354

Gross, J. 1981. Pigment changes in the flavedo of Dancy tangerine (Citrus reticulate) during ripening. Z.Pflanzenphysiol. Bd. 103: 451-457.

Gross, J.; Timberg, R.; Graef, M. 1983. Pigment and ultrastructural changes in the developing pummelo Citrus grandis 'Goliath'. Bot. Gaz. 1983, 144, 401-406.

Hamilton, A.J.; Lycett, G.W. and Grierson, D. 1990. Antisense gene that inhibits synthesis of the hormone ethylene in transgenic plants. Nature, 346: 284-287. 
Harding, P.L.; Winston, J.R. and Fischer, D.F. 1940. Seasonal changes in Florida oranges. U.S. Dep. Agric. Tech. Bull: 753.

Hoeberichts, F.A.; van Der Plas, L.H.W.; Woltering, E.J. 2002. Ethylene perception is required for the expression of tomato ripening-related and associated physiological changes even at advanced stages of ripening. Postharvest Biol. \& Technol., 26: 125-133.

Hofman, P.J. 1990. Abscisic acid and gibberellins in the fruitlets and leaves of the 'Valencia' orange in relation to fruit growth and retention. Sci. Hort., 42: 257-267.

Holland, N.; Menezes, H. C. and Lafuente, M. T. 2002. Carbohydrate as related to the heat-induced chilling tolerance and respiratory rate of 'Fortune' mandarin fruit harvested at different maturity stages. Postharvest Biol. \& Technol., 25, 181-191.

Holland, N.; Sala, J.M.; Menezes, H. C. and Lafuente, M. T. 1999. Carbohydrate content and metabolism as related to maturity and chilling sensitivity of Cv. Fortune mandarins. J. Agric. Food Chem., 47, 25132518.

Huff, A. 1983. Nutritional control of regreening and degreening in Citrus peel segments. Plant Physiol., 73: 243-249.

Huff, A. 1984. Sugar regulation of plastid interconversions in the epicarp of Citrus fruit. Plant Physiol., 76: 307-312.

Iglesias, D.J.; Tadeo, F.R.; Legaz, F.; Primo-Millo, E. and Talón, M. 2001. In vivo sucrose stimulation of colour change in citrus fruit epicarps: Interactions between nutritional and hormonal signals. Physiol. Plantarum., 112, 244-250.

Ikoma, Y.; Komatsu, A.; Kita, M.; Ogawa, K.; Omura, M.; Yano, M. and Moriguchi, T. 2001. Expression of a phytoene synthase gene and characteristic carotenoid accumulation during citrus fruit development. Physiol. Plantarum 111, 232-238.

Iwagaki, I. 1981. Tree configuration and pruning of Satsuma mandarin in Japan. Proc. Int. Soc. Citric., 1: 169-172.

Jacob-Wilk, D.; Holland, D.; Goldschmidt, E.E.; Riov, J. and Eyal, Y. 1999. Chlorophyll breakdown by chlorophyllase: isolation and functional 
expression of the Chlase1 gene from ethylene-treated Citrus fruit and its regulation during development. The Plant Journal, 20 (6): 653-661.

Jahn, O. 1973. Degreening Citrus fruit with postharvest applications of (2Chloroethyl) phosphonic Acid (Ethephon). J. Amer. Soc. Hort. Sci., 98 (3): 230-233.

Jones, W.W. and Embleton , T.W. 1959. The visual effect of nitrogen nutrition on fruit quality of 'Valencia' oranges. Proc. Amer. Soc. Hort. Sci., 73: 234-236.

Kato,M; Ikoma, Y.; Matsumoto, H.; Sugiura, M.; Hyodo, H. and Yano, M. 2004. Accumulation of carotenoids and expression of carotenoid biosynthetic genes during maturation in Citrus fruit. Plant Physiol., 134: 824-837,

Kennedy, R.; Pegg, G. F. and Welham, S. J. 1993. Phytophthora cryptogea root rot of tomato in rockwool nutrient culture: III. Effect of root zone temperature on growth and yield of winter-grown plants. Annals of Applied Biol., 123 (3): 563-578.

Kidd, F. and West, C. 1925. The course of respiratory activity throughout the life of an apple. G.B. Dep. Sci. Ind. Res. Food Invest. Board Rep. 1924: 27-33.

Koo, R.C.J. and Reese, R.L. 1976. Influence of fertility and irrigation treatments on fruit quality of Temple orange. Proc. Fla. State Hort. Sci. Soc., 89: 49-51.

Koo, R.C.J. and Reese, R.L. 1977. Influence of nitrogen, potassium, and irrigation on citrus fruit quality. Proc. Int. Soc. Citriculture, I:34-38.

Kubo, T.; Hohjo, I. and Hiratsuka, S. 2001. Sucrose accumulation and its related enzyme activities in the juice sacs of Satsuma mandarin fruit from trees with different crop loads. Sci. Hort., 91: 215-225.

Kuraoka, T.; Iwasaki, K. and Ishii, T. 1977. Effects of $\mathrm{GA}_{3}$ on puffing and levels of $\mathrm{GA}_{3}$-like substances and $\mathrm{ABA}$ in the peel of Satsuma mandarin (Citrus unshiu Marc.). J. Amer. Soc. Hort. Sci., 102 (5), 651-654.

Kushad, M.M. and Dumbroff, E.B. 1991.Effects of light and plant growth regulators on polyamine metabolism in higher plants. En: Biochemestry and physiology of poylamines in plants. Slocum, R.D. and Flores, H. E. eds. CRC Press, Boca Ratón, Ann Arbor, London, pp 77-91. 
Lafuente, M.T.; Martínez, T.M. and Zacarías, L. 1997. Abscisic acid in the response of Fortune mandarins to chilling. Effect of maturity and hightemperature conditioning. J. Sci. Food and Agric., 73: 494-502.

Lara, I. and Vendrell, M. 2000. Changes in abscisic acid levels, ethlene biosybthesis, and protein patterns during fruit maturation of 'Granny Smith' apples. J. Amer. Soc. Hort. Sci., 125 (2): 183-189.

Lee, H.S. and Castle, W.S. 2001. Seasonal changes of carotenoid pigments and color in Hamlin, Earlygold, and Budd Blood orange juices. J. Agric. Food Chem., 49: 877-882.

Lee, L.S. and Chapman, J.C. 1988. Yield and fruit quality responses of Ellendale mandarins to different nitrogen and potassium fertiliser rates. Aust. J. Exp. Agric., 28: 143-148.

Lewis, L.N and Coggins, C.W. 1964. The inhibition of carotenoid accumulation in navel oranges by gibberellin $A_{3}$, as measured by thin layer chromatography. Plant \& Cell Physiol., 5: 457-463.

Lewis, L.N; Coggins, C.W. and Garberg, M.J. 1964. Chlorophyll concentration in the navel orange rind as related to potassium gibberellate, light intensity and time. J. Amer. Soc. Hort. Sci., 84: 177-180.

Lewis, L.N.; Coggins, C.W. $\mathrm{J}_{\mathbf{R}}$; Labanauskas, C.K. and Dugger, W.M. $\mathrm{J}_{\mathrm{R}}$. 1967. Biochemical changes associated with natural and gibberellin $A_{3}$ delayed senescence in the Navel orange rind. Plant \& Cell Physiol., 8: 151-160.

Lincoln, J. E.; Cordes, S.; Read, E. and Fischer, R. L. 1987.Regulation of gene expression by ethylene during Lycopersicon esculentum (tomato) fruit development. Proc. Natl. Acade. Sci. USA, 84: 2793-2797.

Manera, J.; Ruiz, G.; Fernández, J.C.; Conesa, A.; Robles, J.M. and Porrás, I. 2008. Influencia de la temperature sobre las coordenadas colorimétricas $L$, a y b en la evolución del color externo en los frutos de limón. Levante Agrícola, 65-70.

Maquieira, A.; Climent, M.D.; Puchades, R. and Primo-Yúfera, E. 1984. Fertilization of orange trees with sulfur-coated urea. Nitrogen levels in leaves and fruits. Plant and Soil, 80: 247-254.

Marty, I.; Bureau, S.; Sarkissian, G.; Gouble, B.; Audergon, J. and Albagnac, G. 2005. Ethylene regulation of carotenoid accumulation and 
carotenogenic gene expression in colour-contrasted apricot varieties (Prunus armeniaca). J. Exp. Bot. 56: 1877-1886.

McMurchie, E. J.; McGlasson, W.B. and Eaks, I.L. 1972.Treatment of fruit with propylene gas gives information about the biogenesis of ethylene. Nature, 237:235-236.

Mehouachi, J.; Serna, D.; Zaragoza, S.; Agustí, M.; Talón, M. and PrimoMillo, E. 1995. Defoliation increases fruit abscission and reduces carbohydrate levels in developing fruits and woody tissues of Citrus unshiu. Plant Sci., 107: 189-197.

Mikal E. and Saltveit, Jr. 1993. Internal carbon dioxide and ethylene levels in ripening tomato fruit attached to or detached from the plant. Physiol. Plant., 89 (1): 204-210.

Miller, E.W.; Winston, J.R. and Schomer, H.S. 1940. Physiological studies of plastid pigments in rinds of maturing oranges. J. Agric. Res., 60: 259267.

Molnar, P. and Szabolcs, J. 1980. Beta-citraurin epoxide, a new carotenoid from 'Valencia' orange peel. Phytochemistry, 19: 633-637.

Monselise, S.P. 1947. The growth of citrus roots and shoots under different cultural conditions. Palest. J. Bot., 6: 43-54.

Monselise, S.P. 1977. Citrus fruit development, endogenous systems, and external regulation. Proc. Int. Soc. Citriculture, 2: 6664-668.

Moore, S.; Vrebalov, V.; Payton, P. and Giovannoni, J. 2002. Use of genomics tools to isolate key ripening genes and analyse fruit maturation in tomato. J. Exp. Bot., 53 (377): 2023-2030.

Mulas, M.; Fadda, A.; Cassanova, P. and Schirra, M. 2004. Compositional changes in juice characteristics and certain indicators of senescence in 'Tarocco' and 'Valencia' oranges during development and maturation. Proc. Int. Soc. Citriculture, 3, 1115-1118.

Murti, G.S.R. 1989.Studies on gibberellin-like substances in acid lime (Citrus aurantifolia Swingle), Indian J. Plant Physiol., 32: 57-64.

Nakatsuka, A.; Murachi, S.; Okunishi, H.; Shiomi, S.; Nakano, R.; Kubo, Y.; Inaba, A. 1998. Differential expression and internal feedback regulation of 1-aminocyclopropane-1-carboxylate synthase, 1-aminocyclopropane- 
1-carboxylate oxidase, and ethylene receptor genes in tomato fruit during development and ripening. Plant Physiol., 118 (4):1295-305.

Nambara, E. and Marion-Poll, A. 2005. Abscisic Acid Biosynthesis and Catabolism. Annual Rev. Plant Biol., 56, 165-185.

Nii, N.; Harada, K. and Kadowaki, K. 1970. Effects of temperature on the fruit growth and quality of Satsuma mandarins. J. Jap. Soc. Hort. Sci., 39: 309-317.

Oberholster, R. 2001. The biochemical basis of colour as an aesthetic quality in Citrus sinensis. Tesis, Univ. Natal, South Africa.

Oberholster, R.; Cowan, A.K.; Molnár, P. and Tóth, G. 2001. Biochemical Basis of Color as an Aesthetic Quality in Citrus sinensis. J. Agric. Food Chem., 49: 303-307

Oeller, P.W.; Min-Wong, L.; Taylor, L.P.; Pike, D.A. and Theologis, A. 1991. Reversible inhibition of tomato fruit senescence by antisense RNA. Science, 254: 437-439.

Oetiker, J. H. and Yang, S.F. 1995. The role of ethylene in fruit ripening. Acta Hortic. 398, 167-177.

Ortiz, J.M.; García-Lidón, A.; Tadeo, J.L.; Fernández de Córdoba, L.; Martín, B. and Estellés, A. 1986. Comparative study of physical and chemical characteristics of four lemon cultivars. J. Hort. Sci., 85: 183185.

Pech, J.C.; Bouzayen, M. and Latché, A. 2008. Climacteric fruit ripening: Ethylene-dependent and independent regulation of ripening pathways in melon fruit. Plant Sci., 175: 114-120.

Peng, Y.H. and RABE, E. 1997. Postharvest storage behaviour, respiration rate and ethylene evolution of fruit from deficit and normal irrigation in 'Mihowase Satsuma' trees. J. S. Afr. Soc. Hort. Sci., 7 (2): 44-47.

Périn, C.; Gomez-Jimenez, M.C.; Hagen, L.; Dogimont, C.; Pech, J.C.; Latche', A.; Pitrat, M. and Lelièvre, J.M. 2002. Molecular and genetic characterisation of a non-climacteric phenotype in melon reveals two loci conferring altered ethylene response in fruit. Plant Physiol., 129: 209300.

Perkins-Veazie, P.; Clark, J.R.; Huber, D.J. and Baldwin, E.A. 2000. Ripening physiology in 'Navaho' thornless blackberries: color, respiration, 
ethylene production, softening and compositional changes. J. Am. Soc. Hort. Sci., 125:357-363.

Poerwanto, R.; Inoue, H. and Kataoka, I. 1989. Effects of Temperature on the of the Roots of Trifoliate Orange Morphology Budded withand Physiology Satsuma Mandarin. J. Japan. Soc. Hort. Sci., 58 (2): 267-274.

Pons, J; Almela, V.; Juan, M and Agustí, M. 1992. Use of ethephon to promote colour development in early ripening clementine cultivars. Proc. Int. Soc. Citriculture: 459-462.

Porat, R.; Weiss, B.; Cohen, L.; Daus, A.; Goren, R. and Droby, S. 1999. Effects of ethylene and 1-methylcyclopropene on the postharvevst qualities of 'Shamouti' oranges. Postharvest Biol. \& Technol., 15: 155163.

Purvis, A. and Barmore, Ch. 1981. Involvement of ethylene in chlorophyll degradation in peel of Citrus fruits. Plant Physiol., 68: 854-856.

Purvis, A.C. and Grierson, W. 1982. Accumulation of reducing sugar and resistance of grapefruit peel to chilling injury as related to winter temperatures. J. Amer. Soc. Hort. Sci., 107: 139-142.

Purvis, A.C. and J. D. Rice. 1983. Low-temperature induction of invertase activity in grapefruit flavedo tissue. Phytochemestry, 22: 831-834.

Quiñones, A.; González, M.C.; Montaña, C.; Primo-Millo, E. and Legaz, F. 2004. Fate and uptake efficiency of ${ }^{15} \mathrm{~N}$ applied with different seasonal distributions in Citrus trees. Proc. Int. Soc. Citriculture, 2: 587-592.

Raigón, MD; Pérez-García, M; Maquieira, A; Puchades, R. 1992. Determination of available nitrogen (nitric and ammoniacal) in soils by flow injection analysis. Analysis, 20: 483-487.

Rasmussen, G.K. 1973. The effect of growth regulators on degreening and regreening of citrus fruit. Acta Hortic., 34: 473-478.

Rasmussen, G.K. 1974. Cellulase activity in separation zones of citrus fruit treated with abscisic acid under normal and hypobaric atmospheres. J. Amer. Soc. Hort. Sci., 99: 229-231.

Reid, M.S. and Pratt, H.K. 1970. Ethylene and the respiration climacteric. Nature, 226 (6): 976-77.

Reid, M.S.; Rodhes, M.J.C. and Hulme A. C. 1973. Changes in ethylene and $\mathrm{CO}_{2}$ during the ripening of apples. J. Sci. Fd. Agric. 24: 971-979. 
Reitz, H.J. and Embleton, T.W. 1986. Production practices that influence fresh fruit quality.En: Fresh Citrus Fruits. W.F.Wardowski ed. Avi. Publ. Co. Inc. Westport, Conn, pp: 49-77.

Reuther, W. and Rios-Castaño, D. 1969. Comparisons of growth, maturation and composition of citrus fruit in subtropical California and tropical Colombia. Proc. First Int. Citrus Symp. 1, 277-283.

Reuther, W. and Smith, P.F. 1952. Relation of nitrogen, potassium and magnesium fertilization to some fruit quality of Valencia orange. Proc. Am. Soc. Hort. Sci, 59: 1-12.

Riov, J. and Hausman, R. 1988. Regulation of water-stressed-induced ethylene in citrus leaves. Isr. J. Bot., 37: 83-91.

Riov, J.; Dagan, E.; Goren, R. and Yang, S. F. 1990. Characterization of abscisic acid-induced ethylene production in Citrus leaf and tomato fruit tissues. Plant Physiol., 92: 48-53.

Riov, J.; Monselise, S.P. and Kahan, R.S. 1969. Ethylene-controlled induction of phenylalanine ammonia lyase in citrus fruit peel. Plant Physiol., 44:631-635.

Rivas, F.; Erner, Y.; Alós, E.; Juan, M.; Almela, V. and Agustí, M. 2006. Girdling increases carbohydrate availability and fruit-set in citrus cultivars irrespective of parthenocarpic ability. J. Hortic. Sci. Biotechnol., 81, 289295.

Rock, C.D. and Zeevaart, J.A.D. 1991. The aba mutant of Arabidopsis thaliana is impaired in epoxy-carotenoid biosynthesis. Proc. Natl. Acad. Sci. USA, 88: 7496-7499.

Rodrigo, M.J. and L. Zacarias. 2007. Effect of postharvest ethylene treatment on carotenoid accumulation and the expression of carotenoid biosynthetic genes in the flavedo of orange (Citrus sinensis L. Osbeck) fruit. Postharvest Biol. \& Technol., 43 (1): 14-22.

Rodrigo, M.J.; Alquezar, B. and Zacarias, L. 2006. Cloning and characterization of two 9-cis-epoxycarotene dioxygenase genes, differentially regulated during fruit maturation and under stress conditions, from orange (Citrus sinensis L. Osbeck). J. Exp. Bot., 57 (3):633-643. 
Rodrigo, M.J.; Marcos, J.F.; Alférez, F.; Mallent, M.D. and Zacarias, L. 2003. Characterization of Pinalate, a novel Citrus sinensis mutant with a fruit-specific alteration that results in yellow pigmentation and decreased ABA content. J. Exp. Bot., 54 (383): 727-738.

Romojaro, F.; Banet, E. y Llorente, S. 1979. Carotenoides en flavedo y pulpa de pomelo Marsh. Rev. Agroquim. Tecnol. Aliment., 19 (3): 385-392.

Saito, S.; Hirai, N.; Matsumoto, C.; Ohigashi, H. and Ohta, D. 2004. Arabidopsis CYP707As encode (+)-abscisic acid 8'-hydroxylase, a key enzyme in the oxidative catabolism of abscisic acid. Plant Physiol., 134, 1439-1449.

Saks, Y.; Weiss, B.; Chalutz, E.; Livne, A. and Gepstein, S. 1988. Regreening of stored pummelo fruit. Proc. Int. Soc. Citriculture, 2: 14011406.

Sala, J. M.; Cuñat, P.; Collado, M. and Moncholi, V. 1992. Effect on nitrogenous fertilization (quantity and nitrogen form) in precocity of colour change of 'Navelina' oranges. Proc. Int. Soc. Citriculture., 598-602

Samson, J.A. 1980. Harvest, transport and processing. In: Samson, J.A. (Ed.), Tropical Fruits. Longman, London and New York, pp. 64-118.

Saunt, J. 2000. Citrus varieties of the world. $2^{\text {a }}$ ed. England, Sinclair International Limited. 160p.

Shimokawa, K.; Shimada, S. and Yaeo, K. 1978. Ethylene-enhanced chlorophyllase activity during degreening of Satsuma mandarin (Citrus unshiu Marc.). Sci. Hort., 8: 129-135.

Sing, K.K. 1948. The development of red colour in Blood Red Malta orange (C.sinensis Osbeck). Indian J. Sci., 18: 157-165.

Sing, K.K. 1954.Rootstock effect on the fruit quality of Malta orange. Indian J. Agric. Sci., 14 (1): 92-98.

Sironval, C. and Kander, O. 1958. Photooxidation processes in normal green Chlorella cells. Biochim. Biophys. Acta, 29: 359-368.

Sites, J. W. and Reitz, H.J. 1949. The variation in individual Valencia oranges from different location of the tree as a guide to sampling methods and spot-picking quality. I. Soluble solid in the juice. Proc. Amer. Soc. Hort. Sci., 54: 1-10. 
Slocum, R.D. 1991. Polyamine biosynthesis in plants. En: Biochemistry and Physiology of Polyamines in Plants. R.D. Slocum and H.E. Flores (Eds). CRS Press, Inc., Boca Raton, Florida. pp. 23-40.

Smith, J. H. C. and Benítez, A. 1955. Chlorophylls. In Modern Methods of Plant Analysis; Paech, K.; Tracey, M.M., Eds.; Springer: Berlin: 142-196.

Soonen, H.D.; Lenz, F. and Gross, J. 1979. Einfluss der würzeltemperature auf die carotinoidentwiklung in Fruchtschalen von Citrus unshiu (Marc.) and Citrus madurensis (Lour.). Gartenbauwissenschaft, 44: 49-52.

Soule, J. and Grierson, W. 1978. Citrus maturity and packinghouse procedures. Institute of Food and Agricultural Sciences University of Florida. 355p.

Sozzi, G. 2007. Fisiología de la maduración de los frutos de especies leñosas. En: Árboles Frutales. Ecofisiología, Cultivo y Aprovechamiento. Ed. Gabriel O. Sozzi. pp 669-686.

Speirs,J. and Brady, C.J. 1991. Modification of Gene Expression in Ripening Fruit. Australian Journal of Plant Physiology, 18(5): 519 - 532.

Speirs,J.; Brady, C.J; Grierson, D. and Lee, E. 1984. Changes in ribosome organization and messenger RNA abundance in ripening tomato fruits. Australian J. Plant Physiol., 11: 225-233.

Spiegel-Roy, P. and Goldschmidt, E.E. 1996.The vegetative Citrus tree: development and function. En: Biology of Citrus. $1^{\text {st }}$ edition. Cambridge Univ. Press, UK. 47-69pp.

Stearns, C.R., Young, G.T. 1942. The relation of climatic conditions to color development in citrus fruit. Proc. Fla. State Hort. Soc. 56: 39-61.

Stewart, I and Wheaton, T.A. 1973. Carotenoids in citrus. Proc. Cong. Int. Citriculture, 2: 325-330.

Syverstsein, J.P. and Albrigo, L.J. 1980. Some effects of grapefruit tree canopy position on microclimate, water relations, fruit yield and juice quality. J. Amer. Soc. Hort. Sci., 105: 454-459.

Talón, M.; Zacarías, L and Primo-Millo, E. 1992. Gibberellins and parthenocarpic ability in developing ovaries of seedless mandarins. Plant Physiol., 99: 1575-1581.

Thomson, W. W. 1966. Ultrastructural development of chromoplasts in Valencia orange. Bot. Gaz., 127 (2-3): 133-139. 
Thomson, W.W.; Lewis, L.N. and Coggins, C.W. 1967. The reversion of chromoplast to chloroplasts in Valencia oranges. Cytologia, 32: 117-124.

Trainotti, L.; Pavanello, A. and Casadoro, G. 2005. Different ethylene receptors show an increased expression during the ripening of strawberries: does such an increment imply a role for ethylene in the ripening of these non-climacteric fruits?. J. Exp. Bot., 1-10.

Trebitsh, T.; Goldschmidt, E.E. and Riov, J. 1993. Ethylene induces de novo synthesis of chlorophyllase, a chlorophyll degrading enzyme, in Citrus fruit peel. Proc. Natl. Acad. Sci. USA, 90: 9441-9445.

Treeby, M.T.; Milne, D.J.; Storey, R.; Bevington, K.B.; Lovey, B.R. and Huton, R. 2000. Creasing in Australia: causes and control. Proc. Int. Soc. Citriculture, 2: 1099-1103.

Tucker, M.L. and Laties, G.G. 1984. Interrelationship of gene expresión, polysome prevalence and respiration during ethylene and/or cyanide treated avocado fruit, Persea americana cultiar Hass. Plant Physiol., 74: 307-315.

Tzur, A and Goren, R. 1977. Reducing preharvest drop in 'Temple' orange fruits by $2,4-D$. Role of cellulase in the calyx abscission zone. Sci. Hort., 7: $237-248$.

Valero, D.; Martínez-Romero, D.; Serrano, M. and Riquelme, F. 1998. Influence of postharvest treatment with putrescine and calcium on endogenous polyamines, firmness and abscissic acid in lemon (Citrus limon L.Burm Cv. Verna). J. Agric. Food Chem., 46: 2102-2109.

Van Staden, J.; Cook, E. and Nooden, L.D. 1988. Citokinins and senescense. In: Senescence and aging in plants. Academic Press, Inc. San Diego CA, pp:281-328.

Vendrell, M. and Buesa, C. 1989. Relationship between abscisic acid and ripening of apples. Acta Hortic., 258: 389-396.

Wallace, A. 1953 Nitrogen absorption and translocation by citrus cuttings at different root temperatures. Proc. Amer. Soc. Hort. Sci., 61: 89-94.

Wheaton, T.A. and Stewart, I. 1973. Optimum temperature and ethylene concentrations for postharvest development of carotenoid pigments in citrus. J. Amer. Soc. Hort. Sci., 98 (4): 337-340. 
White, P.J. 2002. Recent advances in fruit development and ripening: an overview. J. Exp. Bot., 53 (377): 1995-2000.

Wilkinson, J.Q.; Lanahan, M.B.; Clark, D.G.; Bleecker, A.B.; Chang, C. 1997. A dominant mutant receptor from Arabidopsis confers ethylene insensitivity in heterologous plants. Nature Biotechnology, 15: 444-447.

Wilkinson, J.; Lanahan, M.; Yen, H.; Giovannoni, J.J. and Klee, H.J. 1995. An ethylene-inducible component of signal transduction encoded by Never-ripe. Science, 270: 1807-1809.

Win, T.O.; Srilaong, V.; Kyu, K.L.; Poomputsa, K. and Kanlayanarat, S. 2006. Biochemical and physiological changes during chlorophyll degradation in lime (Citrus aurantifolia Swingle cv. 'Paan'). J. Hort. Sci. \& Biotech., 81 (3), 471-477.

Yen, H.; Lee, S.: Tanksley, S.; Lanahan, M.; Klee, H.J. and Giovannoni, J.J. 1995. The tomato Never-ripe locus regulates ethylene-inducible gene expression and is linked to a homologue of the Arabidopsis ETR1 gene. Plant Physiology, 107: 1343-1353.

Yokohama, H. and Keithley, J. H. 1991. Regulation of biosynthesis of carotenoids. In Plant Biochemical Regulators, ed. H.W. Gausmann, New York: Marcel Dekker. pp. 19-25.

Yokohama, H. and Vandercook, C.E. 1967. Citrus carotenoids. I. Comparison of carotenoids of mature-green and yellow lemons. J. Food Sci., 32: 4248.

Young, L. B. and Erickson, L. C. 1961. Influence of temperature on color change in Valencia orange. Proc. Amer. Soc. Hort. Sci., 78:197-200.

Zacarías, L.; Talón, M.; Ben, C.W.; Lafuente, M.T. and Primo-Millo, E. 1995. Abscisic acid increases in non-growing and paclobutrazol-treated fruits of seedless mandarins. Physiología Plantarum, 95: 613-619.

Zaragoza, S.; Almela, V; Tadeo, R, Primo-Millo, E. and Agustí, M. 1996. Effectiveness of calcium nitrate and $\mathrm{GA}_{3}$ on the control of peel-pitting of 'Fortune' mandarin. J. Hort. Sci., 71 (2): 321-326.

Zhu, H.L.; Zhu, B.Z.; Fu, D.Q. ; Xie, Y.H.; Hao, Y. L. and Luo, Y. B. 2005. Role of Ethylene in the Biosynthetic Pathways of Aroma Volatiles in Ripening Fruit. Russian Journal of Plant Physiol., 52 (5): 691-695. 
